\title{
AUTONOMÍA Y CO-EVOLUCIÓN: CONSTRUCCIÓN DE UNA PERSPECTIVA ECOLÓGICA COMPLEJA DE LA VIOLENCIA ESCOLAR
}

\author{
Autoras: \\ Carmenza Alfaro Barragán \\ Diana Carolina Cárdenas Vallejo
}

Director de Tesis:

Luz Marina Moncada Torres

Universidad Santo Tomás

División de Ciencias de la Salud

Facultad de Psicología

Maestría en Psicología Clínica y de la Familia

Bogotá

Septiembre 13 de 2017 


\section{Agradecimientos}

Hoy doy gracias a DIOS por permitirme cumplir un sueño plasmado en mi proyecto de vida, a mis padres por su incondicional apoyo que durante el proceso de la formación de la maestría continuamente me brindaron, a mis docentes que hicieron parte de este trabajo, Dora Garzón, Dora Gaitán, Miguel Cárdenas y los jurados, de manera especial agradezco a mi compañera Diana Cárdenas por su trabajo en equipo y esfuerzo plasmado en este documento a lo largo de estos dos años y finalmente a la Universidad Santo tomas por su valiosa formación y a la maestría de psicología clínica por brindarme herramientas que me construyen a nivel personal y profesional. 
Cuando pienso en escribir los agradecimientos se me ocurren todas aquella personas que hicieron parte de este proceso que me hizo crecer como persona y profesional: mi familia, mis docentes, mis directores de tesis, mi compañera de lucha... pero a la vez, cuando pienso en agradecer me pregunto una y otra vez ¿Cuál fue la fuerza que unió a todo aquello por lo cual agradezco y que hizo posible este sueño? Y me respondo a mí misma "el amor”, por esta razón hoy quiero agradecer al amor... ese amor que me motivo a continuar, a seguir adelante en las alegrías y las tristezas, ese amor por escribir y por estudiar, ese amor por mi profesión que me motivo a estudiar Psicología Clínica y... por supuesto agradezco a ese amor que recibí por parte de mi familia, mis padres, mis hermanos, mi pareja, mi compañera Carmenza, mis diversos directores y mi Maestría. Por esta razón este trabajo de grado es y seguirá siendo un motivo de amor que permitió construir y co - construir un nuevo mundo posible en mi vida

\section{Diana Carolina Cárdenas Vallejo}


Tabla de contenido

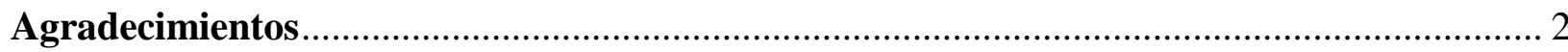

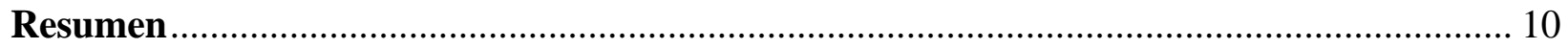

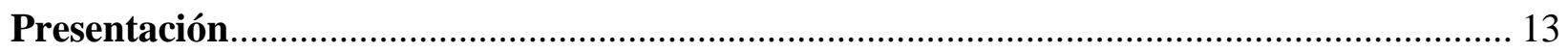

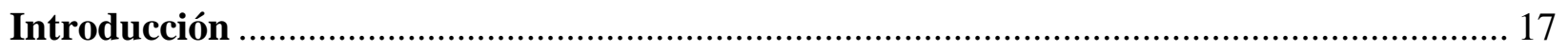

Objetivo General de Investigación/Intervención ................................................... 21

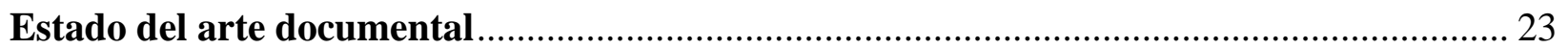

Contextualización Ecológica de la violencia escolar .................................................. 24

Familia y su relación con el Fenómeno de la violencia escolar ................................... 28

Entorno Escolar y otros ámbitos para comprender el fenómeno de la violencia escolar. 32

Conclusiones del estado del arte Documental .............................................................. 35

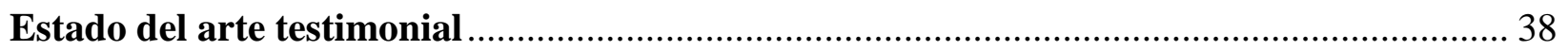

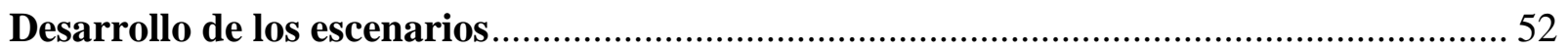

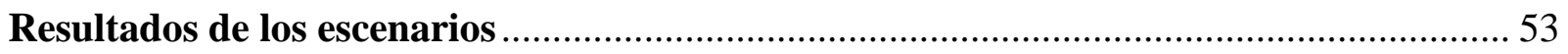

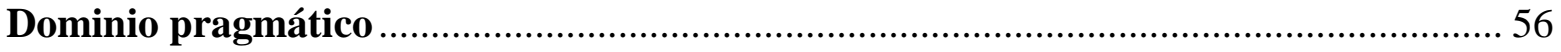

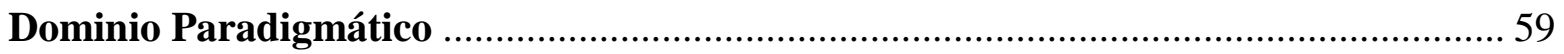

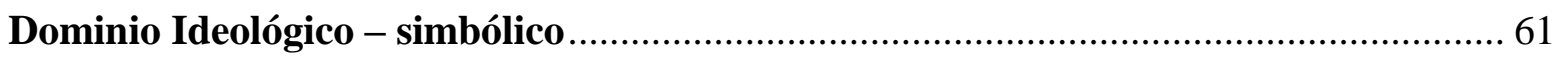

Resultados del estado del arte testimonial ............................................................... 62

Discusión estado del arte testimonial y documental................................................. 68

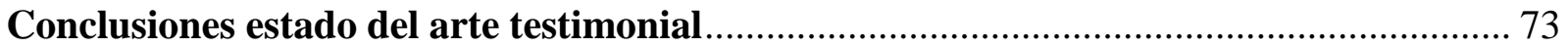


A través del desarrollo del estado del arte testimonial se pudo observar las dinámicas vinculares que se han configurado en el sistema familiar y escolar de los estudiantes participantes en el presente estudio.

Sistema teórico conceptual 77

Aproximaciones desde los órdenes de la complejidad, el construccionismo y

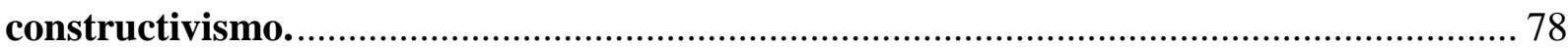

Perspectiva epistemológica y paradigmática de la violencia ....................................... 83

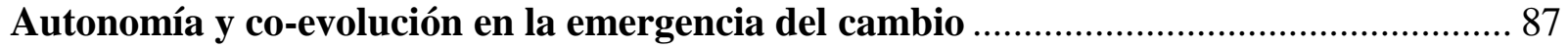

La narrativa conversacional como posibilitadora de cambio. ..................................... 91

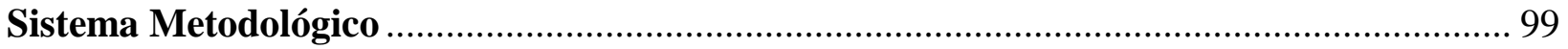

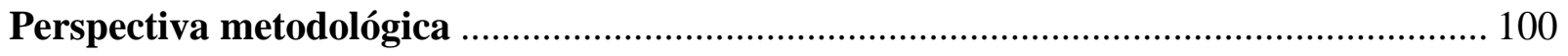

Marco epistemológico y paradigmático de la investigación/intervención. .................. 100

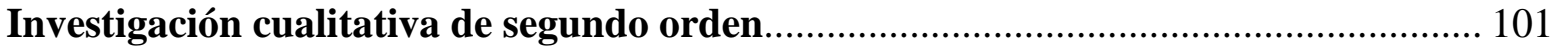

Procesos narrativo - conversacionales de la investigación/intervención ..................... 102

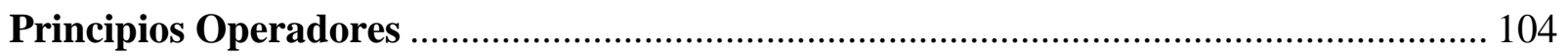

Autorreferencia y reflexividad. ...................................................................... 104

Recursividad y construcción compleja de narrativas. .......................................... 105

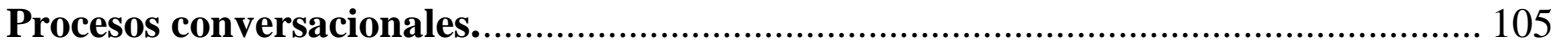

Conceptos metodológicos de la línea de investigación ............................................... 106

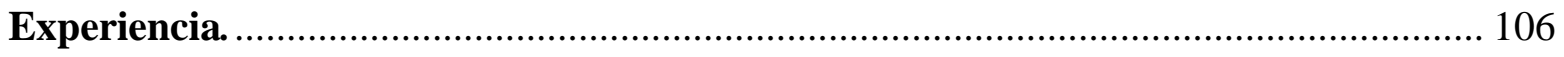




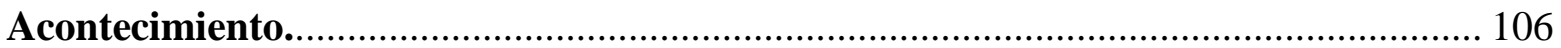

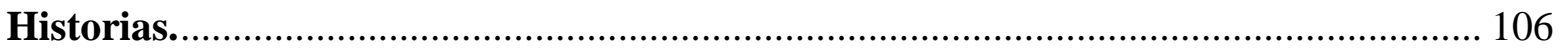

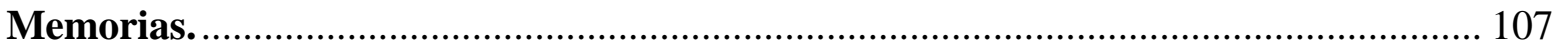

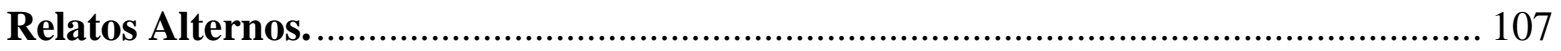

Conceptos metodológicos de la investigación/intervención ........................................ 107

Violencia escolar como una construcción social ................................................. 108

Ecología de las interacciones desde la construcción de mundos posibles y la co-

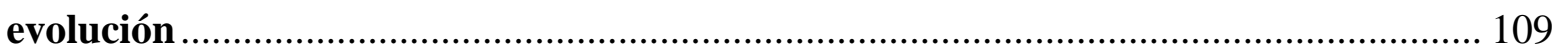

Emergencia del sujeto autónomo desde la multitemporalidad ............................... 110

Contexto y actores de investigación .................................................................... 111

Diseño de escenarios de Investigación/intervención................................................. 113

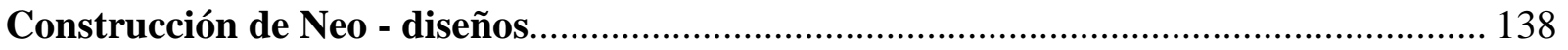

Modelización de la Investigación/Intervención ................................................... 156

Categorización y organización de la información emergente ................................... 161

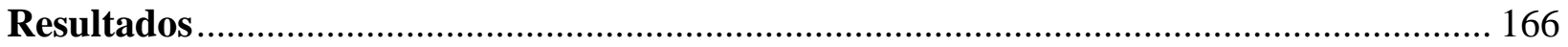

Comprensión ecológica/compleja de la violencia escolar ....................................... 167

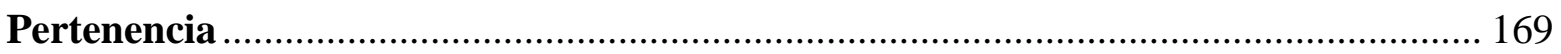

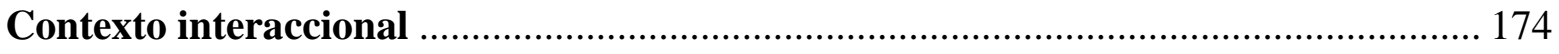

Procesos de cambio narrativo de la violencia escolar ............................................ 177

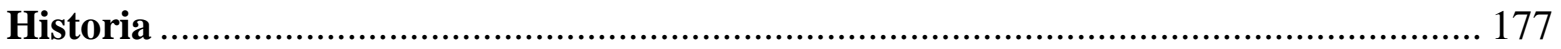


Relatos alternos y memoria 179

Categorías Emergentes: La emergencia del vínculo como potencializador del cambio. 187

Pertenencia 187

Contexto interaccional 189

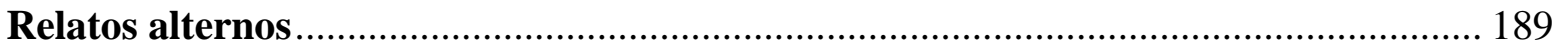

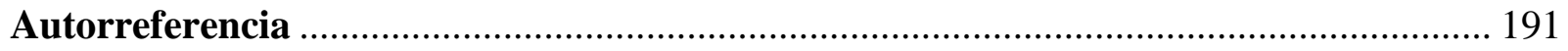

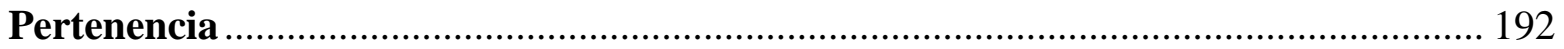

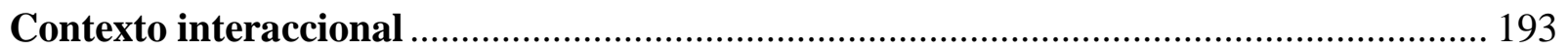

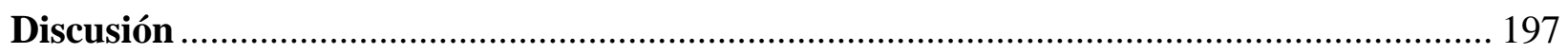

Configuración de la pauta relacional de la violencia. .................................................. 198

Reconfiguración narrativa de los procesos de autonomía hacia la coevolución.............. 202

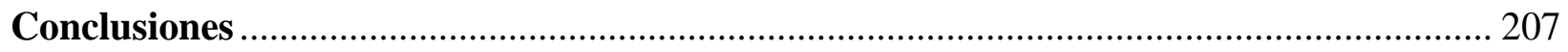

Para la Psicología Clínica y el Fenómeno de estudio. ................................................. 208

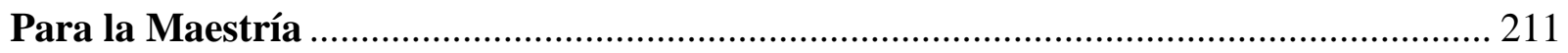

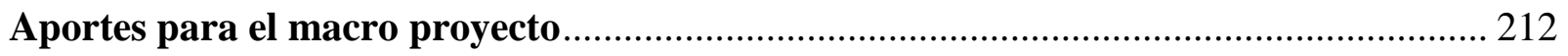

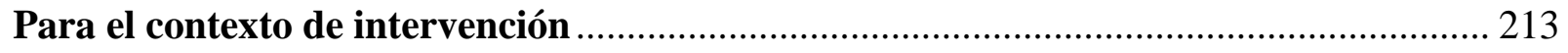

Para la investigadoras/interventoras ................................................................ 215

Aportes para futuras investigaciones/intervenciones........................................... 216

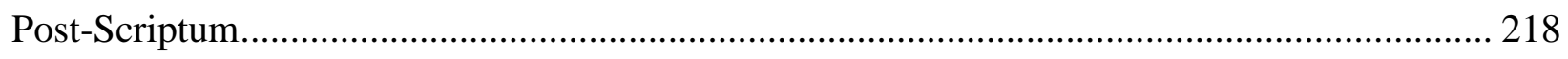

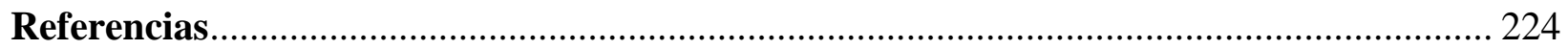




\section{Lista de figuras}

Figura 1. Comprensión de la pregunta de investigación alrededor de los ejes temáticos. . . . . 10

Figura 2. Mapa de comprensión de la relación entre estudiante, familia y escuela... . . . . 31

Figura 3. Sistemas amplios en la emergencia del estudiante desde el sistema escolar . . . . . .61

Figura 4: Nodos de conexión ecológica para el desarrollo de la intervención. . . . . . . . . . 102

Figura 5. Diseño del escenario numero 1: Contextualización. Conexión de los diversos actores

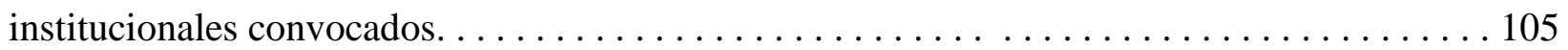

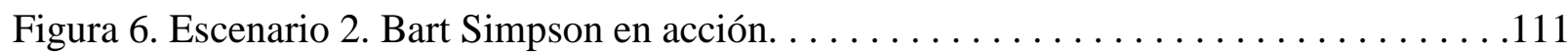

Figura 7. Escenario 3. Sembrando papas. . . . . . . . . . . . . . . . . 117

Figura 8 . Escenario 4 . Somos gestores de convivencia y paz. . . . . . . . . . . . . 121

Figura 9. Escenario 5. Cambia lo superficial, cambia también lo profundo... . . . . . 126

Figura 10: Ejemplo de matriz de categorización y organización de la información. . . . . . . 153

Figura 11. Comprensión del proceso de análisis de resultados. . . . . . . . . . 154 


\section{Lista de tablas}

Tabla 1. Escenario 1. Estado del arte testimonial. . . . . . . . . . . . . 32

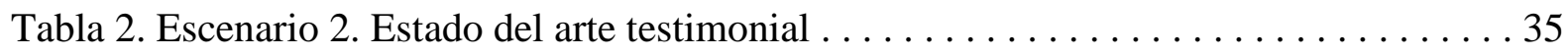

Tabla 3. Escenario 3. Estado del arte testimonial $\ldots \ldots \ldots \ldots \ldots \ldots \ldots \ldots \ldots$

Tabla 4. Escenario 4. Estado del arte testimonial . . . . . . . . . . . . . 41

Tabla 5. Análisis de escenarios testimoniales. . . . . . . . . . . . . . 46

Tabla 6. Voces, actores y participantes de la investigación/intervención. . . . . . . . . . . 100

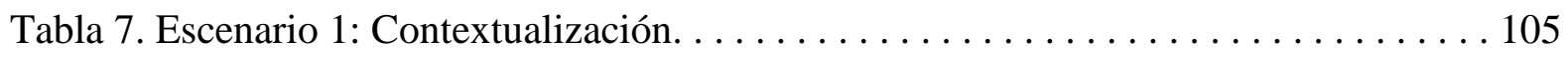

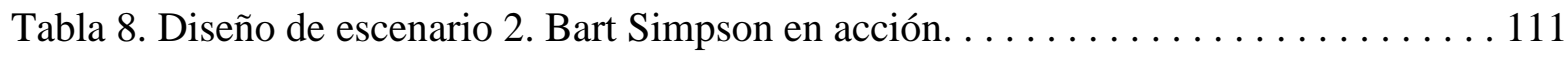

Tabla 9. Escenario 3. Sembrando papas. . . . . . . . . . . . . . . 117

Tabla 10. Escenario 4. Somos gestores de convivencia y paz. . . . . . . . . . 122

Tabla 11. Escenario 5. Cambia lo superficial, cambia también lo profundo... . . . . 126

Tabla 12. Neodiseño 1. Contextualización. . . . . . . . . . . . . . . . . . . . . 129

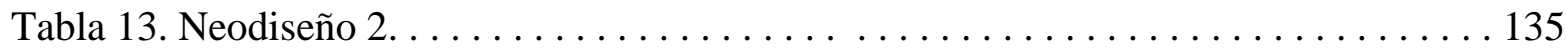

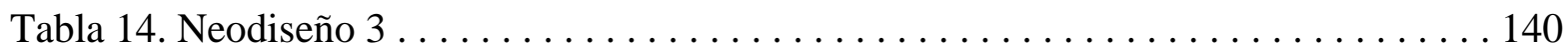




\section{Resumen}

La presente investigación/intervención se planteó en el marco del macroproyecto de investigación "Historias y Narrativas de los Sistemas Humanos en diversidad de contextos", en la cual se abordó el fenómeno de la violencia escolar en una Institución Educativa del contexto rural del Municipio de Turmequé - Boyacá, desde una perspectiva ecológica/compleja lo que favoreció la compresión de la violencia escolar incluyendo una mirada más amplia que permitió visibilizar la red de los distintos sistemas inmersos en el Municipio y así posibilitar la construcción de escenarios de intervención que re - configuraran narrativamente el fenómeno de estudio a través de la creación de diálogos generativos que permitan una conectividad ecológica

por medio del empoderamiento de los niños y jóvenes inmersos en dinámicas escolares violentas como gestores de paz y convivencia que les permitan co - evolucionar en grupo y fortalecer sus procesos de autonomía. En cuanto al método, se asumió una perspectiva sistémicaconstructivista construccionista y compleja, de enfoque cualitativo con diseños de escenarios narrativo - conversacionales basados en equipos reflexivos, los cuales posibilitaron la emergencia de diversas voces y versiones del fenómeno con los actores participantes.

Dentro de los principales aportes, se logró en una primera parte la comprensión de la configuración de la violencia escolar desde una lectura ecológica que permitió dar cuenta de dinámicas relacionales violentas cristalizadas y naturalizadas a través del tiempo por los distintos subsistemas que hacen parte del Municipio y que permean el subsistema escolar, que anudado al poco reconocimiento de la voz de los estudiantes y a una escases de vínculos fuertes y Movilizantes exacerbaban el surgimiento de la violencia escolar. Con lo anterior, en una segunda 
parte se logró reconfigurar narrativamente la violencia escolar por medio del empoderamiento de los niños y jóvenes como agentes autónomos que crean a través de una labor micropolítica espacios de participación y construcción de nuevas formas de relacionarse a través de la sana convivencia.

Palabras clave. Autonomía, Co - evolución, complejidad, micropolítica, violencia escolar.

\section{Summary}

This research / intervention was carried out within the framework of the research project "Histories and Narratives of Human Systems in a variety of contexts", which addressed the phenomenon of school violence in an educational institution in the rural context of the Municipality of Turmequé - Boyacá, from an ecological / complex perspective which favored the compression of school violence, including a broader view that allowed to visualize the network of the different systems immersed in the Municipality and thus enable the construction of scenarios of intervention that re - The phenomenon of study through the creation of generative dialogues that allow ecological connectivity through the empowerment of children and young people immersed in violent school dynamics as managers of peace and coexistence that allow them to co - evolve in groups and strengthen their processes of autonomy. As for the method, a systemic - constructivist and complexist perspective was adopted, with a qualitative approach with designs of narrative - conversational scenarios based on reflective equipment, which enabled the emergence of different voices and versions of the phenomenon with the participating actors. 
Among the main contributions was the first part of the understanding of the configuration of school violence from an ecological reading that allowed the account of violent relational dynamics crystallized and naturalized over time by the different subsystems that are part of the Municipality and Which permeate the school subsystem, which tied to the low recognition of the students' voice and a lack of strong and Mobilizing links exacerbated the emergence of school violence. With the above, in a second part it was possible to reconfigure narrative school violence through the empowerment of children and young people as autonomous agents that create through micropolitical work spaces of participation and construction of new ways of relating through healthy coexistence.

Keywords. Autonomy, Co - evolution, complexity, micropolitics, school violence 


\section{Presentación}

La investigación/intervención se desarrolló en un contexto educativo con niños, niñas y jóvenes pertenecientes al Instituto Técnico Industrial del Municipio de Turmequé - Boyacá en el marco del Macroproyecto de Historias y Narrativas de los Sistemas Humanos en Diversidad de Contextos, como opción de grado en la Maestría en Psicología Clínica y de la Familia de la Universidad Santo Tomás. Este estudio busca investigar e intervenir desde la psicología clínica el fenómeno de la violencia escolar como una construcción social en un contexto rural, con niños, niñas y jóvenes; en el cual el conocimiento y la construcción de historias y narrativas moviliza los procesos de autonomía en el sistema institucional, escolar y familiar por medio de la construcción de diálogos generativos. La investigación/intervención se realizó desde una mirada ecosistémica constructivista construccionista compleja de la institución donde se lleva a cabo este proyecto, por cuanto la mirada ecosistémica implica la movilización de todo el sistema ecológico alrededor de la redefinición de la violencia escolar mediante procesos narrativos conversacionales con la institución educativa, la familia y las diferentes instancias del Municipio.

La investigación/intervención permite visibilizar, cómo dentro de un sistema ecológico se organizan pautas interacciónales que configuran la violencia escolar y que dan cuenta de su relación con historias, experiencias y acontecimientos cristalizadas a través del tiempo en las familias del Municipio de Turmequé permeando modos de interacción en el sistema escolar alrededor de la violencia; de esta manera, se propician miradas ecológicas de la violencia escolar que corresponsabilizan no solo a los estudiantes inmersos en esta pauta, sino también a los sistemas circundantes. Teniendo en cuenta lo anterior, la investigación/intervención brinda nuevas posibilidades tanto a los sistemas amplios como a los estudiantes inmersos en el fenómeno de estudio para realizar comprensiones significativas respecto a la violencia escolar, 
que posibilitan emprender caminos interventivos hacia la potenciación de vínculos con sus sistemas sociales y familiares, así como facilitar el empoderamiento del sí mismo a través del fortalecimiento de los procesos de autonomía. La investigación/intervención contó con la participación de 16 niños, niñas y jóvenes con sus respectivas familias, pertenecientes a todos los grados académicos (desde primero a once). De igual manera se contó con la participación de los entes territoriales (dos funcionarios de comisaría de familia y un funcionario de la alcaldía) y la participación de la institución educativa (rectora, psicopedagoga, profesor, y coordinador). Teniendo en cuenta lo anterior, desde la institución educativa se permitió la construcción de miradas amplias que posicionan al estudiante a partir de posturas no solamente académicas, sino desde posibilidades que permiten un acercamiento basado en el diálogo, el apoyo y la orientación.

Es de interés para la Psicología y para la Psicología Clínica la atención al fenómeno de la violencia escolar dadas sus implicaciones en los procesos psicológicos, sociales, políticos y culturales de los niños, niñas y jóvenes, al estar expuestos en la mayor parte de su crecimiento y desarrollo a situaciones de violencia, que a su vez, propician modos de relación a futuro.

A lo largo del documento se presenta el proceso investigativo/interventivo. En un primer apartado se da cuenta del estado del arte documental en el cual se visualiza los estudios realizados en los últimos diez años que abordan la violencia en contextos educativos en distintas partes del país y el estado del fenómeno de estudio; así como se encuentra el apartado del estado del arte testimonial, el cual integra las voces de los actores y su comprensión respecto al fenómeno, pretendiendo conocer el entorno de las familias Turmequenses, creencias, epistemes, y la cultura que permea este Municipio y por tanto que esta enraizado en la población de estudio. Posteriormente se visualizan las comprensiones teóricas y epistemológicas del fenómeno 
posicionando la investigación/intervención desde una cibernética de segundo orden lo que permitió ampliar la comprensión de la violencia escolar y su re - definición hacia una mirada ecológica - compleja. Como tercer apartado se organiza el sistema metodológico, el cual da cuenta de los escenarios de investigación/intervención, se llevaron a cabo cinco escenarios y tres neo diseños se contó con la participación de estudiantes, docentes, personal administrativo, familias y funcionarios públicos, los encuentros que se llevaron a cabo a través de los escenarios de investigación/intervención permitieron la creación de nuevas realidades frente a la problemática, convocando los diferentes macrosistemas y microsistemas sociales, posibilitando la generación de bucles recursivos a través de la creatividad, la resignificación y la generatividad frente a nuevas alternativas de cambio.

El proceso de modelización muestra la forma en que se operacionalizo este estudio y permitió la creación de los principios metodológicos. Se desarrollan tres apartados finales, en los cuales se describen los resultados de la comprensión de la violencia escolar y su resignificación; la discusión que da cuenta de los antagonismos, concurrencias y similitudes emergentes en el proceso de investigación/intervención; y las conclusiones que le permiten al lector comprender los aportes al contexto, a la psicología Clínica, a la maestría, al macroproyecto y a la investigación/intervención.

A lo largo de este estudio se movilizaron herramientas que facilitaban la construcción del conocimiento por parte de las investigadoras/interventoras frente a la forma en que se organiza la violencia en un contexto rural y las diferentes maneras en que las familias son referentes de sus hijos e hijas en las conductas que a diario practican en sus contextos relacionales, el estudio daba la oportunidad de crear, innovar e imaginar un espacio diferente en la institución educativa frente a situaciones donde los estudiantes podían estar viviendo escenarios de violencia, que 
ocultaban bajo un silencio y al poner en marcha el conocimiento desarrollado por parte de las investigadoras/ interventoras en el trascurrir de la maestría facilitó diálogos generativos donde se conversaba de las diferentes emociones, sensaciones y percepciones que se tejían entre los estudiantes. 


\section{Introducción}

La pertinencia de este estudio da cuenta de los procesos de reconfiguración de la violencia escolar en un contexto rural, puesto que las interacciones que se tejen en contextos urbanos son distintos. Al ser el contexto rural más pequeños y con menor número de habitantes y estudiantes, permite comprender desde una perspectiva ecológica la configuración de la violencia desde sus macro y micro sistemas. El interés de las investigadoras/interventoras, se convierte en un motivo por entender y comprender las interacciones que se configuran entre los niños, niñas y jóvenes, cuando se convoca la violencia dentro de un entorno escolar. El foco de interés de esta investigación/intervención nace al cuestionar sobre ¿Qué está pasando con la violencia en el país? ¿Por qué en sistemas sociales y familiares se continúa perpetuando la violencia?, preguntas que llevaron a las investigadoras/interventoras, a acercar un poco más el zoom y a pensar en aquellos seres humanos a los que se consideran el futuro de Colombia: los niños, niñas y jóvenes, lo que llevó a la emergencia de otros cuestionamientos como: ¿Qué es lo que está sucediendo en los contextos escolares, que se está permitiendo que la violencia se permee y se construyan modos de interacción en torno a esta? ¿Qué es lo que como sociedad no se está visibilizando para que se construya la violencia en entornos escolares?, lo que movilizó a las investigadoras/interventoras en psicología clínica a corresponsabilizarse de un fenómeno que evidentemente está creciendo y está generando perturbaciones en estos seres humanos que son el presente y futuro de Colombia y salir un poco de los consultorios clínicos para realizar lecturas contextuales y culturales de la violencia escolar en un contexto rural del Municipio de Turmequé - Boyacá.

Según el instituto nacional de medicina legal y ciencias forenses (2012), en el año 2011 se dictaminaron 152865 lesiones interpersonales, 51826 a mujeres (33.9\%) y 101039 a varones 
(66.1\%) de los cuales $41.86 \%$ correspondía a víctimas entre cero y veintinueve años de edad, ocurriendo el $2.34 \%$ de los casos en centros educativos, datos que indican la violencia interpersonal en Colombia afectan especialmente a varones adolescentes y adultos jóvenes y que al menos del $2 \%$ de los casos ocurren en la instituciones educativas.

El fenómeno de estudio establece conexiones de las realidades alrededor de la violencia escolar en un contexto educativo y sus configuraciones vinculares con las familias, el ámbito educativo y el contexto rural. Es de esta manera, que la violencia escolar se convierte en un fenómeno importante para la psicología clínica sistémica dados los dilemas que surgen en el sí mismo y en las formas de relación al configurarse la persona alrededor de la violencia escolar cristalizando los procesos de autonomía y co-evolución; es así que por medio de las narrativas y las historias relatadas los estudiantes, familia, profesores e institución educativa dan cuenta de dichos dilemas en el sistema escolar que a su vez se conectan con el medio cultural, social y ecológico. La visibilización del fenómeno desde la psicología compleja, permite comprender la multidimensionalidad de los sistemas y su evolución dinámica que desde sus estructuras de relaciones se autorregulan creando procesos de distinción, que tal como lo menciona Anzola (2003):

El enfoque escolar visto desde el enfoque sistémico - construccionista y desde la acción de la consultoría posee una complejidad cuyas dimensiones son múltiples en el entramado de relaciones que se tejen entre los diversos niveles participantes: alumnos, directivos, administrativos, maestros y padres de familia; constituyéndose así un modelo de red social (p. 230). 
Es así que el fenómeno de investigación da cuenta de las relaciones que se organizan en el contexto escolar que convocan modos de interacción construidos desde entornos familiares, escolares y sociales y que permiten la organización de los niños, niñas y jóvenes en la construcción del sí mismo y de sus procesos de autonomía a través de configuraciones vinculares con el otro que pueden facilitar relaciones movilizantes o que pueden propiciar el surgimiento de la violencia escolar.

El problema de investigación implica comprender la construcción narrativa conversacional de la violencia escolar en un contexto rural en niños y jóvenes de los diferentes ciclos académicos con el fin de comprender como se configura interaccionalmente la violencia escolar desde una perspectiva ecológica/compleja que permita visibilizar la conectividad de la red para configurar el fenómeno y crear procesos de trasformación que le permitan a los niños y jóvenes fortalecerse en sus procesos de autonomía hacia su co - evolución como grupo que fortalezca el sí mismo relacional y el empoderamiento hacia la creación de nuevas herramientas que les permitan construir nuevas formas de relacionarse a través de la sana convivencia y de la continua autogestión de la misma. Teniendo en cuenta lo anterior, se plantea como problema de investigación, la configuración de la violencia escolar en el sistema educativo, su incidencia en los procesos de autonomía y co-evolución de los niños, niñas y jóvenes, y cómo ésta se conecta con la violencia percibida en el Municipio permeada por acontecimientos y experiencias culturales, sociales y generacionales; que a su vez crean sistemas de significados que se configuran en el aula de clases y que darían cuenta de diferentes realidades alrededor de la violencia escolar; lo anterior conectado con procesos vinculares que surgen de la relación que el niño y joven establece con sus sistemas circundantes y que le posibilitan fortalecerse en sus procesos de autonomía. Este problema está asociado, a la necesidad de posibilitar escenarios de 
intervención en las cuales el investigador/interventor hace parte como un facilitador de narrativas emergentes que favorezcan la co - evolución de los procesos de autonomía que le permitan a los niños y jóvenes empoderarse como gestores de sana convivencia que a su vez permita abrir la red y generar puntos de conexión narrativa que los movilice hacia el cambio como institución educativa, familia y Municipio.

Es así, como el problema de investigación se plantea entonces como, el desarrollo de los procesos narrativos conversacionales en la configuración y reconfiguración vincular de niños y jóvenes durante su permanencia en el sistema educativo: inicio hasta transición, primaria (ciclo 1 y 2), primeros años del bachillerato $(6,7$ y 8 , ciclo 3$)$ y últimos años del mismo $\left(9,10,11^{\circ}\right.$, ciclo 4); que darían cuenta de diferentes realidades alrededor de la violencia escolar, las cuales incluyen a su familia y los integrantes del contexto educativo. Este problema estaría asociado, a la necesidad de favorecer narrativas emergentes del vínculo que pueda conllevar a autonomía e individuación del niño y joven con todos los integrantes de su micro y macro sistema.

A partir de la investigación/intervención, se permiten aproximaciones y comprensiones desde la Psicología Clínica y la complejidad en un enfoque constructivista - construccionista alrededor de los procesos de autonomía que co - evolucionan en los entornos escolares. Teniendo en cuenta lo anterior, los actores participantes convocados para el presente estudio se constituyen en familia, niños y jóvenes, escuela, comunidad, entes institucionales del Municipio, y demás sistemas amplios, que desde una psicología compleja se interconectan entre sí, anudando fuerzas alrededor de los procesos de autonomía y co - evolución de los niños, niñas y jóvenes que posibilitarían el afrontamiento a la violencia escolar.

Es así, cómo surgen preguntas referentes a este problema, destacando dos, una respondiendo a la investigación y otra que nace a partir de la intervención. Por una parte, la pregunta de 
investigación, corresponde: ¿Cómo se construye narrativamente la violencia escolar en el sistema educativo y se comprende su función en los procesos de autonomía hacia la co-evolución de los niños, niñas y jóvenes desde una lectura contextual y compleja? Por otra parte, la pregunta de investigación, se plantea de la siguiente manera: ¿cómo se facilitan los procesos de autonomía que posibiliten co - evolucionar en grupo a partir de la intervención narrativa conversacional que redefina la violencia escolar?

Comprendiendo este fenómeno, las autoras proponen como objetivos e hipótesis de la investigación intervención los siguientes:

\section{Objetivo General de Investigación/Intervención}

Comprender los procesos narrativos conversacionales de la violencia escolar, que se configuran en el sistema educativo, con el fin de posibilitar en la intervención procesos de reconfiguración narrativa conversacional de la violencia escolar a partir del fortalecimiento de los procesos de autonomía que permitan co - evolucionar en grupo y fortalecer la dinámica vincular del niño y joven con sus sistemas circundantes que hacen parte de su ecología.

\section{Objetivo Específico de Investigación}

Comprender cómo se configura la pauta relacional de la violencia escolar desde una perspectiva ecológica y su incidencia en los procesos de autonomía.

\section{Objetivo Específico de Intervención}

Posibilitar espacios de intervención con el contexto educativo, la familia y sistemas amplios para favorecer la reconfiguración narrativa conversacional de la violencia escolar, que conlleven procesos de autonomía hacia la co - evolución, en la dinámica vincular de niños, niñas y jóvenes, durante su permanencia en el sistema educativo. 


\section{Hipótesis de Investigación}

La violencia escolar se configura alrededor de las relaciones que los niños, niñas y jóvenes construyen con los diferentes integrantes de su contexto ecológico a partir de procesos vinculares, donde se construyen historias permeadas por la experiencia del Municipio y del entorno escolar incidiendo en el fortalecimiento de sus procesos de autonomía los cuales les permiten co - evolucionar y crear nuevas formas de relacionarse.

\section{Hipótesis De Intervención}

La narrativa conversacional facilita procesos de reconfiguración de la violencia escolar en la intervención, posibilitando la emergencia de la autonomía que posibilita co - evolucionar en la dinámica vincular de los niños, niñas y jóvenes, durante su permanencia en el sistema educativo en la relación con este sistema, su familia y sistemas amplios. 


\section{Estado del arte documental}

El presente estado del arte documental inicia contextualizando al lector en lo referente a la violencia escolar, considerando sus diferentes definiciones y las distintas miradas que permiten visualizar los enfoques y los estudios que se han desarrollado alrededor de este fenómeno. Como un aspecto alterno a este mismo apartado, se desarrollan las características de la violencia escolar y su relación con la familia, la escuela y los sistemas amplios. Lo anterior permite, considerar una visión diferente de dicho fenómeno, donde se citarán algunos autores que contribuyen desde una mirada sistémica a la comprensión de la realidad desarrollada en torno a la violencia.

Luego de ello, se proponen algunos puntos de los procesos narrativos y los diálogos generativos, recurriendo algunos autores, a sus estudios y resultados, con la intención de conectar la construcción de narrativas con la co - evolución de los procesos de autonomía en los niños, niñas y jóvenes alrededor del presente fenómeno. 


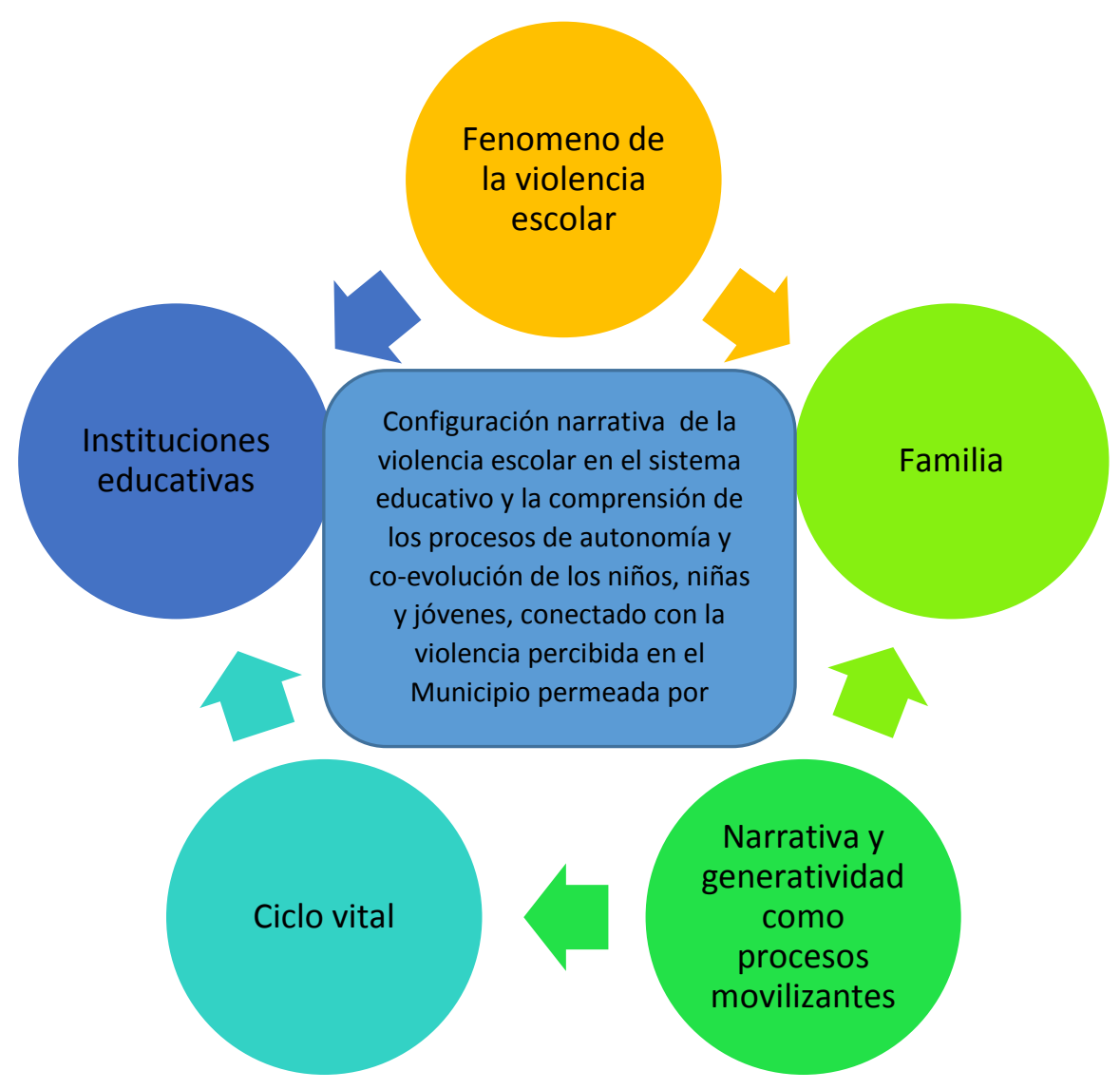

Figura 1. Comprensión de la pregunta de investigación alrededor de los ejes temáticos.

\section{Contextualización Ecológica de la violencia escolar}

En la comprensión del fenómeno de la violencia escolar, es importante tener en cuenta algunos de sus factores asociados, tal como lo menciona Castillo (2011) el contexto social, cultural, y familiar, su origen, nivel socioeconómico, institución educativa y el concepto que la sociedad genera sobre la violencia, se relaciona de manera directa e indirecta con la aparición y desarrollo de este fenómeno.

Teniendo en cuenta lo anterior, se citan a Benítez y Justicia (2006), quienes refieren que el conjunto de violencia física y psicológica entre un grupo de iguales se establece bajo relaciones de poder entre los estudiantes, y que por su frecuencia, duración e intencionalidad crea daños en 
la integridad de las personas y en específico entre los compañeros de clase. Dan Owelius en 1983 fue el primero en hablar de violencia escolar; teniendo en cuenta este fenómeno, la violencia generada en el entorno escolar y que mantiene desde sus relaciones de poder y/o desigualdad alrededor de la agresión física, verbal y psicológica de un grupo hacia una persona en específico.

Por su parte Garzón (2006) refiere que la violencia en la familia tiene relación directa con la violencia en el país, dado que la familia es construida desde una cultura de la violencia, quizás una construcción desde la incidencia social y política.

Consolidando lo anterior, es importante tener en cuenta las consecuencias percibidas, generadas por la violencia, en este sentido, Garaigortdobil, M., \& Martínez-Valderrey, V. (2015) refieren que sea cual sea la razón por la cual emerge la violencia, esta tiene devastadoras consecuencias físicas y psicológicas. En este orden de ideas, este fenómeno, se puede considerar como un tipo de violencia en un contexto específico que atenta con el bienestar psicológico de los estudiantes y que establece relaciones de poder en un contexto cultural especifico lo que no favorece el crecimiento personal de los niños y jóvenes.

Estos mismos autores (Garaigortdobil, M., \& Martínez-Valderrey, V. 2015), refieren que cada uno de los actores manifiestan diferentes grados de sufrimiento, resaltando que no solamente los perpetuadores y los heridos por la violencia son los únicos afectados, sino también los observadores, quienes se encuentran expuestos a aprendizajes negativos y, por lo tanto, dicho entorno se encuentra expuesto a sufrir un desajuste psicosocial.

En este punto, es importante para la investigación/intervención realizar una comprensión ecológica de los estudios que se han realizado alrededor de esta temática, los estudios son numerosos en el tema de violencia escolar, esto permite dar cuenta de la importancia que ha 
tenido y el alto impacto de las agresiones entre estudiantes que día a día han ido en aumento. Para esta investigación/intervención se tomaron estudios a partir del año 2005 para conocer los diferentes focos de intervención e investigación, donde se resaltan los siguientes, como bases para observar, cómo este fenómeno se desarrolla en su mayoría a partir de relaciones de causalidad (violencia familia igual violencia escolar); sin embargo, es importante rescatar el esfuerzo de muchos investigadores por visualizar este tipo de violencia desde una perspectiva sistémica.

En el año 2005, los investigadores Hoyos, Aparicio y Córdoba (2005), analizaron una muestra de 332 estudiantes de sexto a noveno grado, niños y niñas, describiendo las generalidades y la caracterización del fenómeno en colegios de la ciudad de Barranquilla, teniendo en cuenta no solo las circunstancias en las que se presenta sino a todos sus protagonistas: agresores, víctimas y testigos. Como metodología utilizaron, un enfoque clásico / experimental, y la aplicación de un cuestionario. Dentro de los resultados encontrados, se evidencian las manifestaciones de abuso del poder y maltrato (tanto de tipo físico, psicológica, verbal, sexual, entre otras).

Por otra parte, los investigadores colombianos Enrique Chaux y Ana María Velásquez (2005), con el objetivo de observar las manifestaciones de agresión, violencia y delincuencia entre estudiantes de establecimientos educativos oficiales y no oficiales en el Distrito Capital y los municipios cercanos de Soacha, Sibaté, Cota, Chía, Funza y Mosquera, realizaron su investigación utilizando una metodología experimental. Dentro de los resultados más relevantes de este estudio, se encuentran la prevalencia de maltrato de tipo emocional y la delincuencia percibida entre los mismos participantes del contexto escolar.

Por otro lado en Cali - Colombia, se llevó a cabo el primer estudio exploratorio de la violencia escolar, por Paredes, Álvarez, Lega, Vernon (2005), quienes siguieron una línea 
metodológica experimental, utilizando como herramienta un cuestionario con el fin de identificar la problemática; de esta manera, los resultados demostraron presencia del fenómeno expresado por medio de la agresión física, verbal y psicológica; revelando mayor aparición de la violencia verbal en presencia de otros estudiantes y profesores en el aula de clases.

Los estudios anteriores, revelan las formas de investigar alrededor de la violencia escolar, investigaciones de corte cuantitativo que focalizan y estereotipan las interacciones entre los actores inmersos en el fenómeno, considerando aún, las relaciones de víctima y victimario y la priorización de dicho fenómeno como un síntoma que debe ser curado. Dentro de estos estudios e investigaciones, cabe resaltar el siguiente programa de intervención que logro incluir a los actores dentro de un espacio de participación y empoderamiento:

En el departamento de Cundinamarca con el apoyo de la Cámara de Comercio de Bogotá (2006), se propone el Programa para la gestión del conflicto escolar "Hermes", el cual en la actualidad aún se aplica para la intervención de la violencia escolar, con el objetivo de fomentar el diálogo y la tolerancia en la escuela, buscando resultados e incidencia en el medio social, cultural y familiar, convocando como actores principales a estudiantes y profesores. Teniendo en cuenta lo anterior, este programa utiliza como metodología la utilización de una serie de herramientas pedagógicas a través del diálogo y la resolución de conflictos donde estudiantes y maestros son capacitados para desempeñar un rol de conciliadores de conflictos; de esta manera este programa obtiene resultados significativos, resaltando el esfuerzo por incluir a los jóvenes y empoderarlos en cuanto a las dinámicas violentas, invitándolos a crear métodos de conciliación diversos, lo que ha permitido replicar dicho programa en diversos municipios.

Por otro lado, en Finlandia es construido y desarrollado el método KIVA diseñado por su gobierno en el año 2007 para contrarrestar el Bullying en el contexto escolar. Una de las 
precursoras de este método es Christina Salmivalli, el proyecto se fue incorporando de manera aleatoria a los colegios hasta que el $90 \%$ de los centros educativos implementaron el método. La palabra KIVA significa contra el acoso escolar. Años después de haberse puesto en marcha el método obtiene como resultados el $80 \%$ de disminución de Bullying lo cual fue un método que encantó a la comunidad internacional y se ha venido implementando.

Es tal la eficiencia del método que inclusive los alumnos y alumnas mejoraron en sus calificaciones; este método recibió un premio europeo de prevención del crimen en el año 2009, la estrategia del método está diseñada para que cuando el agresor intercepte a su víctima, los testigos no participen indirectamente en el acoso, esta situación se logra a través de un equipo que organiza la institución comprendido por unos adultos, que son los docentes y los alumnos donde se sensibilizan a través de unos encuentros donde se realizan charlas, videojuegos, manuales para los profesores, vigilancia en el recreo, largometrajes y un buzón de sugerencias para reportar un caso de acoso escolar.

\section{Familia y su relación con el Fenómeno de la violencia escolar}

Teniendo en cuenta la familia, como ente crucial para la formación y aprendizaje Polaino (2013), refieren desde una mirada clásica, que la violencia juvenil está directamente relacionada con la violencia percibida en la familia, manifestando que la violencia social refleja todas las particularidades de la violencia Familiar y por lo tanto existe una violencia encubierta. En este sentido, los autores consideran que todo tipo de violencia tiene un origen en la violencia y agresividad vivida, percibida o experimentada en el ámbito familiar, dicha violencia que no cesa, incrementa una violencia social que cataloga al individuo cómo violento que nace, crece y se desarrolla en un ambiente violento. 
Hernández y Bravo (2008) explican que los rituales elaborados establecidos en el entorno familiar hacen parte de los niveles que en algunos casos coinciden con la violencia intrafamiliar. De esta manera la ritualización generacional conlleva al surgimiento de comportamientos que se trasmiten no solo en el entorno familiar, sino también se llevan a cabo en el entorno social. En el caso de la violencia escolar, la familia y sus relaciones vinculares conllevan a la elaboración de hábitos e interacciones sociales, que en el caso de los adolescentes se trasmite a sus pares y compañeros de clase. Este foco orienta la participación de la familia en el desarrollo de la violencia, considerando que desde la crianza y las pautas interacciónales en torno a la sana convivencia y a las manifestaciones de violencia (sea física o psicológica), se forman pautas heredadas desde la convivencia y los patrones de comunicación entre los miembros de un grupo familiar. En este sentido, dichas pautas se trasladan a diversos contextos de interacción reflejando modelos construidos desde el propio hogar.

Para Ferrer, B. M., Ochoa, G. M., Muñoz, L. A., \& Gimeno, M. M. (2012), el desarrollo de recursos significativos en los adolescentes tiene una incidencia directamente relacionada con el apoyo parental que indudablemente se conectan en el desarrollo y la percepción de las relaciones escolares. Teniendo en cuenta esto, para dichos autores los padres o cuidadores influyen de manera diferente en el adolescente; en este sentido, por su parte el padre protege a su hijo de los actos violentos, conectado en desarrollo de la autoestima dentro del entorno escolar y familiar; por otro lado, la madre incide más en las percepciones de la escuela considerando que en estos entornos se debe desarrollar el crecimiento personal, la autoestima y el auto concepto.

Las familias, generalmente realizan ciertos tipos de intercambio que son predecibles dentro de su sistema familiar, lo que permitiría desde un punto de vista terapéutico la construcción de una coreografía, un mapa familiar donde se configure la tipología de familia, la cultura, su 
evolución, su presente, su pasado, las normas interiores y los entes de autoridad. Minuchin (1998) enfatiza el conflicto familiar comparándolo con los puntos de vista diferentes de cada miembro de la familia, lo que genera una cierta tensión equilibrada, donde cada persona tiene sus propias perspectivas, únicas, que permiten diferenciarse uno del otro; sin embargo, cuando no existe ese tipo de tensión equilibrada se llega al punto de generar espacios en blanco, donde la familia no afronta las situaciones difíciles. En este punto se resalta la importancia de los roles que los diferentes miembros de la familia desempeñan dentro del sistema, considerando que cada uno tiene un papel importante, que transmite información relevante al desarrollo de los niños, niñas y adolescentes. Lo anterior permite considerar, la importancia de estudiar el fenómeno desde las relaciones de jerarquía y de poder que ejercen, en este caso los padres o cuidadores, en el rol dinamizador y comunicacional de los estudiantes.

Según Kuang-Hui YehWei-Chun TsaoWei-Wen (2010), las relaciones de afecto y reciprocidad negativas entre padres e hijos conllevan a la ruptura de la relación intergeneracional creando conflictos que producen problemas de externalización provocando en los adolescentes conductas de riesgo como la entrada a grupos sociales de influencia negativa, búsqueda de refugio en otras personas para generar el vínculo que falta en la relación con los padres, aumentar el riesgo de fumar, beber, o generar comportamientos agresivos y antisociales.

Para Hernández y Bravo (2008) los vínculos que se adoptan desde relaciones de expresión de emociones diversas (amor, odio, rabia, empatía, altruismo...), conllevan al desarrollo de vínculos ambivalentes y que inciden en el desarrollo de las personas y la implicación de su discurso. En este sentido según los vínculos que se generen dentro del núcleo familiar pueden emergen situaciones de amenaza, conflicto, discusión, violencia, que amenazan la supervivencia de las 
personas. De la misma forma si los vínculos son fortalecidos puede llevar al fortalecimiento de la vida la familia y de sus miembros.

Comprendiendo que dentro de la familia se construyen relaciones que favorecen el cuidado entre los miembros, la protección y el desarrollo de cada uno de ellos, los vínculos débiles que se generan con los padres o cuidadores conlleva a la externalización de interacciones diferentes al núcleo familiar; de esta manera dichas interacciones pueden causar búsqueda de distintos vínculos y conexiones que en ocasiones no favorecen el desarrollo del bienestar psicológico del joven, incurriendo en comportamientos agresivos hacia los demás.

Complementando lo anterior, Hoyos, Aparicio, Romero, Valega y Olmos (2008) proponen en sus estudios realizados sobre creencias de padres y madres acerca del maltrato entre iguales por abuso de poder y exclusión social. Con una muestra de 267 padres y madres de diversas instituciones educativas de la ciudad de Barranquilla, y utilizando una metodología de corte cualitativo, evidencian como resultados la percepción que tienen los padres acerca de la violencia escolar, quienes manifiestan que este es un problema que los estudiantes no pueden solucionar por sí solos, sin embargo se manifiesta, en algunos casos que los padres no consideran las agresiones verbales como significativas en el desarrollo de los adolescentes. Por otro lado, en este mismo estudio los padres de familia manifiestan que este conflicto se da debido al carácter conflictivo de los adolescentes y por otro lado manifiestan que la sobreprotección favorece la elaboración del rol de víctima; cómo causas sociales en este estudio los padres refieren que se debe a una influencia de los medios de comunicación y a una relación con el clima de violencia de la sociedad y la convivencia dentro del centro educativo. De igual manera los padres consideran que sus hijos confiarían el cien por ciento en ellos para contar sus dificultades escolares y que como padres tomarían acciones sí llegaran a percibir situaciones de violencia 
escolar en sus hijos; sin embargo, consideran que es necesario que el colegio intervenga en la resolución de conflictos de los escolares.

Lo anterior, permite reflexionar sobre la importancia de concebir a la familia dentro de los estudios del fenómeno de la violencia escolar, con el fin de observar y conocer las diferentes conceptualizaciones de los padres respecto a la convivencia escolar de sus hijos y el apoyo de la familia en la construcción de la autonomía de los niños, niñas y adolescentes.

\section{Entorno Escolar y otros ámbitos para comprender el fenómeno de la violencia escolar.}

Según Orozco, G. M., Méndez, P. A. M., \& García, M. Y. E. (2015), los niños dentro de una institución educativa perciben fácilmente el medio social en el que se encuentran, donde se resaltan las relaciones de poder delimitadas por reglas y ordenamientos. De esta manera el poder actúa como un catalizador para evitar los abusos. El niño al encontrarse inmerso dentro de una cultura, se encuentra inmerso en una serie de reglas universales. Teniendo en cuenta esto, los autores mencionan, que dentro de la escuela la única violencia que se ejerce no es la violencia escolar; sin embargo, el foco de atención más grande está dirigida hacia esta. Aunque la escuela debe mantener una posición pacificadora, en muchas ocasiones lo que busca dentro de las soluciones es "interpelar" y "disciplinar" con el fin de formar sujetos "normales" para una sociedad.

Hernández y Bravo. (2008) al hablar de psicología compleja refieren que el ser humano se encuentra inmerso dentro de la interdependencia entre lo cultural, lo subjetivo, lo cerebral y lo biológico; de esta manera las interacciones y los significados operan alrededor de los vínculos que se crean en un grupo social. Teniendo en cuenta lo anterior, los vínculos que se desarrollan entre los estudiantes se encuentran relacionados con el tipo de interacciones que se desenvuelvan en el ámbito escolar, ya sean sólidas, distantes, agresivas, todo esto alrededor de la construcción 
del propio individuo en su ámbito familiar, cultural y social, considerándolo como fundamental en la comprensión del fenómeno dado que no se limita a lo familiar ni a lo escolar, proponiéndolo como un interjuego de escenarios que participan tanto para mantenerlo como para transformarlo.

Por otro lado, no solo las relaciones de poder y el rol de la familia tienen su incidencia en la construcción de la violencia en el aula, sino también las relaciones con los pares y sus respectivas interacciones, en este orden de ideas, para Macintyre, C. (2009) las diferencias culturales, familiares, físicas, personales, las experiencias fuera y dentro de la casa, las diferencias temperamentales, entre otras, implican diferentes formas de interacción, la forma de interactuar con los miembros de un grupo y la motivación para aprender. Por otro lado, la forma de ver el mundo y las experiencias individuales influyen en la forma de percibir los pensamientos y sentimientos del otro, lo que facilitaría o impediría relacionarse con los demás. De esta manera, a los niños se les debe enseñar y explicar que, ciertas formas de comportarse podrían considerarse acoso escolar y por lo tanto, es necesario permitir que desarrollen la empatía, la comprensión del otro y el altruismo, encontrando que, estos factores son clave para el reconocimiento de los sentimientos de los demás.

Teniendo en cuenta lo anterior, las diferencias entre un niño y otro, muestran la existencia de distintas clases de conductas de acoso escolar: abuso físico, insinuaciones disimuladas, agresión verbal, amenazas, entre otras. Es así, como los procesos interacciónales construyen distintas formas de relación donde se tiene en cuenta la cultura, los problemas y vicisitudes en el surgimiento de la violencia que se desarrolla y configura en dichas relaciones; en este orden de ideas la violencia emerge de las mismas condiciones sociales y como resultados de la desigualdad de la estructura social, los valores y el sistema de creencias culturales (Estupiñan, 
Garzón, Niño 2006). De esta manera, se hace necesario citar a Hernández, Bravo. (2008) quienes se refieren a las vinculaciones y desvinculaciones que se dan a partir de la construcción de la realidad que generan vínculos frágiles o sólidos y que constituyen un proceso de inclusión social.

Según Kaplan, C. (2009), para poder explicar un fenómeno social, como lo es la violencia escolar, es necesario considerar dicho fenómeno, no desde la individualidad, sino desde las propiedades estructurales de los grupos, observar y analizar las redes de interdependencia que caracterizan a las diferencias de poder dentro de un grupo social equilibrado. Lo anterior, se refiere a que las relaciones entre los diversos actores involucrados son interdependientes, es decir la relación depende del comportamiento del otro, donde entran en juego deseos, identidades, estrategias, miedos, entre otros. Un aspecto importante a mencionar, y referido por este mismo autor, es que la violencia se considera como la "ausencia de sentido de los actos sociales".

De acuerdo a lo anterior, las interacciones humanas dentro del fenómeno social, se trasladan no solamente a estar desde la individualidad, sino desde las interacciones con los demás. En este sentido apoyando la premisa planteada por Bateson (1972) "el funcionamiento espiritual es inmanente a la interacción de "partes" diferenciadas. Las "totalidades" son constituidas por esa interacción combinada".

Finalmente se incluye un estudio realizado en la Maestría de psicología clínica y de la familia de la universidad Santo Tomás acerca de la reconfiguración del Ciberbullying en un contexto escolar, Buitrago, Silva y Rada (2015) a través de lecturas sistémicas realizaron comprensiones en torno a las relaciones que se construyen en el ciberespacio a través de meta historias mediante procesos interactivos organizando la experiencia humana a partir de fragmentaciones y deshumanizaciones cuando se privilegian relatos dominantes frente a la imposibilidad de generar cambios, esta investigación generó una emergencia en la población de estudio cuando se 
reconfigura este tipo de violencia y permite restablecer la confianza y la solidaridad en nodos conversacionales escolares.

Lo que da cuenta de la importancia de la narrativa conversacional como fuente de cambio en los diferentes procesos en los que está inmerso el ser humano, si existe una mirada deficitaria los demás contextos interacciónales están inmersos en esta ideología, por su parte cuando hay una narrativa generativa creativa genera bifurcaciones produciendo cambios que potencian las diferentes dimensiones de vida.

\section{Conclusiones del estado del arte Documental}

Concluyendo lo anterior, la violencia en general y específicamente la violencia escolar emerge de las construcciones que se prestan a través de las interacciones, de esta manera la familia, los amigos, los compañeros de clase y los profesores de un sistema escolar favorecen o desfavorecen el surgimiento del fenómeno. Teniendo en cuenta lo anterior las condiciones sociales y culturales que rodean a dichos sistemas de interacciones construyen diversas realidades y por lo tanto diferentes formas de actuar y comportarse según el escenario social; en este sentido es relevante contemplar otros actores que participan en el desarrollo de los estudiantes y que por lo tanto pueden ayudar a transformar los vínculos que favorezcan los procesos de autonomía de los participantes en el contexto educativo.

En el fenómeno de estudio las diferencias sociales, culturales y familiares (dinámica y crianza familiar) posicionadas en un solo espacio temporoespacial, conlleva a que los estudiantes (actores sociales en el aula de clases) perciban con mayor detenimiento dichas diferencias y por lo tanto se generen malentendidos, discusiones y violencia escolar. 
Teniendo en cuenta lo postulado por los autores citados, para el fenómeno de estudio se hace necesario considerar que todas las acciones violentas son construcciones caóticas de la realidad, es importante destacar que este fenómeno no solamente incluye a los miembros donde se hace efectiva la violencia, sino también tiene efectos en las construcciones futuras de los observadores o el grupo de estudiantes de un aula. Lo anterior brinda un punto importante, teniendo en cuenta que dichas interacciones en el aula inciden en realidades alternas, es decir en la vida cotidiana de cada uno de los niños, niñas y jóvenes que son observadores de un acto violento en el aula de clases.

En el colegio así como en otros sistemas institucionales, existen jerarquías y relaciones de poder que se determinan en las diferencias interacciónales; en las instituciones educativas, estas relaciones de poder se ven reflejadas en los profesores quienes cumplen el rol catalizador y pacificador con el fin de encontrar un equilibrio entre las leyes universales (la familia y la sociedad) y las leyes de la institución educativa; sin embargo en muchas ocasiones tal como lo mencionan los autores citados, esta intención pacificadora de los entes de poder institucional se pierde en la necesidad de cumplir con las exigencias de la educación y la disciplina formadora. Lo que permite observar como se ha limitado la comprensión de la violencia escolar a unas pautas de poder entre pares, o por eventos familiares, pero no en relación a otros actores que son parte del ámbito educativo.

En este orden de ideas, la lealtad entre los estudiantes de un salón de clases incluye la aceptación y encubrimiento de todo tipo de situaciones como si se tratase de una familia. En apoyo a la idea anterior, en el fenómeno de la violencia escolar llaman la atención las coaliciones que se presentan entre los miembros de un grupo, donde dichos miembros encubren y apoyan la 
violencia que se genera dentro de un espacio escolar. De esta manera cabe preguntar ¿Cómo se construyen los vínculos y las narrativas de los estudiantes en su contexto escolar?

Es necesario tener en cuenta la educación, la crianza, las interacciones familiares y las experiencias individuales de cada uno de los estudiantes de la institución educativa.

En este punto es necesario reflexionar sobre lo importante de las narrativas y los vínculos dentro de las interacciones que se dan entre los estudiantes de una institución educativa, dado que como lo mencionan los autores, las respuestas agresivas pueden ser un resultado de la mala interpretación de los significados que cada uno de ellos le atribuye, que se relaciona directamente con los significados construidos desde la propia cultura, la familia y las experiencias vividas.

Es así que los títulos que se contemplan en el estado del arte documental buscan tener una conceptualización clara de los aportes realizados por los autores, en los diferentes estudios de esta manera se puede tener una visión amplia frente a la violencia escolar.

El fenómeno de la violencia presenta varios orígenes ya sea social, cultural, familiar, económico e incluso el papel de la sociedad en el desarrollo integral de una persona.

Otro punto a tener en cuenta son las relaciones de poder que se construyen entre pares manteniendo comportamientos tales como agresión física, verbal y psicológica, no se puede olvidar que la violencia que ha caracterizado a Colombia tiene incidencia en actos violentos, como también rituales que se establecen en el entorno familiar donde coinciden con la violencia, formando pautas heredas de convivencia.

Este fenómeno siempre va a dejar devastadoras consecuencias en las personas que la viven tanto en lo físico como en lo emocional. Donde el sufrimiento está presente no solo en estas personas sino también en observadores. 
En los estudios realizados con metodologías experimentales y exploratorias se demostró que existe mayor tendencia a hacer uso de la violencia verbal y el maltrato emocional.

Los estudios buscan contrarrestar episodios de violencia a través de soluciones como son el diálogo y la resolución de conflictos.

De esta manera se han generado recomendaciones en realizar estudios del fenómeno a partir de las relaciones de poder y jerarquía que ejercen los padres, cuando existen relaciones de afecto y reciprocidad negativa entre padres e hijos se generan conflictos provocando conductas de riesgo, sin embargo los sistemas parentales han manifestado que hay una gran influencia de los medios de comunicación en dichas conductas aprendida por sus hijos e hijas.

La violencia vista como un fenómeno no se debe considerar desde lo individual sino desde las propiedades estructurales de los grupos y las redes de interdependencia que se generan al interior del grupo.

\section{Estado del arte testimonial}

Posterior a la revisión concienzuda de los ejes temáticos planteados en el estado del arte documental, y considerando como aspectos importantes el fenómeno, el problema, las hipótesis y los objetivos e Hipótesis de investigación/intervención, se abrió pasó la construcción del estado del arte testimonial considerando, la construcción de los distintos escenarios en relación con los resultados encontrados en él estado del arte documental, y escuchando las voces de los actores participantes de este estudio.

Teniendo en cuenta lo anterior, se acordó desarrollar el estado del arte testimonial en la institución educativa técnico e industrial que funciona en el municipio de Turmequé - Boyacá, institución que estuvo interesada en desarrollar procesos de conversación. Se plantearon tres 
escenarios en el colegio y un escenario con una persona experta en el tema. Por lo tanto estos escenarios se distribuyeron de la siguiente manera: a) Un escenario diseñado para dialogar con el cuerpo directivo de la institución educativa técnico e industrial con el objetivo de observar:

Cómo se comprende el fenómeno de la violencia escolar desde la mirada institucional y cómo se comprenden los procesos de coevolución y autonomía de los estudiantes; b) un escenario diseñado para convocar las voces de la familia con el fin de comprender la narrativa y la semántica alrededor del fenómeno y la vinculación entre familia, estudiante, escuela, comunidad y fenómeno; c) un escenario diseñado para los estudiantes con el fin de convocar las voces y observar la interacción que se desarrolla alrededor del fenómeno; d) un escenario donde se convoca las voces de un experto en el tema con el fin de escuchar las diversas formas de intervenir y su perspectiva como profesional acerca del fenómeno.

Lo anterior permitió entender los sistemas de vinculación entre los diversos actores, su comprensión y la realidad percibida alrededor de la violencia escolar. En la siguiente gráfica, describe la comprensión alrededor de la experiencia vivida por los estudiantes en la relación con sus compañeros. 


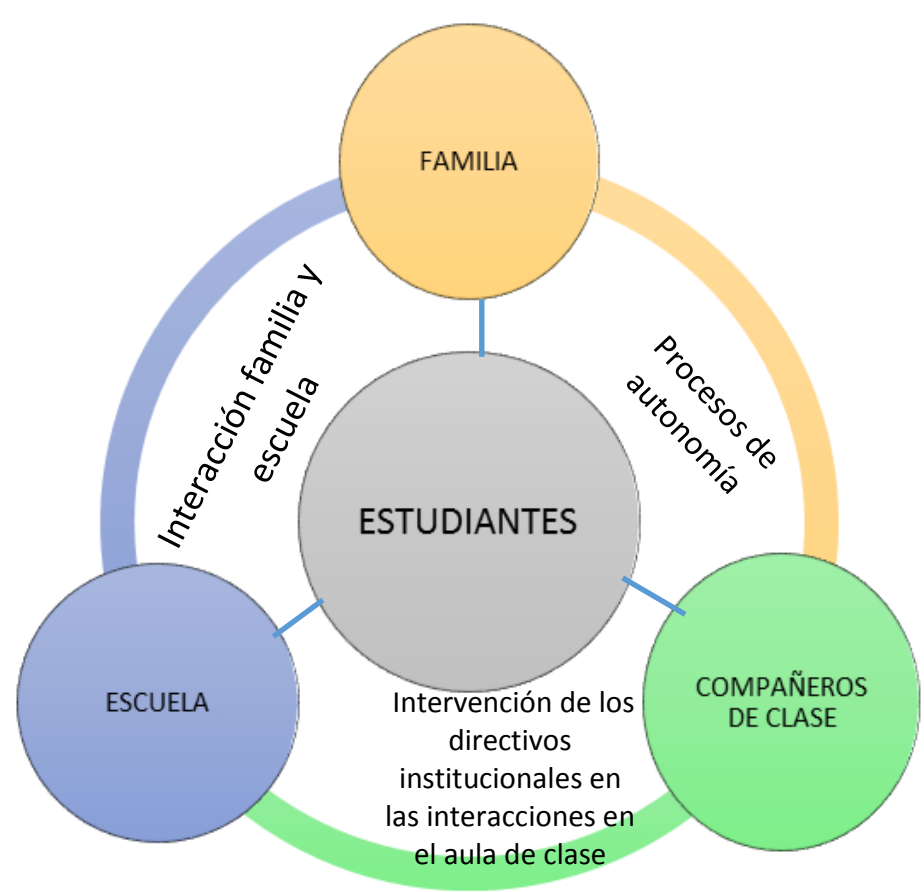

Figura 2. Mapa de comprensión de la relación entre estudiante, familia y escuela.

A continuación se presentan las tablas donde se proponen los escenarios de acuerdo a los objetivos, las preguntas orientadoras, los focos y las escenas de cada encuentro donde se desarrolló el estado del arte testimonial, junto con las investigadoras/interventoras y los diferentes actores del contexto de investigación/intervención:

\title{
Escenario 1.
}

Tabla 1. Escenario 1. Estado del arte testimonial.

\author{
Actores convocados Directivos de la Instituciones Educativa técnico - industrial de \\ Turmequé - Boyacá: rectora y coordinador de la institución \\ educativa.
}

Objetivo del escenario Comprender desde las voces del cuerpo directivo con el fin de 
cómo se construye el fenómeno de la violencia escolar desde

la mirada institucional.

Identificar y definir los intereses y expectativas de los miembros directivos de la institución educativa.

Objetivos específicos de la Identificar cómo participan los procesos de vinculación investigación familiar y su relación con el fenómeno de la violencia escolar. Identificar los procesos de autonomía de los niños, niñas y jóvenes estudiantes que participan en el fenómeno estudiado. Comprender los procesos narrativos conversacionales que mantienen y favorecen la emergencia del fenómeno y las semánticas de la familia y la institución alrededor de dicho fenómeno.

Construir y movilizar los procesos de autonomía por medio de diálogos generativos que posibiliten y favorezcan la emergencia de narrativas con los niños, niñas y jóvenes estudiantes.

\section{Preguntas orientadoras} ¿Cómo se configuran las interacciones entre los estudiantes de un aula de clase?

¿Cómo se construyen las interacciones entre el sistema escolar?

¿Cómo participa la familia en relación con el fenómeno de estudio?

¿Cómo incluir los sistemas familiares y escolares en la 


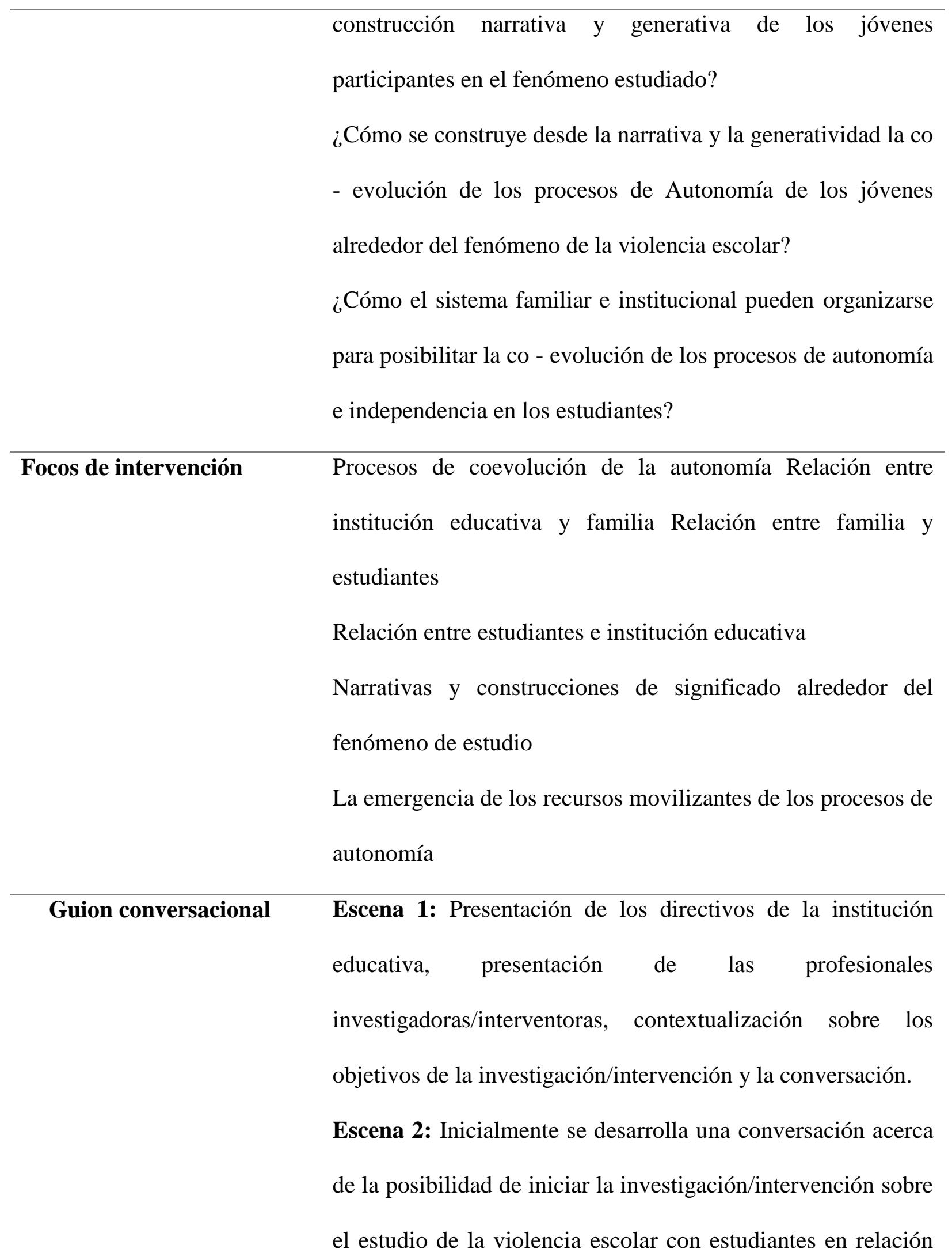


con la familia y la institución educativa. Posteriormente se orientara la conversación hacia las siguientes cuestiones:

¿Cómo se presenta la violencia escolar en su institución educativa? ¿Cómo se relaciona la familia en cuanto a la resolución de los conflictos de sus hijos e hijas? ¿Cuál es el rol del maestro en los procesos formativos y disciplinarios de los estudiantes? ¿Cómo intervienen los docentes y la institución en la resolución de conflictos de los estudiantes? ¿Cómo institución qué acciones realizan para enfrentar la violencia escolar en sus estudiantes? ¿Qué tan relevante es para la institución la aparición del fenómeno de la violencia escolar?

Escena 3: Conclusiones de lo conversado y lo logrado durante el encuentro. 


\section{Escenario 2.}

Tabla 2. Escenario 2. Estado del arte testimonial

Actores convocados

Familias, padres o madres de la Institución Educativa técnico industrial de Turmequé.

Objetivo del escenario Construir un contexto conversacional que permita comprender la perspectiva de la familia alrededor del fenómeno de la violencia escolar.

Objetivos específicos de la Identificar como participa los procesos de vinculación familiar investigación/intervención y su relación con el fenómeno de la violencia escolar. Comprender los procesos narrativos conversacionales que mantienen y favorecen la aparición del fenómeno de la violencia escolar y la semántica de la familia y la institución alrededor de dicho fenómeno.

Identificar los procesos de autonomía de los jóvenes estudiantes que participan en el fenómeno estudiado.

Construir y movilizar los procesos de autonomía por medio de diálogos generativos que posibiliten y favorezcan la aparición de narrativas emergentes en los niños, niñas y jóvenes.

Preguntas orientadoras ¿Cómo se configuran las interacciones entre los estudiantes de un aula de clase? ¿Cómo se construyen las interacciones entre el sistema escolar? ¿Cómo participa la familia en el fenómeno? ¿Cómo incluir los sistemas familiares y escolares 
en la construcción narrativa y generativa de los niños, niñas y jóvenes participantes en el fenómeno estudiado? ¿Cómo se construye desde la narrativa y la generatividad la co evolución de los procesos de Autonomía e independencia en los niños, niñas y jóvenes alrededor del fenómeno? ¿Cómo el sistema familiar e institucional pueden organizarse para posibilitar la co - evolución de los procesos de autonomía en los niños, niñas y jóvenes?

\section{Focos de intervención}

Procesos de coevolución de la autonomía.

Relación entre institución educativa y familia.

Relación entre familia e hijos.

Relación entre estudiantes e institución educativa.

Narrativas y construcciones de significado alrededor del fenómeno.

La emergencia de los recursos movilizantes de los procesos de autonomía. Escena 1: Presentación de las investigadoras/interventoras, contextualización sobre el objetivo de la investigación y la entrevista, reconocimiento de la configuración familiar.

Escena 2: Inicialmente se desarrolla una conversación acerca de las distintas estructuras y configuraciones familiares. Posteriormente se orientara la conversación hacia las siguientes cuestiones: 
¿Qué conoce usted acerca de la violencia escolar?

¿Por qué cree usted que se presentan conflictos entre los estudiantes en el colegio?

¿Conoce usted algún caso de algún familiar o amigo que ha estado en alguna situación de violencia escolar?

¿Cómo familia, como aportaría a evitar la violencia escolar en uno de sus hijos o familiares?

¿Qué opina usted, acerca de las acciones disciplinarias de la institución educativa?

¿Cómo cree que los niños, niñas y jovenes pueden solucionar sus conflictos?

¿Cómo se solucionan los conflictos en su hogar?

¿Qué haría usted como padre o madre para que su hijo o hija le comente si está viviendo acciones de violencia escolar?

Escena 3: Conclusiones de lo conversado y lo logrado durante el encuentro. 


\section{Escenario 3.}

Tabla 3. Escenario 3. Estado del arte testimonial

\begin{tabular}{|c|c|}
\hline Actores convocados & $\begin{array}{l}\text { Estudiantes de la Institución Educativa técnico - industrial } \\
\text { de Turmequé - Boyacá. De edades entre } 12 \text { a } 14 \text { años. }\end{array}$ \\
\hline Objetivo del escenario & $\begin{array}{l}\text { Comprender su visión acerca de la configuración del } \\
\text { fenómeno de la violencia en el entorno escolar, y en sus } \\
\text { interacciones con sus pares. }\end{array}$ \\
\hline $\begin{array}{l}\text { Objetivos específicos de la } \\
\text { investigación/intervención }\end{array}$ & $\begin{array}{l}\text { Identificar como participa los procesos de vinculación } \\
\text { familiar y su relación con el fenómeno de estudio. } \\
\text { Comprender los procesos narrativos conversacionales que } \\
\text { mantienen y favorecen la aparición del fenómeno de la } \\
\text { violencia escolar y la semántica de la familia y la institución } \\
\text { alrededor de dicho fenómeno. } \\
\text { Identificar los procesos de autonomía de los jóvenes } \\
\text { estudiantes que participan en el fenómeno estudiado. } \\
\text { Construir y movilizar los procesos de autonomía por medio } \\
\text { de diálogos generativos que posibiliten y favorezcan la } \\
\text { aparición de narrativas emergentes en los jóvenes } \\
\text { estudiantes. }\end{array}$ \\
\hline Preguntas orientadoras & $\begin{array}{l}\text { ¿Cómo se configuran las interacciones entre los estudiantes } \\
\text { de un aula de clase? ¿Cómo se construyen las interacciones } \\
\text { entre el sistema escolar? ¿Cómo participa la familia en el }\end{array}$ \\
\hline
\end{tabular}


fenómeno de la violencia escolar? ¿Cómo incluir los sistemas familiares y escolares en la construcción de una narrativa generativa de los niños, niñas y jóvenes participantes en el fenómeno estudiado? ¿Cómo se construye desde la narrativa y la generatividad la co - evolución de los procesos de Autonomía de los jóvenes alrededor del fenómeno de estudio? ¿Cómo el sistema familiar e institucional pueden organizarse para posibilitar la co evolución de los procesos de autonomía e independencia en los estudiantes?

Focos de intervención

\section{Guion conversacional}

Procesos de coevolución de la autonomía.

Relación entre institución educativa y familia.

Relación entre familia y estudiantes.

Relación entre estudiantes e institución educativa.

Narrativas y construcciones de significado alrededor del fenómeno de la violencia escolar.

La emergencia de los recursos movilizantes de los procesos de autonomía.

\section{Escena 1: Presentación de los profesionales} investigadores/interventores, contextualización sobre el objetivo de la investigación y la entrevista, y el porqué de la entrevista en el aula de clases.

Escena 2: Inicialmente se desarrolla una conversación 
desarrollando un preámbulo que genere el interés de los estudiantes alrededor de la violencia escolar. Posteriormente se orientará la conversación hacia las siguientes preguntas: ¿Qué conocen ustedes como violencia escolar? ¿Porque creen que algunos niños y niñas son agresivos con los demás? ¿Qué harían ustedes para evitar que se presente este fenómeno? ¿Qué acciones toma el colegio y los docentes para solucionar los conflictos que se presentan en el colegio? ¿Cómo creen que la familia se ve involucrada en este fenómeno? ¿Cuáles creen que son las consecuencias derivadas del fenómeno de la violencia escolar?

Escena 3: Conclusiones de lo conversado y lo logrado durante el encuentro.

\section{Escenario 4.}

Tabla 4. Escenario 4. Estado del arte testimonial

Actores convocados Egresada de la Maestría de Psicología Clínica y de la Familia de la Universidad Santo Tomás, experta investigadora/interventora en CyberBullying, investigadoras/interventoras. 
permita la comprensión a partir de las experiencias de la experta participante en CyberBullying.

Objetivos específicos de la Identificar como participa los procesos de vinculación familiar investigación y su relación con el fenómeno de la violencia escolar

Comprender los procesos narrativos conversacionales que mantienen y favorecen la aparición del fenómeno de la violencia escolar y la semántica de la familia y la institución alrededor de dicho fenómeno.

Identificar los procesos de autonomía de los niños, niñas y jóvenes que participan en el fenómeno estudiado.

Construir y movilizar los procesos de autonomía por medio de diálogos generativos que posibiliten y favorezcan la aparición de narrativas emergentes en los niños, niñas y jóvenes participantes de la investigación/intervención.

Preguntas orientadoras ¿Cómo se configuran las interacciones entre los estudiantes de un aula de clase?

¿Cómo se construyen las interacciones entre el sistema escolar?

¿Cómo participa la familia en el fenómeno de la violencia escolar?

¿Cómo incluir los sistemas familiares y escolares en la construcción de narrativas generativas de las personas participantes en el fenómeno estudiado? 
¿Cómo se construye desde la narrativa y la generatividad la co

- evolución de los procesos de Autonomía e independencia en los niños, niñas y jóvenes alrededor del fenómeno de estudio? ¿Cómo el sistema familiar e institucional pueden organizarse para posibilitar la co - evolución de los procesos de autonomía e independencia en los estudiantes?

Focos de intervención Procesos de coevolución de la autonomía.

Relación entre institución educativa y familia.

Relación entre familia y estudiantes.

Relación entre estudiantes e institución educativa.

Narrativas y construcciones de significado alrededor del fenómeno de la violencia escolar.

La emergencia de los recursos movilizantes de los procesos de autonomía.

\section{Guion conversacional}

Escena 1: Presentación de las profesionales
investigadoras/interventoras, contextualización sobre el objetivo de la investigación y la entrevista, y el porqué de la entrevista a la experta.

Escena 2: Se realiza un primer contacto telefónico donde se manifiestan las intenciones de las interventoras/investigadoras para el desarrollo de la investigación que se está iniciando en el estudio de la violencia escolar. Posteriormente se contacta por vía virtual donde, durante la conversación se realizan las 
siguientes preguntas: ¿Desde su experiencia que nos puede compartir sobre su investigación sobre el Cyberbullying? ¿Qué autores puede sugerirnos para la orientación de esta investigación? ¿Cuál fue el plan de trabajo que ustedes dejaron como legado en su investigación? ¿Qué impacto les genero a ustedes como investigadores?

Escena 3: Conclusiones de lo conversado y lo logrado durante el encuentro, donde se ampliaba las miradas complejas ecosistemicas alrededor del fenómeno de estudio.

\section{Desarrollo de los escenarios}

Los escenarios se desarrollaron alrededor de la dinámica institucional, donde las investigadoras/interventoras partieron sobre su comprensión del sistema relacional entre los estudiantes, la institución y la familia. El ingreso a la institución fue efectivo gracias al aporte y la disposición de la institución educativa, donde los directivos de la institución recibieron a las investigadoras/interventoras con la motivación de colaborar en el desarrollo del estudio.

De esta manera en un primer momento, se contactó directamente con el coordinador y la rectora de la institución educativa, con quienes se conversó acerca del desarrollo de los escenarios propuestos, y quienes expusieron su perspectiva acerca del fenómeno de la violencia escolar en la institución educativa, realizando un esbozo de la cultura y la convivencia familiar y municipal. 
Teniendo en cuenta la percepción de las directivas de la institución, se acordó trabajar con niños, niñas y jóvenes que pertenecen al comité de convivencia de la institución desde el grado primero de primaria hasta grado once.

\section{Resultados de los escenarios}

Se desarrollaron cuatro escenarios: el escenario con los directivos de la institución, en esta ocasión se trabajó únicamente con la rectora de la institución con la intervención de una investigadora/interventora. Por otra parte se desarrolló el escenario con niños y niñas de grado sexto en la institución educativa en el aula de clases, donde se obtuvo la presencia de todos los estudiantes, pero se evidenció la participación de 10 estudiantes bajo la observación de una investigadora/interventora. De igual manera se realiza el escenario con las madres de forma voluntaria quiénes permitieron realizar la grabación y conversar acerca del fenómeno de la violencia escolar con una investigadora/interventora. Finalmente se desarrolló el escenario con una experta en el tema del fenómeno de ciberbullying, de igual forma y con una investigadora/ interventora.

Una vez realizados los escenarios las conversaciones fueron transcritas de forma literal y analizadas en una matriz de escenarios testimoniales (ver apéndice A) permitiendo desarrollar las compresiones en el orden pragmático, paradigmático e ideológico simbólico. Desde lo pragmático, se realizó un análisis en torno al cómo se organizan y configuran las relaciones entre los estudiantes, familia e institución educativa alrededor de la violencia escolar, de igual forma se observa la semántica utilizada por las familias, los niños, niñas y jóvenes de la institución educativa respecto a las percepciones que cada uno de ellos tiene en cuanto a la aparición del fenómeno de la violencia escolar. Desde el orden paradigmático, se observa el cómo los participantes plantean diversos paradigmas conceptos y epistemologías, en torno al fenómeno y 
la relación de este con la institución y la familia. Desde el orden ideológico simbólico, se encuentran las representaciones, las experiencias y las creencias autorreferenciales de los actores participantes de dichos escenarios en relación con el contexto en el que se encuentran.

A través de los estados de arte documental y testimonial se realizó un análisis que convoca a construir los distintos ejes temáticos en relación con el fenómeno de la violencia escolar, es así que la familia, la institución y los sistemas amplios cooperan en la construcción de la coevolución, autonomía, y narrativas de los participantes de este estudio.

A continuación se presenta una imagen de las tablas de análisis de los escenarios testimoniales:

Tabla 5. Análisis de escenarios testimoniales 


\begin{tabular}{|c|c|c|c|}
\hline TEXTO & PRAGMATICO & PARADIGMATICO & $\begin{array}{l}\text { IDEOLOGICO- } \\
\text { SIMBOLICO }\end{array}$ \\
\hline 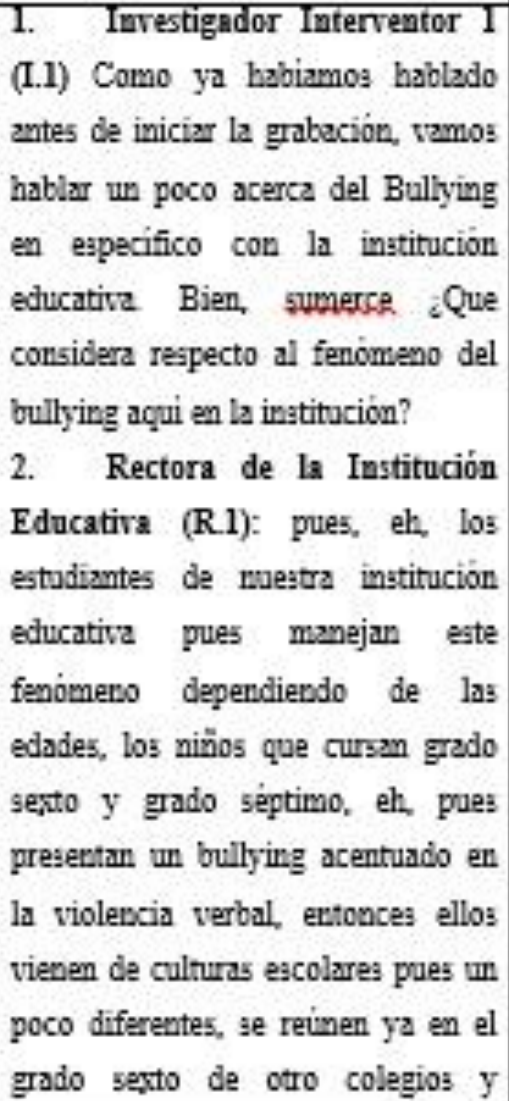 & $\begin{array}{l}\text { Se marca el } \\
\text { contexto } \\
\text { conversacional } \\
\text { entre los } \\
\text { participantes } \\
\text { convocados }\end{array}$ & $\begin{array}{l}\text { La propuesta del } \\
\text { investigzdor, define } \\
\text { su interes } \\
\text { investigativo, desde } \\
\text { las preguntas } \\
\text { desarrolladas. De esta } \\
\text { manera, la pregunta } \\
\text { revela la inquietud de } \\
\text { la investigadora por } \\
\text { conocer la percepción } \\
\text { de la rectora acerca } \\
\text { del bullying eycolar. } \\
\\
\text { Del grado en el que } \\
\text { ge encuentren los } \\
\text { estudiantes favorece } \\
\text { la aparición del } \\
\text { fenomeno de distintas }\end{array}$ & \\
\hline
\end{tabular}

\begin{tabular}{|c|c|c|c|}
\hline $\begin{array}{l}\text { tambiem de la sedes de aca del } \\
\text { colegio, y pues alli hay una } \\
\text { convergencia de maneras de pensar, } \\
\text { de actuar, de culturas de maneras de } \\
\text { aplicar los valores y pues lo que se } \\
\text { ve es la violencia verbal de esos } \\
\text { nin̈os, de los unos coutra los otros. } \\
\text { Ya superadas esas edades los niřos } \\
\text { ya empiezan a enfocarse un poco } \\
\text { hacia la parte del caracter técrico de } \\
\text { la institución, eso hace cue los } \\
\text { chicos, lo próctico, mmm, como que } \\
\text { los cambia un poco, el trabajo } \\
\text { practico, extonces pues ya vieve su }\end{array}$ & $\begin{array}{l}\text { encuentren, } \\
\text { donde se } \\
\text { relacionan } \\
\text { intereses, } \\
\text { interacciones y } \\
\text { cambios segin la } \\
\text { edad. } \\
\text { encontrandose } \\
\text { diferencias en los } \\
\text { estudiantes de } \\
\text { sexto - septimo, } \\
\text { octavo - noveno, } \\
\text { y decimo - once. }\end{array}$ & $\begin{array}{l}\text { maneras: } 2 \text {. R.I: } \\
\text { "pues manejan este } \\
\text { fenómeno } \\
\text { dependiendo de las } \\
\text { edades, los nin̈os que } \\
\text { cursan grado sesto y } \\
\text { grado septimo, eh. } \\
\text { pues presentan un } \\
\text { bullying acentuado en } \\
\text { la violencia verbal" }\end{array}$ & $\begin{array}{l}\text { De la rectora } \\
\text { emerge la } \\
\text { ideologia de cue }\end{array}$ \\
\hline
\end{tabular}




\section{Dominio pragmático}

Este dominio representa los significados que, para los actores implica las diferentes descripciones, acciones y condiciones propias del fenómeno.

Desde el sistema institucional, es posible observar la prevalencia de las normas disciplinarias y los resultados académicos de los estudiantes, respecto a sus comportamientos y a sus formas de interactuar entre ellos. Para las directivas de la institución (rectora) las interacciones que se presentan en el entorno educativo dependen en cierta medida del momento vital en el que se encuentran los niños, niñas y jóvenes y sus diferencias de edades, favoreciendo o no la aparición de la violencia escolar.

De igual manera, se comprende a la familia como ente responsable de los comportamientos que reflejan los estudiantes en la institución educativa y las interacciones que se desarrollan con sus pares.

En este punto, cabe mencionar, la relevancia para las directivas del colegio, el componente cultural y el cómo se estructura esté y el fenómeno. Al hablar de cultura es necesario hablar del contexto familiar y de las tipologías familiares en las que se desenvuelven los niños, niñas y jóvenes que según lo manifestado por la institución educativa existe un gran número de casos de violencia intrafamiliar que posiblemente se encuentren interconectadas con la aparición del fenómeno al interior de la institución.

Por otra parte, el accionar de la institución educativa, se encuentra desarrollado en los procesos de selección de los estudiantes, según su perfil disciplinario, considerado por docentes y directivas al inicio de cada año; en este sentido, para la rectora tener un espacio ecosistémico 
en paz es ganancia tanto para los docentes, como para los estudiantes, directivas y familias de la institución, porque un aula sin violencia es tener un aprendizaje asertivo.

Para la institución educativa, los procesos de selección de algunos docentes no facilitan los procesos comunicacionales dadas las diferencias motivacionales de los docentes en cuanto a la resolución de conflictos internos dentro de un aula de clase, negándose a resolverlos.

Desde el escenario familiar, la estructura familiar, es importante para el reconocimiento de los miembros de este sistema, en cuanto a una organización visible y ritualizada: padre, madre, hijos y hermanos, donde se resalte una disciplina y valores, que mantengan la distinción del orden y los roles entre los miembros de la familia. Es así como en la familia se perciben las interacciones que se dan entre los niños, niñas y jóvenes como el conjunto de valores que se resuelven alrededor de las relaciones interpersonales en un aula de clases; esto permite entender y ver al colegio como el ejemplo a seguir para los niños, niñas y jóvenes. Por otro lado, las diferencias de edades influyen en las relaciones que se configuran en el aula de clases, dada la tendencia a repetir los comportamientos de los niños y niñas mayores.

Las relaciones que se construyen en el interior del contexto educativo muchas veces están precedidas por la agresión y la grosería; por tanto los niños, niñas y jóvenes quieren replicar estos comportamientos y terminan por agredir a otras personas que no tienen la capacidad y poder para responder, lo que propicia que se continúe presentando esta situación.

De acuerdo a lo conversado se plantea que las comprensiones de los niños, niñas y jóvenes en el aula de clase alrededor del fenómeno se desenvuelven a partir de las agresiones percibidas tanto físicas como psicológicas en las interacciones y relaciones que se llevan a cabo entre ellos. 
Se identifica la interconexión que los estudiantes realizan entre la violencia escolar y la violencia percibida desde la cultura y las costumbres llevadas a cabo en el Municipio. Para los niños, niñas y jóvenes el papel que perciben del profesor es evitar el fenómeno de la violencia; por tanto ésta dificulta los procesos de co- evolución en el sistema escolar; los niños, niñas y jóvenes refieren que aunque se han comentado casos de violencia los profesores hacen caso omiso a esta información, por lo tanto el fenómeno tiende a prolongarse y los estudiantes utilizan medidas defensivas por sus propias manos.

En cuanto a las interrelaciones que se construyen en los contextos educativo y familiar, es importante abordar el fenómeno de la violencia escolar, ya que allí se puede dar cuenta de que tipo de interrelación construyen los niños, niñas y jóvenes que mantienen la violencia escolar.

Por otro lado, el fenómeno del ciberbullying no pasa desapercibido, dado que cada vez que el fenómeno se presenta cobra mayor relevancia y mayor número de personas involucradas, que empiezan fácilmente por redes sociales, aceptando invitaciones de personas que no conocen lo que se va convirtiendo en un juego peligroso.

De esta manera el rol de las investigadoras/interventoras se transforma en comprender y escuchar las voces de los diferentes contextos, tanto estudiantes, instituciones educativas y familia con el fin de aunar fuerzas en la proposición de soluciones que favorezcan las relaciones e interacciones en el sistema y de esta manera se pueda movilizar y encontrar una manera diferente de visualizar el fenómeno de la violencia escolar. 


\section{Dominio Paradigmático}

El dominio paradigmático permite comprender los escenarios desarrollados por los autores, desde sus propios referentes teóricos, y las situaciones que se reconocen desde la conversación y la comprensión del Estado del arte documental.

De esta manera se inició la comprensión de las soluciones teniendo en cuenta los referentes de los actores en la institución educativa. Posteriormente se visualizarán las compresiones de la familia, los estudiantes y los expertos invitados en los conversatorios alrededor del fenómeno de estudio, desde un entramado colectivo.

La institución educativa reconoce el contexto disciplinario con vivencias de los estudiantes como una salida a la expresión propia de las diferentes edades según el curso o grado en el que se encuentran los niños, niñas y jóvenes.

Partiendo desde el contexto familiar, la institución educativa enmarca la necesidad de que haya una familia comprometida, que busque el bienestar de sus hijos e hijas acompañándolos en cada una de las necesidades que se puedan presentar en los procesos académicos, disciplinarios de los niños, niñas y jóvenes interconectando las pautas de crianza y la estructura familiar en la que se encuentre inmerso el niño, niña y joven. Encontrando esto como una alternativa de vinculación entre familia y escuela, con el fin de buscar soluciones efectivas a las problemáticas de violencia escolar.

Por otro lado la institución educativa observa y supervisa el rol del docente como primordial para la resolución de conflictos que se dan entre los estudiantes de los grados sextos a once; sin embargo se evidencia que el papel del profesor no se percibe como solucionador de situaciones conflictivas en el entorno escolar. 
Para la familia es muy importante establecer todos los valores que imparten en casa, como lo es el respeto, la disciplina, la constancia, el amor, ya que muchos de estos valores se han ido perdiendo porque se da importancia a otros factores, y que esos están desviando lo que significa que cada niño, niña y joven establezca en sus relaciones el respeto para así tener una mejor convivencia, donde sí se presentan los conflictos hallar alguna manera resolutiva.

De igual manera para la familia la confianza que se debe tener entre los miembros de ésta, ya sea de hijo a padres, y entre padre y madre, es primordial para el desarrollo personal y social de los niños, niñas y jóvenes en sus diferentes contextos.

Por su parte los niños, niñas y jóvenes observan la violencia escolar como un aspecto que no es solucionable desde el entorno escolar y los docentes consideran que sus voces no son escuchadas omitiendo estos riesgos que se pueden considerar nocivos para la salud mental de los niños, niña y joven. Un aspecto a resaltar en la observación de los estudiantes, es la violencia percibida y vivida en su entorno cultural, social y familiar como un ejemplo a seguir en sus pautas interacciónales en el entorno escolar, naturalizando este fenómeno.

A partir de la experiencia que vivió la experta en el fenómeno de estudio, comenta que la violencia es vista de una manera muy fragmentada, lo cual hace perder el foco de la investigación sin tener en cuenta que esta precedido por la forma en que se relaciona el niño, niña y joven con su contexto y en cada una de sus interrelaciones llámese familia, amigos, vecinos, colegio y todas las instituciones inmersas en el aprendizaje y crecimiento del niño, niña y joven. 


\section{Dominio Ideológico - simbólico}

Teniendo en cuenta la cultura la ideología y las creencias de los actores y de las investigadoras/interventoras se resuelve el dominio ideológico simbólico, realizando comprensiones de la violencia escolar.

A partir de lo que emergió en los diálogos que se llevaron a cabo con los actores, las investigadoras/interventoras evidenciaron por parte de la institución educativa, que se tejen creencias en torno a la familia donde se ha perdido la estructura y se han perdido los roles.

La rectora habla sobre lo que significa el rol del profesor, donde se puede evidenciar que muchos de ellos no están comprometidos realmente con la educación de estos niños, niñas y jóvenes a pesar de las dificultades entre ellos; no hay la disponibilidad resolutiva al fenómeno que se presenta en la institución como es la violencia escolar.

De igual manera se perciben las creencias de la estructura familiar típica nuclear, mamá, papá, hijos, hermanos, como esencial para el desarrollo de los niños, niñas y jóvenes; en este sentido las creencias se desarrollan alrededor de las figuras de autoridad que se deben ejercer desde los roles de los padres, y las madres como una crianza basada en el amor, la disciplina y la confianza.

Por otro lado la familia percibe al docente como un agente que permite resolver los conflictos desde su posición de autoridad, rigor y disciplina, sin embargo se manifiesta que la actualidad a los docentes se les dificulta encontrar dichas características por los cambios de la sociedad, la educación y la permisibilidad que existe al interior de las familias. 
De igual forma la familia considera las influencias escolares de niños, niñas y jóvenes mayores como nocivas para el comportamiento de sus hijos e hijas ya que existe la tendencia a repetir comportamientos agresivos.

Cuando los niños, niñas y jóvenes se refieren a la violencia escolar especifican que es una manera donde ellos deben aprender a valerse por sí mismo, a defenderse por sí mismo ya que no hay otra persona que pueda solucionar esta situación.

También es importante la forma en que ellos han visto como en su contexto cultural han crecido en medio de discusiones, riñas y peleas convirtiéndose en la forma en que los adultos solucionan sus conflictos.

\section{Resultados del estado del arte testimonial}

A través del análisis concienzudo de lo que fueron los tres dominios paradigmático, pragmático e ideológico se puede evidenciar que cada uno de los actores convocados percibe el fenómeno de la violencia de manera distinta, de acuerdo a lo que son sus interrelaciones y el contexto de su vida cotidiana.

En una primera parte, haciendo un llamado a las voces de los niños, niñas y jóvenes participantes del Estado del arte testimonial, es posible rescatar cómo ellos comprenden la Pauta de la violencia escolar desde la intimidación y las diferencias físicas y culturales: “cuando agredimos a un compañero porque es otro color de piel, o porque no sabe, o lo agredimos físicamente o psicológicamente" (N 2 - E3). En estos términos los niños, niñas y jóvenes se hacen partícipes de esta pauta interaccional, refiriéndose a sí mismos como actores que propician de una u otra manera dicho fenómeno. Añadido a lo anterior, es posible observar cómo los niños desde su desenvolvimiento escolar, prefieren dejar pasar esta situación como una secuencia 
interaccional cotidiana que debe ser resuelta por ellos mismos, atribuyendo esto a la falta de apoyo de los entes correctivos de la institución educativa: N1: “pues dejarlos por que qué más...” N2: "como los profesores no hacen justicia toca por sus propias manos".

Teniendo en cuenta lo anterior, los niños, niñas y jóvenes, manifiestan entre sus narrativas dominantes, cierta desesperanza por las acciones que toman frente a esta pauta tanto directivos de las instituciones, profesores y familia: N3: "Porque los profesores no son de confianza..." N4: "no hacen nada los profesores" considerando que como tal no se percibe un ente orientador y pacificador en situaciones que para ellos desde su rol de estudiantes es importante, y por lo tanto una necesidad de ser escuchados: N5: “yo le había dicho al coordinador cuando me habían chuzado con un esfero y ahí le dio igual".

Como un punto importante a referir, se encuentra la comprensión que tienen los niños y jóvenes de la violencia percibida en el Municipio, respecto a la observación que ellos tienen de la violencia en entornos y situación distintas al sistema escolar: N6: "En el pueblo hay peleas, y se apuñalan y todo...” N7: "En Turmequé, allá en el pueblo, hacen apuestas cuando pelean eso Dios mío". Lo anterior permite dar cuenta de la violencia percibida desde un punto de vista ecológico, lo que transpola dicha comprensión de la violencia hacia el conocimiento de los sistemas amplios que constituyen el Municipio y que a su vez, conforman la cultura de la familia y del entorno educativo.

Desde un segundo punto, ahora haciendo un llamado a la voz de la institución educativa, más exactamente la rectora como miembro directivo de la institución, desde un primer plano, se percibe la pauta de la violencia escolar desde las diferencias de edades y los distintos ciclos académicos, refiriendo la vivencia de esta pauta interaccional de manera particular según el grado en el que se encuentre los niños, niñas y jóvenes: R1: "pues, eh, los estudiantes de nuestra 
institución educativa pues manejan este fenómeno dependiendo de las edades, los niños que cursan grado sexto y grado séptimo, eh, pues presentan una violencia acentuada en la violencia verbal... Ya superadas esas edades los niños ya empiezan a enfocarse un poco hacia la parte del carácter técnico de la institución, eso hace que los chicos, lo práctico, mmm, como que los cambia un poco, el trabajo practico, entonces pues ya viene su crecimiento su desarrollo, pasar de la infancia a la adolescencia y pues viene otro tipo de violencia escolar, el cibernético entonces los chicos, pues se, se agreden también a través de las redes sociales, pero ya los grandes decimo, once, noveno".

Lo anterior permite comprender el cómo las construcciones sociales cambian según el ciclo escolar, lo que permite ampliar la mirada hacia la complejidad de los sistemas escolares y de las etapas de desarrollo de los niños, niñas y jóvenes. Por otro lado, desde el punto de vista de la institución educativa, se amplía un poco más la visión de esta pauta de la violencia escolar, conectando la edad de los niños, niñas y jóvenes, los ciclos escolares, el entorno escolar, los profesores y la familia. Es así como la familia toma fuerza en esta co- construcción narrativa, comprendiendo el sistema familiar, como el ente orientador, que propicia el aprendizaje de valores, normas, pautas y modelos de interacción: R1: "Eso es una, digamos que eso es un mal heredado, eso es algo que definitivamente el niño transmite todo lo que vive en su entorno, en su entorno social, familiar... Entonces se ve más bien muy acentuado lo que el niño aprende en casa... la mayoría de las familias hay mucha violencia intrafamiliar”. Es en este sentido se resalta a la familia como un ente posibilitador de valores, creencias y rituales que se transportan a otros contextos, sin embargo, cabe aclarar que no es posible observar a la familia como el único sistema orientador para los niños, niñas y jóvenes. 
Teniendo en cuenta lo anterior, se observa ahora, a la institución educativa y más exactamente a los profesores, como actores primordiales en el desarrollo de los niños, niñas y jóvenes; es así que retomando las voces de la rectora, se comprende que aunque existen docentes lo suficientemente preparados en pedagogía, se evidencia pocas acciones por parte de los profesores y poca comprensión frente a las situaciones vividas por los estudiantes en conductas violentas: R1: "pues muchos que tienen profesión docente son modelos antivalores para los niños desafortunadamente, pero que aprovechamos que tengo la profesión docente y me dan la autoridad académica para ser docente pero definitivamente aquí los llamados somos los que tenemos la autoridad moral para hacer eso".

Ahora bien evocando las voces de las madres entrevistadas, se observa una concepción de la violencia escolar, como un comportamiento que hace sentir mal a los niños, niñas y jóvenes que influye en la percepción que ellos tienen de sí mismos (características físicas y psicológicas) M1: “yo pienso que también a veces como cuando ven a un niño que es juicioso que es como muy pilo porque entre otras palabras que le decían al niño que se me olvidó decirle es que era un nerd, era un qué? Un chupa cuadernos dicen y eso entonces eso le decían, entonces como que a él lo ven que es como muy juicioso como muy entregado a su estudio entonces yo pienso que hasta por eso es que le comienzan a decir cosas como para poderlos ofender como para poderlos molestar".

Son estos comportamientos que se presentan en determinado momento para herir, juzgar o burlarse de los niños, niñas y jóvenes que pueden generar múltiples formas de problemáticas.

Es relevante para los padres y madres el querer acercarse a sus hijos a través del diálogo, para generar confianza en ellos y que estos a su vez puedan comentarles las diferentes situaciones que viven a diario en la institución educativa: entre ellas los conflictos que se puedan generar 
entre pares u otras relaciones que se tejen en el contexto educativo, para orientarles de manera adecuada y de ser necesario recurrir a los conductos regulares al interior del Colegio con el fin de evitar situaciones, que pueda poner en riesgo la integridad de sus hijos.

Añadido a lo anterior, el respeto que se inculca en casa basado en valores y compresiones acerca del significado que tiene las interrelaciones es fundamental para la familia en la prevención de la violencia escolar: M1: “por ejemplo yo creo que uno como papá debe inculcarles a ellos que tiene que respetar ellos a sus compañeritos y lo que yo les decía o yo por lo menos les digo a mis hijos tienen ustedes que empezar primero a respetar a sus compañeritos y que ellos los respeten también y también que si ellos les habla con agresividad pues que ellos no lo hagan de la misma forma, que ellos no le vayan a responder de la misma agresividad, sino ellos traten de ser educados"

Por otro parte, para la familia, el ejemplo que brindan los profesores, también juega un papel muy importante en la enseñanza de niños, niñas y jóvenes; los docentes como referentes de comportamientos al interior del aula de clase puede proliferarse a sus distintas áreas de vida; sin embargo, existe una percepción contraria a la expectativa que los padres mantienen de los profesores como sujetos de resolución de conflictos M1: “pues por lo menos que tuviera más autoridad ¿no? O sea como les digo yo, o sea que un profesor le dijera a mí me hace el favor y me respeta y ese niño por lo menos hiciera caso, pero ahorita ya no se ve eso.”

Por último, se recogen las voces de la experta en Ciberbullying como punto de referencia ya que su labor ha estado en el marco de un colegio y ha estado involucrada con estudiantes, donde se amplía la mirada de esta investigación realizando aportes valiosos para continuar con este estudio. 
En este punto, es indispensable entender cómo se interactúa en el ciberespacio, ya que existe un lado oculto de esta práctica: E1. "Abordamos el fenómeno a partir de tres ejes: A partir de lo humano, A partir de cómo nosotros entendemos el contexto del ciberespacio y todo lo que se genera al interior del ciberespacio. Nosotros tenemos unas lógicas diferentes. La lógica presencial y la lógica virtual. A partir de eso tuvimos que entender como es la lógica virtual, como son las interacciones en el contexto virtual, en el ciberespacio, que tipo de lenguaje se utiliza en el ciberespacio"

Teniendo en cuenta lo anterior, el enfoque sistémico ofrece una mirada ecológica que permite comprender este fenómeno desde varios puntos de vista lo cual emerge en narrativas que se construyen a través de las vivencias y reflexiones que cada niño, niña o joven rescata de pasar por esta situación: E1: "Importante que tengan en cuenta que las dinámicas que emergen en la familia, en el contexto escolar o con los docentes, todas son distintas...Y en este momento hay algo con el bullying y es que todo el mundo habla del bullying, suena mucho, pero nadie sabe qué hacer, nadie tiene la respuesta y nada de lo que se hacen funciona. Entonces ésta es un poco la justificación, del para qué de la propuesta misma y la pertinencia de abordar a partir de un enfoque sistémico; entonces no desligas, por ejemplo en nuestro caso ya haciendo la intervención y llevando a cabo la metodología y la parte final de la investigación, nosotros no desarticulamos todos los actores, sino que los pudimos vincular en un solo escenario y los mismos protagonistas padres de familia, directivos, las personas del cuerpo docente, del equipo administrativo y los mismos jóvenes, traen a la pertinencia, la prioridad y la bondad del mismo enfoque de la misma intervención, porque esa posibilidad de qué todos los actores confluyan en un solo contexto y puedan entre todos escucharse, validar las voces, conocer que piensa, cómo se siente el otro y 
tener ese espacio para poder estar, en la apertura de lo humano, porque es que las relaciones sobre todo en el ciberespacio."

En este sentido, las distintas formas de violencia que se tejen en un entorno escolar vale la pena analizarlas de manera detenidas ya que allí pueden pasar aspectos importantes de manera invisible, que solo teniendo una mirada ecológica se les puede dar un significado distinto.

\section{Discusión estado del arte testimonial y documental}

Cuando se une las experiencias de lo que fue el estado de arte testimonial y el estado documental, se hace una comprensión de cómo los niños, niñas y jóvenes se encuentran en relación con su familia y el contexto educativo, incluyendo la cultura en la que han estado inmersos durante toda su vida y cómo han aprendido a resolver sus distintas dificultades que se presentan en su vida cotidiana.

Los autores que fueron consultados y enlazados para orientar esta investigación/intervención permiten tener una mirada sistémica acerca de la Pauta de fenómeno de estudio y cómo los niños, niñas y jóvenes crean sus espacios de socialización.

El estado del arte orientó este estudio en cuanto a los fundamentos teórico que se han construido en torno al eje temático, lo que posibilita un desarrollo conceptual y metodológico en las herramientas y estrategias que se abordaran durante el desarrollo de la presente investigación.

El estado del arte testimonial recoge las voces de los participantes reconociendo cuáles son las ideologías, epistemes, y creencias que forman el tejido cultural de las personas inmersas en esta investigación por cuanto se empieza a comprender el fenómeno de estudio y generar aperturas en las investigadoras/interventoras en esa ruta de cambio que se va a construir en la medida que avanza el proceso de estudio. 
Las voces de la familia, los estudiantes y la escuela, se interconectan y coinciden con algunas conceptualizaciones de los autores, percibiendo dicho fenómeno de forma lineal, donde se transpola el término hacia una forma de estereotipar o etiquetar a los comportamientos de los estudiantes en el aula de clase: Benítez y Justicia (2006), refieren que el conjunto de violencia física y psicológica entre un grupo de iguales que se establece bajo relaciones de poder entre los estudiantes, y que por su frecuencia, duración e intencionalidad crea daños en la integridad de las personas y en específico entre los compañeros de clase, se puede considerar acoso escolar.

Aunque la visión de la institución educativa y de algunas familias resulte ser un poco lineal en cuanto a - maltrato en la familia, igual, a violencia en la escuela - este punto de vista, permite revelar a la investigación la conexión de los diversos sistemas, inmersos en la percepción y comprensión de violencia, desentrañando dicha observación, desde el estudiante y su entorno educativo, las interacciones con los compañeros de clase, la familia, el Municipio y sus sistemas amplios:

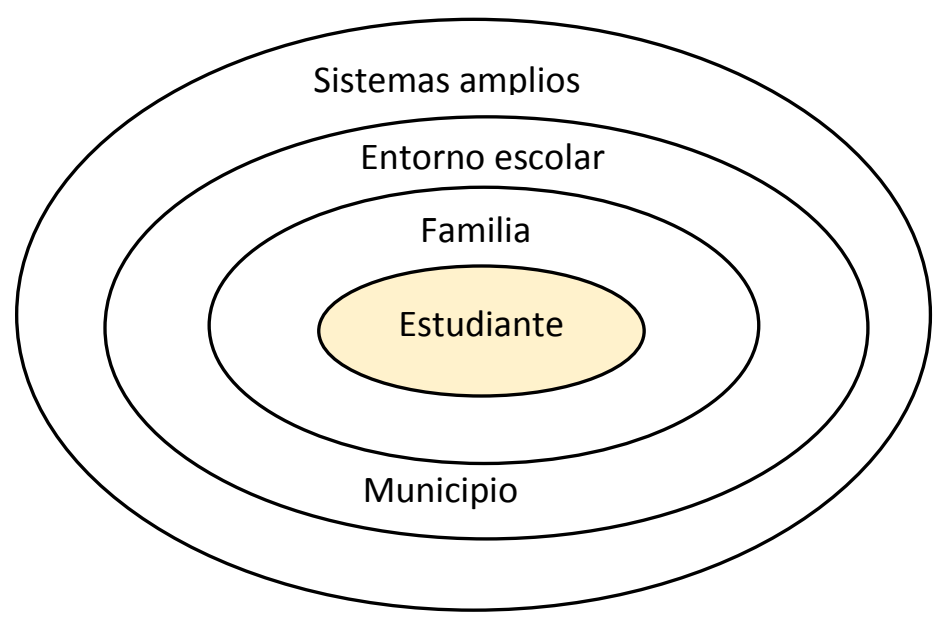

Figura 3. Sistemas amplios en la emergencia del estudiante desde el sistema escolar 
Esta conceptualización, se trasforma al observar más a profundidad, los diferentes puntos y focos de relación y de interacción, en donde se encuentran inmersos los sistemas familiar, social, escolar e institucional. Hoy, se une el conocimiento que ha propiciado la Maestría en Psicología Clínica y de la Familia, en cuanto a la comprensión de una mirada ecosistémica donde está involucrada la institución, los padres, los docentes, los directivos, los niños, niñas y jóvenes, sistemas amplios que hacen parte de procesos de estudio, permitiendo tener una mirada y un análisis profundo de lo que son las interrelaciones, y la semántica de la violencia escolar.

Por otro lado, y retomando nuevamente las voces de los participantes; se observa una coincidencia en la visualización del niño, niña y joven como generador de conflictos dentro de un sistema escolar, que a su vez es rodeado por diferentes interacciones y contextos que no le permiten desenvolverse dentro de su proceso de autonomía.

Añadido a lo anterior, se comprenden los procesos institucionales como motivo para disciplinar, resolver conflictos y situaciones en las aulas de clase, sin embargo se visualiza al docente en algunos casos como ausente en los mismos procesos resolutivos. A partir de este estudio se puede evidenciar que el colegio en algunos momentos desconoce las necesidades propias de los niños y jóvenes correspondientes a su ciclo de edad y tienden a ser juzgados por sus comportamientos, sin tener en cuenta que estos hechos son etapas que ellos deben vivir en la formación de su identidad y autonomía de acuerdo a su edad; poniendo en juego la palabras de los niños, niñas y jóvenes, y por lo tanto sus procesos de autonomía. Evocando lo propuesto por Hernández, Bravo (2008), los procesos de autonomía se pueden considerar como un reto, en cuanto a la dependencia e independencia, en el mismo orden de los contextos grupales y familiares. De esta manera, se observa la multiplicidad de significados construidos a través de la historia de vida de los personajes, tal como lo explica Gergen (2006), el Yo no es un producto de 
la independencia, por el contrario, el Yo es un subproducto de la vinculación y de la relación con los demás, que crea la propia identidad.

Es así, como entender estos actores convocados, cada uno con percepciones distintas, de acuerdo al rol que ocupan en la institución y en la familia en cuanto a la Pauta que se presenta de violencia escolar, permite reconocer la importancia de considerar una intervención, que pueda dar una respuestas significativa tanto a los docentes, niños, jóvenes y familia en la búsqueda de soluciones viables para todos.

Para Zlachevsky (2003) los relatos de las personas desde su individualidad son únicos y diferentes y por lo tanto el significado atribuido a las situaciones depende de la forma en como cada uno signifique su historia.

Esos relatos dan cuenta de las diferentes experiencias que han vivido a lo largo de su vida, y de esta manera se construye formas interacciónales, que se permean de generación en generación y muchas de estas experiencias trae consigo una pauta de actos violentos como formas de defenderse de posibles arbitrariedades.

Benítez y justicia (2006) mencionan la violencia física y psicológica que se da a partir de relaciones de poder. Según este teórico y unido a las voces de los participantes este poder esta precedido por burlas que se da entre compañeros por cualquier situación que ponga en desventaja a un niño, niña o joven, por ejemplo lo mencionado por una madre cuando describía a su hijo muy comprometido con las labores académicas, sin embargo era objeto de burlas, y por ello recibía apodos que afectaba su integridad.

Es así que Owelius (1983) evoca la desigualdad alrededor de agresiones físicas y psicológicas, desigualdad que afecta los procesos identitarios de quien está recibiendo constantes 
escaladas de agresiones por parte de sus compañeros ya que lo conduce a sentirse reducido por estos comentarios.

Estupiñan, Niño y Garzon (2006) manifiesta que la violencia que se vive en la familia está transversalizada por la violencia que vive Colombia, de esta manera se puede entender que si al interior del sistema familiar existen conductas que potencian actos violentos se puede convertir en un pauta que se quiera repetir, por parte de los hijos e hijas en diferentes contextos relacionales dejando naturalizado que estos actos son hábitos normales de vida, de esta manera se va construyendo socialmente la violencia.

Aunque estas pautas generan sufrimiento como bien lo menciona Garaigortdobil, M., \& Martínez-Valderrey, V. (2015), al interior de las familias que son devastadoras, estas consecuencias se pueden convertir en emociones desesperanzadoras que posicionan a los niños, niñas y jóvenes en condiciones vulnerables.

Hoyos, Aparicio, Romero, Valega y Olmos (2008) mencionan las manifestaciones de abuso de poder y maltrato, este apartado va de la mano con lo referido por la institución en voz de la psicoorientadora al referirse que en muchas de las familias turmequenses existe violencia intrafamiliar por tanto son comportamientos que tienden a repetirse, y los estudiantes refieren acerca de las riñas que se ocasionan en el pueblo donde la violencia es la pionera en actos resolutivos frente a sus desavenencias.

Tiina (2015) en el estudio Kiva realiza una sensibilización a través de charlas, manuales y buzones de sugerencias donde incorpora a la comunidad estudiantil en formas diferentes de interrelaciones basadas en el respeto. Este estudio genera bifurcaciones y bucles recursivos en las investigadoras/interventoras para darle una mirada generativa a las situaciones que se presentan al interior de la institución donde la violencia escolar está presente y se pueda resignificar esta 
pauta comportamental en compañía de los diferentes contextos relacionales de las personas inmersas en este estudio y se potencie procesos de autonomía y co - evolución, a través de los escenarios donde se cucharon las voces silenciadas de los participantes creando espacios de resignificación y aperturas a un nuevo estilo de vida.

Minuchin (1998) hace referencia a la importancia de los roles en la familia a través de una jerarquía estructurada, que permita tener un equilibrio cuando se presente algún tipo de conflicto, lo cual fortalece la relación de parte de los padres, y madres encargados de brindar herramientas que posibiliten maneras resolutivas viables en sus hijos e hijas. Estos roles en las familias participantes se caracterizan al observar sus diferentes tipologías en cuanto a la organización familiar (nuclear, monoparental, extensa), que inciden en la formas en las que se relacionan en el manejo de autoridad en el interior de la familia.

Por último Ferrer (2012) refiere la importancia del apoyo parental; este autor convoca fortalecer los procesos vinculares el interior de la familia lo cual estaría facultando a los niños, niñas y jóvenes a tener un sentido de pertenencia en su familia basado en afecto, comprensión y apoyo. De lo anterior, se rescata las voces de los niños, niñas y jóvenes al expresar la necesidad de vincularse con su sistema familiar desde la escucha activa y el apoyo en las situaciones generadas por la violencia.

\section{Conclusiones estado del arte testimonial}

A través del desarrollo del estado del arte testimonial se pudo observar las dinámicas vinculares que se han configurado en el sistema familiar y escolar de los estudiantes participantes en el presente estudio.

En el primer escenario que se desarrolló con la rectora de la institución hay una convicción por parte de ella respecto a la violencia escolar, de acuerdo a sus epistemes construidos en su 
experiencia puede evidenciar que la violencia cambia según el ciclo vital en que el estudiante se encuentre, dónde la influencia del grupo social es fuerte teniendo en cuenta la edad y el grado que cursa, percibiendo con mayor relevancia la violencia verbal, sobre todo en el grado sexto.

Otros aspectos a tener en cuenta son la cultura, las creencias, el entorno social y las familias con grandes dificultades, en las que el estudiante está creciendo, puesto que muchas de las conductas violentas adquiridas son aprendidas en estos contextos.

El segundo escenario se desarrolló con la familia, donde se podía hacer diferentes lecturas con respecto a las epistemes organizadas por las personas que participaron de este encuentro, la violencia escolar se comprende a través de actos discriminatorios que sucede entre compañeros como apodos, y burlas ocasionadas por diferencias físicas, como el color de piel, estatura, exceso de peso o cuando académicamente hay muchos logros.

También existe una creencia fuerte y es el ejemplo de la casa, si los padres tienen problemas entre ellos los niños así se comportaran y habrá una tendencia en repetir estas conductas que se aprenden al interior del hogar.

Con relación a los docentes se percibe en la actualidad que muchos de ellos presentan una autoridad débil donde se ha perdido el respeto por esta figura de parte de los estudiantes, lo cual genera dificultades en la las relación creando ambientes tensos.

Frente a la institución se visualiza una problemática y es el ingreso de estudiantes que vienen de otros municipios sin tener un conocimiento previo de estas personas, al llegar de otros colegios traen consigo comportamientos que son generadores de actos violentos.

Por otro lado los padres manifiestan que en esta época se ha perdido los valores y lo mejor es buscar orientación de personas expertas de la institución para que les digan cómo debe ser la 
crianza para sus hijos, contar siempre con el apoyo de la pareja y tener confianza entre todos los integrantes de la familia no ocultando cosas entre los esposos y estar siempre al tanto del cuidado de sus hijos y finalmente la fe en DIOS es importante a la hora de educar a los hijos.

El tercer escenario se llevó a cabo con estudiantes, comprenden la violencia como todas aquellas situaciones que se viven en el aula de clase como burlas, apodos y comentarios mal intencionados, manifiestan que niños grandes se aprovechan de los que son más pequeños, y los profesores no hacen nada por cambiar la situación. En el sistema de creencia de los niños esta la emergencia de poder encontrar ayuda externa ya sea de un profesor, padre de familia o incluso la policía que pueda contrarrestar la situación. Los estudiantes aportan soluciones para minimizar este tipo de violencia y es atravesó de una mayor cercanía entre padres y docentes generando diálogos que busquen cambiar estas situaciones que se presentan al interior del institución.

Un último escenarios se llevó a cabo con una experta en ciberbullying, comprendiendo el fenómeno de la violencia escolar desde una mirada sistémica, permitiendo tener una visión detallada y clara sobre la situación, y la construcción narrativa que se organiza en el ciberespacio y la diferentes interrelaciones que se tejen dando significado a las infinitas experiencias que a diario se vive a través de espacios interactivos.

Es importante redefinir el papel que juega la familia en los procesos escolares de sus hijos, así como contraer una percepción distinta donde la familia no sea vista como una causal determinista de los comportamientos agresivos de los niños, niñas y jóvenes, sino como una parte que se interconecta con otras situaciones que generan el surgimiento de la violencia. 
Es interesante conectar cómo los mismos procesos autorreferenciales de los docentes posibilitan o no una resolución de conflictos armoniosa con el estudiantes o el surgimiento de la violencia escolar entre docente estudiante.

Es importante tener en cuenta cómo la violencia percibida en los sistemas amplios del Municipio transita por otros escenarios que permean la cultura, las costumbres y la ideología configurando formas de relación alrededor de la violencia dentro de los habitantes del Municipio, lo que por órdenes de recursividad traspala al sistema escolar.

En este orden de ideas la creación de los escenarios conversacionales permitió tener procesos de reflexión a las investigadoras/interventoras ampliando focos de miradas sistémicas complejas y transitando por las diferentes necesidades que emergían de cada uno de los participantes para hacer uso de la imaginación, creatividad y novedad que acompañaría el desarrollo de la investigación. 


\section{Sistema teórico conceptual}

A partir de lo elaborado en los estados del arte documental y testimonial, la presente investigación/ intervención se ha nutrido en la forma de estudiar el fenómeno; enriqueciéndose epistemológica y conceptualmente en relación a los procesos narrativo conversacionales de la violencia escolar de los niños, niñas y jóvenes durante su permanencia en el sistema educativo, donde se amplía la mirada hacia una perspectiva ecológica.

En este orden de ideas, el enfoque sistémico y la perspectiva construida desde los órdenes de la complejidad, permitieron convocar diversidad de elementos que se entretejen alrededor del fenómeno de violencia escolar, donde emergen los sistemas amplios que correlacionan la cultura, las instituciones gubernamentales del Municipio, la institución educativa, la familia y los niños, niñas y jóvenes estudiantes que se interrelacionan y convergen a través de la violencia. Es así, como en este mismo orden, se convocan comprensiones constructivistas y construccionistas, que permiten resaltar la autonomía, la narrativa y la coevolución de todos los actores en la construcción de su desarrollo social, cultural, psicológico, emocional y subjetivo.

A medida que la investigación/intervención se fue nutriendo, emergieron cambios en los ejes temáticos lo que posibilitó los niveles de recursividad en el proceso de investigación/intervención. De esta manera, el desarrollo del sistema teórico tiene en cuenta los tres principios metodológicos: la violencia escolar como una construcción social, la ecología de las interacciones desde la construcción de mundos posibles y la co-evolución, y la emergencia del sujeto autónomo desde la multitemporalidad.

Por lo anterior, el presente sistema teórico se organiza de la siguiente manera: se iniciará este recorrido teórico proponiendo en un primer apartado las aproximaciones desde los órdenes de la complejidad, el construccionismo y construccionismo; en un segundo apartado la perspectiva 
epistemológica de la violencia, un tercer apartado titulado autonomía y co-evolución en la emergencia del cambio y un último apartado la narrativa conversacional como posibilitadora de cambio asociado a la narrativa conversacional.

\section{Aproximaciones desde los órdenes de la complejidad, el construccionismo y} constructivismo.

Para comprender el fenómeno de estudio desde una perspectiva construccionista / constructivista, es necesario comprender en un primer punto las aproximaciones epistemológicas de la complejidad y la cibernética de segundo orden. Keeney (1987) en sus escritos sobre la estética del cambio, plantea la necesidad de posicionar al ser humano dentro de una epistemología diferente, que se pueda diferenciar de la epistemología lineal progresiva. Es así que, Keeney (1987), hace pleno hincapié en la importancia de ver el mundo desde un punto de vista ecológico, sistémico y posicionado desde una epistemología cibernética.

De esta manera, posicionar al ser humano desde una epistemología de segundo orden implica realizar lecturas ecosistémicas relacionales e intervenciones en las cuales el ser humano se visualice como un ser complejo y recursivo. En este orden de ideas Munnè (2005) refiere que todo ser humano es complejo, por lo tanto no existe espacio para la simplificación, permitiendo entrever la importancia de posicionar al psicólogo clínico en la construcción de explicaciones lo más complejas posibles donde se eviten los reduccionismos del "reducir - predecir - controlar" y se posicione la triada alternativa de la complejidad de "prevenir-orientar-promover".

El paradigma de la complejidad convoca a pensar en las interacciones que emergen en un grupo o conjunto de seres humanos, en este caso en los grupos de estudiantes de un sistema académico, para Munnè (2004) no es posible la complejidad si no se entienden los grupos sociales. Es así que los grupos humanos son sistemas complejos que emergen de las 
interacciones existentes entre sí, lo que Munnè (1995) conecta con la teoría del caos al referirse a: "sin caos, no hay grupo", por lo tanto un grupo social se caracteriza de equilibrios y desequilibrios, de naturaleza dinámica y no determinista, de impredecibilidad e incertidumbre que permiten la interacción y construcción constante de nuevas realidades. De esta manera, es importante comprender cómo se organiza el grupo de los niños, niñas y jóvenes alrededor del fenómeno de la violencia escolar, en la cual surgen historias y experiencias cargadas de incertidumbre e impredecibilidad las cuales construyen las diversas formas en cómo ellos interactúan con sus sistemas circundantes. De la misma manera, posicionarse desde la incertidumbre le permite a las investigadoras/interventoras y al grupo de actores participantes crear y co - construir estéticamente nuevas formas de interactuar desde la sana convivencia, resignificando la violencia escolar y propiciando un espacio de participación.

Sin embargo, para la presente investigación/intervención es importante comprender la teoría del caos desde lo propuesto por Kauffam (2003) en la primera y la cuarta ley para la co construcción de una biosfera. En este sentido, se entiende cómo las comunidades de agentes autónomos constructibles co - evolutivamente, en este caso los actores participantes y las investigadoras/interventoras, pueden evolucionar, a partir de la co - construcción de los novedoso que dé apertura a nuevas posibilidades de cambio, hasta alcanzar un orden en el límite del caos, la auto organización y la co - evolución hacia los adyacentes posibles.

En un mundo complejo, se entiende a los agentes autónomos como los actores participantes que se relacionan unos con otros, se organizan y evolucionan, lo que citando a Kauffam (2003): “son el medio a través del cual nuestra biosfera existe, co - construida en realidad por sus actividades, accidentes, esfuerzos y fracasos y por su persistente avance hacia lo adyacente posible" (P. 221). 
En este sentido, según la primera ley "la frontera dinámica del caos"; los agentes autónomos transitan por entre tres regímenes básicos: ordenado, caótico y otro de transición entre el orden y el caos. El régimen ordenado, se asemeja a un estado de "equilibrio" inestable en el cual existen atractores, estados que tienden atraer al sistema en el mismo orden; lo que llevando en términos de la investigación/intervención se consideran como aquellos sistemas que mantienen el equilibrio de la pauta de violencia. Por otro lado, se encuentra el régimen caótico el cual se asemeja a la crisis o bifurcación en el cual el sistema se encuentra en una alta sensibilidad a las condiciones iniciales, lo que conectándolo con el objetivo de intervención, la inclusión de las investigadoras/interventoras como agentes externos y la inclusión de una metodología sistémicamente orientada posibilita la perturbación del sistema generando crisis o bifurcación. Por último, el orden en el límite del caos tal como lo indica Kauffam (2003) “donde la células pueden cambiar haciendo discriminaciones fiables y actuar con resolución a ellas” (p. 237).

Complementando lo anterior los agentes autónomos al re - organizarse desde la crisis posibilitan la co - evolución constante de sus procesos de autonomía lo que citando a Hernández (2008) los procesos de autonomía se construyen y reconstruyen en el hacer diario de las personas a partir de sus interacciones que se organizan en los diferentes contextos, por tanto estos son modificables de acuerdo a la necesidad del medio. Hernández y Bravo (2008), "expone que la autonomía es una aventura riesgosa, de unión y diferenciación personal y grupal donde cada uno deviene de sus organizaciones familiares y sociales" (Pág. 23). De la misma manera, Hernández citando a Miermont (1995) mención que "La autonomía es la capacidad de un sistema complejo para organizar por sí mismo sus propios comportamientos, para autodeterminarse, constituir, organizar y administrar sus propios recursos, y sobre todo para intercambiar signos de 
reconocimiento de esta autodeterminación en los contextos vitales que habita y que contribuye a crear".

Es así que para la investigación/intervención la autonomía se co - construye en el quehacer de los agentes autónomos a partir de sus recursos en un proceso autoorganizativo que les permite co - evolucionar en grupo. En este sentido, los procesos de autonomía hacia la co - evolución de los actores participantes, se explican desde la complejidad a partir de la cuarta ley de Kauffam (2003) la cual hace referencia a la expansión crítica y autoorganizada de lo adyacente posible. En este sentido, la búsqueda de posibilidades de lo adyacente posible permite que los sistemas no se extingan y se auto organicen con los recursos de su entorno.

En este orden de ideas, dar apertura a la creación de adyacentes posibles permitiría a los agentes autónomos para la presente investigación/intervención co - evolucionar en grupo, según Duque (2015) la influencia recíproca posibilita la transformación de sistemas y entornos a partir de la unidad; esta influencia recíproca a su vez es una red ecológica que se moviliza y se transforma en grupo en los contextos amplios, gracias a la interconexión de la red.

En este punto, el proceso de investigación/intervención posiciona a los actores que participan en la trasformación de la violencia escolar y la re - organización del sistema hacia adyacentes posibles como agentes autónomos que co - evolucionan en grupo dentro de una biosfera terapéutica que facilita la apertura a la novedad; en palabras de Duque (2015):

Una biosfera coevolutiva en este marco, es un entramado autoorganizado de procesos colectivos que favorecen la producción de conocimiento novedoso a través de movimientos reflexivos, interacciones y procesos de búsqueda para avanzar hacia lo posible. El comportamiento colectivo que caracteriza a los 
diálogos experimentales de estas biosferas, se autoorganiza dirigiéndose hacia la invención de posibilidades, proceso que ajusta constantemente a las interacciones entre los agentes autónomos que la componen (p. 301).

Desde esta perspectiva los procesos narrativo conversacionales de la violencia se comprenden desde su diversidad, desde la complejidad de los grupos, la teoría del caos (Munné, 1995; Kauffam, 2003) y la multitemporalidad (Boscolo y Bertrando, 1996)

La mirada ecológica - compleja de la investigación/intervención, lleva a hacer una conexión del fenómeno con la multitemporalidad, dado que es en los diversos tiempos en los que se organizan los agentes autónomos donde surgen procesos que mantienen la pauta de violencia escolar, y así mismo es en estos mismos diversos tiempos, en los que se da surgimiento a la novedad permitiendo la apertura a adyacentes posibles de cambio. De esta manera, se comprende la multitemporalidad en un sistema escolar, como el tiempo individual, familiar y colectivo que experimenta la persona desde su intersubjetividad y que le proporciona una visión distinta de los acontecimientos y que por lo tanto se conecta con la forma de narrarse dentro del sistema escolar. Es así, que para hablar del tiempo individual, es preciso citar a Boscolo y Bertrando (1996) quienes introducen el concepto de multitemporalidad, al referirse que el tiempo no puede medirse o estandarizarse, dado que existe un tiempo subjetivo, que no es común a todos los seres humanos, considerándose como el verdadero tiempo de cada sujeto y por lo tanto refiriendo en palabras de Boscolo y Bertrando (1996): "El conocimiento del tiempo es, por tanto, múltiple. Cada concepción tiene su tiempo.” (p. 38).

De igual manera, Prigogine (1983) al referirse al tiempo, manifiesta un tiempo que no puede considerarse únicamente parte de la irreversibilidad, el devenir y la evolución, dado que el tiempo, posibilita la apertura de un tiempo del sí mismo "nuestro tiempo". Es así, que el tiempo 
precede a la existencia, permitiendo el nacimiento de nuevos universos. En este sentido, el tiempo que se posibilité en la biosfera terapéutica creada en la investigación/intervención posibilita el surgimiento de un tiempo del sí mismo el cual se conecta con los procesos de autonomía de los actores participantes en relación con el crecimiento, la autoorganización y la co - evolución.

Teniendo en cuenta lo anterior, Gergen (1996) plantea las diferencias que goza el ser humano al mantener historias y narraciones individuales que hacen parte del propio tiempo experiencial de las personas. Es así que las historias de cada de los niños, niñas, jóvenes y sus sistemas circundantes hacen la vida significativa, le dan sentido con cada narración y experiencia contada, donde cada acto tiene relación con el otro, generando una cadena de eslabones que representa todo lo vivido, lo deseado, lo soñado y las creencias individuales; las historias encierran cada idea, lo cual forja el carácter moral de cada uno de los individuos, es la manifestación de la realidad por medio de la narración de sucesos que contienen un comienzo, un intermedio y un desenlace, encerrando la expectativa futura, dentro del mundo subjetivo construido por cada persona. En este sentido, los niños, niñas y jóvenes emergen desde las historias narradas que los posicionan en un tiempo pasado, presente y futuro el cual les permite construir a partir de la experiencia creencias y diversas formas de relacionarse con el mundo circundante; partiendo de estas historias se deconstruye narrativamente la violencia escolar, generando nuevos significados co - construidos en el grupo de actores participantes que les posibilita desde un presente un futuro guiado por el camino del cambio.

\section{Perspectiva epistemológica y paradigmática de la violencia}

La comprensión de la violencia escolar a partir del enfoque sistémico demanda una comprensión relacional del entorno académico, social, cultural y familiar, donde la emergencia 
de la violencia confluye en el sistema educativo y en la forma en cómo se construyen las interacciones en el entorno escolar. Es así como, la violencia es percibida desde un punto de vista ecológico - complejo que permite ampliar la mirada de este fenómeno hacia una construcción social más amplia que la mera violencia escolar de unos pocos sujetos.

La violencia escolar es comprendida como una construcción social que emerge de las interacciones de un grupo de estudiantes sujeto a la incertidumbre, al equilibrio y desequilibrio. Teniendo en cuenta lo anterior, para el construccionismo, según Gergen (1996), es importante poder enriquecer el discurso dentro de las prácticas sociales en el proceso de relación entre los individuos, ya que cada vez que se entabla un vínculo relacional la persona se auto-narra y narra una historia que puede ir desde la niñez hasta relatos de la familia, con el fin de posibilitar una proximidad con el otro y como medio de identidad. De esta manera, la violencia escolar se conecta con los vínculos que se crean en un sistema escolar que se encuentran cargados de discursos narrativos que crean significados, a partir de la cultura y los rituales de cada sistema familiar, respecto a cómo relacionarse con el otro y cómo actuar al presentarse la violencia escolar.

$\mathrm{Al}$ crearse vínculos en el sistema escolar que pueden ser tanto destructivos como generativos se generan diversos posicionamientos que surgen en el sistema escolar al organizarse las interacciones alrededor de dominios de poder, autoridad y participación. Teniendo en cuenta lo anterior y citando a Baudrillard y Morín (2003) la violencia en el mundo se encuentra ligada siempre al poder, un poder dentro del orden mundial, de las potencias mundiales, y de lo que cada una de estas potencias representa para los sujetos que coexisten en el mundo; por lo tanto la violencia no es vista como algo real de lo real, sino como un acto ficticio que convierte algo "cerca a ocurrir" a ser algo "real" que busca un desequilibrio de lo inimaginable, que rompe de 
forma abrupta con lo lineal generando desconcierto de lo que pasó y lo que no ha pasado. De esta manera, se plantea la violencia que existe en el mundo, desde un trasfondo dentro de las guerras y atentados, en búsqueda del poder contra el mismo poder.

Desde este punto de vista, la violencia convoca a pensar en el poder, lo que para White (2002) se convierte en una analogía del texto que abarca una información más amplia y en diferentes contextos, que no solo logra dar una información de la experiencia sociopolítica de la persona, sino también proporciona los efectos y las acciones del poder dentro de la misma. Para Foucault (1983) el poder va enmarcado junto con el conocimiento, lo que conlleva al poder a ser constructivo para los individuos, llevándolo a los efectos positivos y determinantes de su vida, en donde no todos los individuos ejercen o sufren de igual forma los efectos de dominación del poder. Es así, que entender cómo se organizan los niños, niñas y jóvenes alrededor del poder posibilitan procesos de cambio al comprender el poder como constructivo y generativo para el crecimiento de cada actor participante, la co - evolución en grupo y el fortalecimiento de los procesos de autonomía desde el empoderamiento como seres que hacen parte de un contexto sociopolítico en el cual participan.

White (2002) abre un campo en cuanto a la visibilización del poder y la narrativa, dentro del discurso, en el cual la persona a través de la historia ha estado sujeta al poder de las masas dentro de la cultura, las tradiciones, pensamientos, costumbres en la vida y su impacto notorio en el entorno; sin embargo, plantea cómo también el individuo contemporáneo se ha visto envuelto en la búsqueda de la "verdad” de sí mismo, de la naturalidad de lo que es en sí su ser y cómo el sujeto se cuestiona por medio de sus propias experiencias en términos problemáticos y enfocándose en la represión que éstas hacen dentro de su proceso de desarrollo y en lo distante que está de su propia naturaleza. 
En este sentido, la violencia dentro de un contexto escolar se encuentra ligada a los órdenes de poder construidos y constituidos en una institución educativa que trasciende no solo del sujeto (estudiante) y sus interacciones, sino que se encuentra enmarcado por los órdenes de poder de los contextos más amplios. Teniendo en cuenta lo descrito por Fernández (2007) la violencia tiende a ser una recurrencia que involucra al contexto familiar, institucional y cultural, que jamás es arraigado dentro de sí, y, al ser un acto violento, desprende factores de vulnerabilidad tanto física y psicológica en los sujetos, dada su tendencia a ser intencional y recurrente, en la búsqueda de poder y de sometimiento.

En cuanto al contexto cultural, White (2002) resalta cómo el individuo al separarse de sus problemas tiende a cosificarse no solo a sí mismo sino también a las demás personas, esto debido netamente al entorno cultural en donde se encuentra; por lo tanto cuando se habla de una externalización del problema se busca la “des cosificación” que tiene arraigado el individuo de sí mismo y de los demás, lo cual genera en ellos una liberación y así una posición independiente de sus problemas; según Foucault (1983), ésta práctica de la cosificación dentro de la sociedad se da con el fin de mejorar y extender un control social, trayendo consigo la subyugación de los individuos a través del tiempo por medio del cómo se maneja el poder en el estado, teniendo en cuenta el gobierno de las personas y de sus cuerpos viéndose como "cuerpos dóciles" en busca de una individualidad.

Este proceso de investigación/ intervención orienta su interés en las distintas percepciones alrededor de la violencia escolar, donde converge la construcción de interacciones en el contexto escolar según la edad de los niños, niñas y jóvenes, la cultura, las subjetividades e intersubjetividades emergentes del encuentro e interacción y el contexto de la familia. Es relevante la vida académica de los niños, niñas y jóvenes, dado que desde la escuela se 
construyen diferentes interrelaciones con pares, docentes, personas de otras edades y

descubrimiento del mundo a partir de las diferentes pautas de interrelación que cada niño, niña y joven mantienen durante su permanencia en el sistema educativo; allí se da inicio a la construcción de la identidad, donde paulatinamente se va creando idiosincrasia de las diferentes visones de la vida, la construcción de su autonomía e identificación de grupos con los que se está en constante permanencia.

Dentro de esta recurrencia, es necesario considerar el rol de la familia dentro de la construcción y deconstrucción de la violencia, en este orden tal como lo manifiesta Fernández (2007), a través de la historia la familia se ha considerado como la base de toda sociedad dado que culturalmente, es en ella en donde se fundamentan y se aprenden los valores, principios, normas, entre otras; es dentro de la familia donde se empiezan a generar los rasgos de individualidad de las personas, el carácter, los roles de género (niña -niño) sus funciones dentro de la sociedad, y es dentro de la familia, donde se inicia el ejercicio de poder que define la relación con los demás.

\section{Autonomía y co-evolución en la emergencia del cambio}

Los procesos de socialización para los seres humanos son fundamentales en el desarrollo co evolutivo, ya que permiten las diferentes interacciones en los determinados contextos donde se desenvuelve a diario el sujeto, facilitando la expresión de sentimientos, gustos, miedos y diferentes sensaciones inherentes al sí mismo.

En este orden de ideas, se destaca la autonomía de los niños, niñas y jóvenes, entendiéndose cómo la capacidad que posee un individuo para organizar sus comportamientos, para administrar sus recursos, para empezar a contribuir dentro de su entorno, por sí mismo dentro del contexto vital en el cual convive. 
Para Morín (2003) la autonomía como ciencia se funda en nociones diferentes tales como:

1 La vida como juego del orden, desorden, de las probabilidades, siendo estas las que traen consigo el devenir.

2 La auto organización, como manejo de las relaciones de los individuos como unidad organizada para construir y mantener la autonomía

3. La autonomía sistémica - organizacional se entiende en los conceptos de emergencia y retroacción, donde emergencia es la cualidad que llegan de la organización y que vuelve a actuar en las condiciones de su formación para salvaguardar la duración del sistema. Y la retroacción entendiéndose como el reintegro del efecto sobre las condiciones que lo han producido.

4. La vida existe a través de organizaciones activas capaces de auto producirse y auto realizarse generando así mismo su autonomía y su existencia por medio de la recursividad.

5 La autoproducción, que genera el ser y la existencia misma pues están sometidos a las necesidades y a los azares de la vida.

6. Los seres vivos auto organizadores, los cuales los ven como sistemas cerrados que protegen su identidad e integridad y abiertos en donde se ve el intercambio de información, energía; por eso se refiere a ellos como seres auto- eco organizadores en donde la autonomía se construye "dentro y por la dependencia ecológica" en donde se ve envuelto el individuo.

7. Auto organización, la cual opera por computación (calculo y operaciones lógicas en la toma de decisiones) en donde se forma la autonomía de cada individuo en relación con el ambiente. 
8. Los animales superiores poseen un sistema neurocerebral mucho más complejo, por lo tanto se puede construir estrategias de conocimiento y de acciones lo cual genera situaciones de toma de decisiones, lo cual implicaría un individuo autónomo.

Por consiguiente los procesos de autonomía en los niños, niñas y jóvenes se fortalecen cuando a partir de la participación se crean diferentes posibilidades que se tienen de elegir, de tomar decisiones en diferentes escenarios por medio de la reflexión y la organización. En este sentido la violencia y los conflictos sociales se pueden entender como expresiones del sufrimiento humano por la imposibilidad de ejercer la autonomía en diferentes contextos vitales y en donde se presentan confusiones o incoherencias, y estos se mantienen en un plano de asociación por una perturbación a nivel comunicacional en los diferentes sistemas asociados a él, como sus creencias, valores, de conocimiento y reconocimiento los cuales normalmente operan en una construcción de vínculos y los procesos de autonomización (Hernández, 2010).

Teniendo en cuenta lo anterior, la autonomía les posibilita a los niños, niñas y jóvenes posicionarse como seres sociales y políticos que se empoderan desde su participación en los procesos de cambio de su medio social. Es de esta manera, que la autonomía les posibilita a los actores participantes de - construir la violencia escolar y construir posibilidades de cambio que tienen un algo impacto ecológico dada su participación y empoderamiento como seres sociales y políticos. Es en este punto donde la ecología de la interacción tiene una alta importancia en los procesos de cambio, dado que al posibilitar el fortalecimiento de los procesos de autonomía no solo se conecta con un cambio individual sino que también se posibilita un cambio en los sistemas circundantes. Conectando con Bateson (1972), la ecología en torno a lo psicológico reside en la interacción, complejidad, diferencias y sobre todo en la supervivencia de las especies (seres, sistemas, programas) inmersos dentro de la naturaleza de forma jerárquica, donde se 
generan dependencias, alineaciones no necesariamente lineales, sino en las cuales todo tiene un orden en pro de la conservación del ser por medio de un equilibrio establecido, en donde una idea es una diferencia por lo cual es pensamiento y a la vez es información que ha de ser compartida dentro del proceso de comunicación en un entorno. En este sentido, Bateson (1972) propone diferentes conceptos que son importantes para este proceso, encontrando el contexto como el medio en donde las personas pueden ser entendidos extensamente puesto que están dentro de su entorno y ecosistema social determinado; es así que la transmisión de información, hace parte fundamental dentro del ecosistema planteado por él ya que al transmitirse información se están enviando ideas, se está comunicando y hasta dentro de este proceso de intercambio social los silencios hacen parte fundamental de supervivencia de los seres en donde sobrevivir es el "fin" de todos los sistemas existentes.

Complementando lo anterior, Niño y Castañeda (2010) menciona que la perspectiva sistémica familiar da cuenta las diversas construcciones tanto en lo ecológico como en lo contextual, por tal motivo la construcción de las realidades de los niños, niñas y jóvenes está relacionado directamente por la forma en que a través de su desarrollo integral ha aprendido a relacionarse con el medio que le rodea. Los anteriores autores, mencionan que los contextos de interacción de las personas afectan y son afectados por las diversas experiencias que se organizan de las interacciones sociales, en los cuales según el tipo de relación que se construya existen situaciones que tienden a dominar el medio y por tanto a repetir comportamientos aprendidos para hacer parte del grupo.

Al reconocer el contexto ecológico que circunda el sistema escolar se reconoce la importancia de corresponsabilizar en los procesos de cambio a la familia, la escuela y el Municipio. Niño y Castañeda (2010) hace referencia a la pauta de corresponsabilidad entre institución educativa y 
familia, reconociendo las diferencias de cada uno, como sistemas que conversan en un diario vivir donde pueden enfocar al niño, niña, joven a ser solidarios en sus dinámicas de aprendizaje y desarrollo propias de la edad de los estudiantes. El trabajo en equipo que se pueda organizar con la familia y la institución al mismo tiempo puede permitir un mayor acercamiento hacia el estudiante, y por tanto conocer cuáles son las necesidades que tiene el niño, niña y joven por tanto pueden ser suplidas de manera eficiente. Dabas (2006) afirma que en los últimos tiempos la escuela ha considerado la importancia de involucrar a la familia en los procesos educativos preocupándose por el tipo de relación que se construye al interior del sistema familiar.

El desconocimiento de las actividades escolares por parte de la familia, genera un distanciamiento entre padres e hijos, lo cual facilita que haya una fragmentación en esta relación, por tanto es para la institución vital incorporar a la familia en los procesos educativos, donde se pueden fortalecer las relaciones, tanto colegio, familia, como padres, madres e hijos. Dabas (2006) manifiesta que para que haya un cambio en el proceso educativo, todos los actores inmersos en este contexto debe generar un cambio para sí mismo, de esta forma es pasar de lo individual a lo colectivo. De igual manera la relación entre familia y escuela debe significarse alrededor de una relación de oportunidad y fortaleza.

\section{La narrativa conversacional como posibilitadora de cambio.}

Un eje importante en la construcción de las interrelaciones de los estudiantes dentro de un aula de clases y su expansión hacia los sistemas amplios en la construcción y deconstrucción de la violencia y por lo tanto en la redefinición de la misma, es la función de los procesos narrativos conversacionales que se tejen alrededor del fenómeno o pauta de la violencia escolar. Es así, que en una primera instancia se retoma la narrativa como un posibilitador de la emergencia del sujeto cultural, social, familiar e institucional. 
Teniendo en cuenta lo anterior, el lenguaje se encuentra construido por seres micro políticos, que se construyen dentro de procesos sociales, culturales y políticos que crean realidades distintas sobre las cuales el ser humano opera dentro del mundo. Es así que entendiendo al ser humano, como un ser micropolítico se convierte la política en una política local de las microsociedades existentes en las cuales se emerge, y en dónde se entiende el poder en cuanto a la oportunidad para definir realidades; Pakman (2006) considera que como seres micro políticos los seres humanos tienen la capacidad de producir ciertas transformaciones en nuestra sociedad, sin embargo a partir de actos poéticos se crean momentos discontinuos, generativos, interpretativos que producen una desarticulación de la continuidad dando apertura a nuevas posibilidades.

Es así que, propiciar un momento poético se convierte en un reto para el investigador/ interventor teniendo en cuenta que es necesario considerar tanto lo dicho como lo no dicho, lo pensable y lo impensable, los pequeños momentos que pueden dar apertura a eventos generativos... momentos que se convierten en actos poéticos. Es de esta manera que Pakman (2006), parte de la percepción minimalista del lenguaje, para llegar a postular la poética del lenguaje, donde da apertura a un movimiento de lo ya dicho hacia el decir, tejiendo, hacia lo poético de lo conversado desde la micro política de objetos ya determinados y abriendo espacio para la subjetividad del ser y para la configuración del sí mismo.

Teniendo en cuenta lo planteado por Estupiñàn, Garzón, Niño (2006), dentro de la sociedad, cada ser desarrolla una individualidad y una interpretación de los diferentes contextos, entornos y ecosistemas presentes dentro del proceso evolutivo; sin embargo, es necesario que se entienda a cada individuo como un ser netamente social, en donde la narrativa hace parte de la significancia e interpretación de las situaciones, de la historia, de su política, sus creencias, su cotidianidad; 
convirtiéndose la narrativa en un instrumento de reproducción, donde busca mantenerse y transformar la realidad de los demás grupos culturales junto a sus integrantes. Por esta razón, la narración siempre guiará la relación que se tiene entre el sujeto y su entorno, siendo necesario observarla desde un orden cultural, dada la información por donde y por la cual la sociedad se informa otorgando un valor legal y real dentro de la misma.

Es así como, todo signo lingüístico posee una carga dentro del entorno, según Echeverría (2002) es posible observar cómo un pequeño gesto lingüístico puede trasformar y aportar hacia la propia construcción del ser humano. Teniendo en cuenta ésta, es importante comprender al individuo como una construcción lingüística, que se relata a sí mismo a través de su historia y que también se construye dentro de una sociedad; es en esta sociedad donde el individuo se crea como un fenómeno social que comparte discursos históricos dentro de una comunidad.

El lenguaje se compone de relatos y construcciones sociales, el lenguaje implica una acción que va más allá de su significado, teniendo en cuenta esto, el lenguaje es la coordinación de la coordinación del comportamiento que, por lo tanto está presente en las acciones, en la forma en como enfrentan las cosas y en la forma en cómo se construye el ser humano dentro de una sociedad. Es así que como seres ontológicos sociales, la construcción del comportamiento humano se encuentra muy ligado al sistema en el que se esté inmerso, teniendo en cuenta de esta manera, que el sujeto se construye a partir del sistema, sin embargo, el sistema también es construido por el mismo sujeto (Echeverría; 2002).

En este orden de ideas, para las narraciones construidas alrededor de la violencia escolar confluyen diversos relatos que expresan tanto lo construido social y culturalmente, como lo relatado desde la intersubjetividad de cada uno de los actores inmersos en esta pauta percibida como una problemática dentro de la sociedad. A partir de las narraciones es que surgen los 
sistemas de significados construidos culturalmente, por esta razón a partir de la intervención desde lo narrativo emergen procesos que posibilitan cambio en el medio social y cultural a medida que se empodera el carácter micropolítico de los niños, niñas y jóvenes.

El pensamiento narrativo y la construcción de los significados, se desarrollan con fundamento en las experiencias vividas, por medio de una asociación ya sea de imágenes, analogías, sentimientos y todas aquellas semejanzas dentro del discurso narrativo lo cual trae consigo diferentes interpretaciones en los actores implicados y donde el conocimiento no se percata dentro de las narrativas en sí, más sí en los significados del sí mismo dentro de las interacciones. Dentro de su escrito, Estupiñàn, Garzón, Niño (2006) señala diferentes propiedades de las metarepresentaciones, de tal manera es importante entender la estructura y proceso del pensamiento narrativo como parte fundamental en la organización de pensamientos, motivaciones, memorias y experiencias de la vida que dan coherencia a las vivencias de los individuos. Ahora, dentro de un proceso de intervención clínica y de consultoría cabe resaltar la importancia que tiene la narrativa dentro del mismo, puesto que es aquí donde se comprenden los procesos evolutivos y co-evolutivos del ser humano dentro de los procesos adaptativos de la experiencia narrada y vivida.

Es así como el proceso de investigación/intervención planteado desde la posibilidad de crear mundos posibles a través de la narrativa, cobra fuerza al entender y comprender los procesos conversacionales en la construcción de nuevos relatos que permitan desde la emergencia de los procesos co-evolutivos la resignificación de la violencia vivida en el entorno escolar y reorganizada desde ordenes más amplios.

Cabe resaltar que el proceso narrativo dentro de la sociedad para Estupiñàn, Garzón, Niño (2006), se convierte en un mecanismo de adaptación acogido culturalmente mediante el proceso 
evolutivo, esto debido a la necesidad de los seres humanos de interactuar, de narrar los hechos, sucesos, y acontecimientos partiendo de sus experiencias para darle sentido a lo acontecido y darle significado a lo narrado de forma organizada y jerarquizada dentro de su entorno.

Ahora, en torno al contexto escolar y la intervención, la investigación/intervención se centra en el significado de la conversación, en la cual no hay palabra que se defina o afirme, sino, tal como lo menciona Anderson (2000) una serie de características que la encierran: el marco de referencia (identidad), el contexto donde se encuentran los estudiantes (cultural, social histórico), favorece y no favorece hechos que se correlacionan (pasado, presente y futuro). En concordancia con lo planteado por Gergen (1996) las narraciones son consideradas como recursos conversacionales que no necesitan una estructura cognitiva para poder entablar una relación solo basta con la narración como implemento lingüístico para sostener una conversación en donde cada ser humano es el autor de su propia vida.

Ahora bien, para Estupiñàn, Garzón, Niño (2006) dentro del contexto psicológico - social, la narrativa conversacional ayuda a identificar, explicar y comprender los diferentes relatos y los patrones cognoscitivos dentro de estos, generando la construcción y transformación de las narrativas dentro del mismo proceso de interacción. A través de la resignificacion de la violencia escolar, en la investigación/intervención se invita a la polivocalidad en el desarrollo de los escenarios, escuchando las posturas de cada participante, haciendo visible aquellos actos poéticos que aunque no son notorios han sido significativos en la construcción social de la violencia escolar.

Teniendo en cuenta los puntos de vista anteriores y resaltando la importancia de las narrativas, como interrogantes guía para la generación de identidad y acción, Gergen citando a Wittgenstein (1953) resalta como elemento crucial dentro de una conversación y por lo tanto dentro de la 
construcción de narrativas, la metáfora generadora, dado que según este autor las palabras obtienen significado a partir de la interacción social donde se desarrollan los juegos de lenguaje combinadas con nuestras acciones y con los objetos del entorno.

Concluyendo lo anteriormente dicho, se observa la multiplicidad de significados construidos a través de la historia de vida de los personajes, quienes consideran como cierto y verídico los hechos de su propia realidad, desarrollando una creencia que apoya y sostiene a la persona; pero también, se observa una consultoría que favorece la multiplicidad de narraciones pero que no se compromete con ninguna, dado que las construye en conjunto, con la interacción. Tal como lo explica Gergen (1996), el Yo no es un producto de la independencia, por el contrario, el Yo es un subproducto de la vinculación y de la relación con los demás, que crea la propia identidad.

En este sentido, para Zlachevsky, Ojeda (2003) los relatos de las personas desde su individualidad son únicos y diferentes y por lo tanto el significado atribuido a las situaciones depende de la forma en como "cada persona signifique los acontecimientos que está relatando", añadido a esto, las comprensiones del significado dependen de los que fueron adquiridos durante la vida, en las interacciones con los demás, es decir, dichos significados se construyen con las personas con quienes se comparten significaciones y con las situaciones y los entornos en donde se encuentre inmersa la persona. Teniendo en cuenta lo anterior la autora refiere que las narrativas son diferentes para cada persona. En relación con el foco, las narrativas que emergen en los niños, niñas y jóvenes, se manifiestan en los significados que han adquirido a lo largo de sus experiencias, en la cuales tanto los relatos como las interpretaciones de significados son distintos y dominantes en relación con las interacciones con los demás.

Es aquí donde la forma de cómo cada sujeto narra los diferentes hechos o acontecimientos que ha vivenciado y requiere un razonamiento sistemático que a pesar de ser individual y separado 
del otro personaje con quien se "comparte" dicha vivencia toma cada uno un rol, un inicio, desarrollo y un final dentro de cada historia la cual se entrelaza dentro del argumento y genera una trama dentro de la evidencia global y esa trama narrativa termina siendo las redes de significación conjunta que evidencia la elaboración de significados no solo de forma personal sino en la convivencia conjunta lo cual hace que cada personaje pueda anticipar lo que es posible esperar de sí mismo o del otro, o crear sin número de expectativas, ya sea de lo posible o lo imposible dentro del circulo en el cual conviven y se empieza a pasar a ser la "realidad" para cada individuo (Zlachevsky, 2003).

Teniendo en cuenta lo anterior y la importancia de las narrativas y de los significados que cada ser humano construye a partir de sí mismo en un eje social, cabe resaltar dentro de un proceso terapéutico no como la búsqueda de un cambio o una intervención secuencial y procesal, sino una "colaboración" a la búsqueda de la interpretación que cada uno de los actores le dé a los hechos, un dialogo constante y/o una relación de inclusión con lo relatado asumiendo la capacidad de colaborar en la creación de nuevos futuros o expectativas generadas por medio de relatos de auto-reflexión, atribuyendo a los hechos lo que determina el comportamiento de cada individuo.

En este orden de ideas, según Gergen (1996) las auto narraciones no son propiamente de la persona, sino que son el resultado de la interacción con los demás, es el resultado de una interacción netamente social, donde las experiencias vividas y el potencial futuro están íntimamente ligadas entre sí. Al hablar de una autonarración, se habla de vivencias de los eventos relevantes en la vida del individuo a través del tiempo en donde se crean conexiones coherentes entre todos los eventos existentes, así, la identidad que emerge a través del tiempo es posible por la relación y vinculo que se ha creado con el orden narrativo. 
Según White (1996) cuando un sujeto se relata a través de una situación problemática, se detecta una narración dominante, cuando al contextualizar su problemática solo narra los diferentes aspectos “inútiles, insatisfactorios y cerrados” y muestra poca información de la experiencia en general vivida, no representando suficiente información acerca de la experiencia real; es aquí cuando, al hablar de una intervención, se supone que dentro de ella deben existir aspectos que contradigan las narraciones dominantes, con las cuales se hace necesario trabajar. Para White (1996) los problemas y sus efectos están unidos por una dependencia, en donde el problema necesita para existir de los efectos y los efectos constituye el sistema que deja con vida al problema; de esta forma dentro de la intervención al identificar los acontecimientos extraordinarios de la situación ayudará a los seres humanos a concientizarse de los efectos del problema y de la resistencia que se genera entorno a ellos, aquí al identificarse y al darle otro significado a lo acontecido, el problema deja de tener fuerza, dejando de someterse a los efectos que estos conllevan, tomando así otro camino, abriéndose a nuevas posibilidades de significancia en relación al problema principal.

Ahora bien, cuando para intervenir se esperaría que de la persona emergiera una resignificación de la situación problemática de forma satisfactoria, donde sean utilizadas el resto de experiencias de ese mismo acontecimiento que no fueron tenidas en cuenta a la hora de la narración problemática por el individuo; a estas experiencias se les llama según Goffman (1955) “acontecimientos extraordinarios"; que aunque no estén presentes de forma directa están presentes de manera que puede ser interpretada por los sentimientos, sucesos, intenciones pensamientos en una situación pasada, presente o futura.

Es así que, al comprender las voces de los actores y el posicionamiento de la violencia alrededor de la víctima y victimario, emerge la necesidad de redefinir estas semánticas 
bivalentes, que encasillan y estereotipan el comportamiento de los estudiantes en su contexto académico lo que no posibilita escuchar la necesidad vincular de las dos partes involucradas. Por otro lado al comprender la naturalidad con la que todo una Municipio ha aceptado la violencia desdibujando su incidencia en los contextos escolares, es necesario trabajar según lo mencionado por White (1996) en pro de la externalización del problema en la cual se genere en las personas una separación de los relatos, puesto que al sacar a los actores de su contexto problemático se están generando nuevas narraciones, favoreciendo hacia una separación de puntos de vista y una re- significación en la cual el individuo por medio de los cuestionamientos precisos de las investigadoras/interventoras construye nuevos significados de los acontecimientos extraordinarios; tomando un papel dentro de la intervención de actor y publico dentro de sus representaciones lo cual genera en él un cambio de "pensamiento" y aquellos acontecimientos vistos anteriormente como problemas cerrados, llegan a un acontecimiento simplemente abierto luego de la intervención.

\section{Sistema Metodológico}

El presente sistema metodológico da cuenta de la forma de operar e intervenir en un contexto escolar, partiendo de comprensiones epistemológicas y metodológicas que configura el fenómeno de estudio, primando los procesos conversacionales y la narrativa como posibilitadores de la emergencia del sujeto en un contexto educativo, social, cultural y familiar.

En primera instancia se hace presente el sistema conceptual que postula los procesos y principios metodológicos de la línea de investigación desde una perspectiva sistémica constructivista construccionista y que son particulares de esta investigación/intervención. En segunda instancia se contempla la visión conceptual de las investigadoras/interventoras dando cuenta de los conceptos metodológicos de la investigación/intervención proponiendo la violencia 
escolar como una construcción social, la ecología de las interacciones en el entorno escolar y la emergencia del sujeto autónomo desde la multitemporalidad.

Así mismo, en tercer lugar se lleva a cabo la propuesta de los diseños de escenarios, correspondiente al planteamiento de actores involucrados, escenarios propuestos, objetivos de los escenarios, focos de intervención y guiones.

\section{Perspectiva metodológica}

\section{Marco epistemológico y paradigmático de la investigación/intervención.}

El estudio sobre violencia escolar corresponde a un enfoque investigativo / interventivo orientado hacia las aproximaciones y comprensiones desde la Psicología Clínica y la complejidad desde un enfoque constructivista - construccionista alrededor de los procesos de autonomía que co-evolucionan en los entornos escolares; es así como la co - construcción de nuevas experiencias y relatos alternos posibilitan la emergencia del sujeto desde la activación de sus propios recursos.

De esta manera comprender los procesos narrativos conversacionales de la violencia escolar, que se configuran en el sistema educativo durante la permanencia de los niños, niñas y jóvenes en sus diferentes momentos del ciclo académico, se convierte en una posibilidad para intervenir, desde la reconfiguración narrativa asociada a procesos de autonomía en la dinámica vincular del niño y joven, su familia, los integrantes del contexto educativo y sistemas amplios que hacen parte de su ecología.

Teniendo en cuenta lo anterior, esta propuesta incluye a las investigadoras/interventoras como co-constructoras de nuevos relatos y experiencias frente al fenómeno de la violencia escolar y como agentes posibilitadoras de cambio que permitan hacer un llamado a la polivocalidad de los sistemas amplios que confluyen alrededor del sistema escolar: 
“... la presunción de polivocalidad abre la puerta a nuevas formas de metodologías de investigación. Ya hemos tratado los métodos en que se da entrada a las múltiples voces en el ámbito interpretativo: las voces de los participantes en la investigación, la literatura científica, la visión privada de los investigadores, los medios de comunicación, etcétera. Sin embargo, el reto de la polivocalidad es más radical, en cuanto que nos sensibiliza respecto a la posibilidad de que todas las partes de la investigación pueden “contener multitudes".” (Gergen. 2007; pag. 265)

En este sentido, la perspectiva sistémica - construccionista - compleja, mantiene su apuesta encaminada a la comprensión de los sujetos a partir de sus recursos, permitiendo la potencialización de lo humano y empoderamiento del sí mismo en la emergencia de la creación de nuevas posibilidades viables hacia la trasformación de la vida. Por este motivo desde los procesos auto - reflexivos y colaborativos en torno a los fenómenos sociales, políticos y culturales, confluyen con las experiencias y relatos compartidos en un ejercicio de observación y metaobservación en la construcción de posibles procesos de cambio generados en el acto investigativo/interventivo que se consolida en el contexto educativo y en sus sistemas amplios.

\section{Investigación cualitativa de segundo orden}

El método cualitativo de la investigación emerge de la construcción epistemológica, la intención metodológica de la investigación/intervención y el contexto de intervención, donde se permita realizar comprensiones de segundo orden ya lo afirma Jailler (2003) esta investigación busca la realidad a partir de reflexiones sobre el conocimiento a través de metaobservaciones y donde el observador entra a formar parte de la misma. También se llevan a cabo construcciones narrativas alrededor del fenómeno de estudio. Es así, que el objetivo se convierte en un motivo 
para comprender las diversas realidades que se han construido en un contexto escolar y que por los mismos órdenes de recursividad emergen en los sistemas amplios.

En apoyo a lo anteriormente descrito, Foerster (1991) señala que al incluir al observador en una cibernética de segundo orden, se incluía al investigador/interventor como parte del sistema rescatando como capacidades el proceso autorreferencial y la autológica, donde las nociones de circularidad hacen parte de los procesos de observación.

Como un punto favorable y propio de la psicología sistémica, la cibernética de segundo orden sitúa al observador como observador participante y como un agente de cambio que posibilita la emergencia de relatos alternos y la co - construcción con los diversos actores participantes a partir del ejercicio conversacional. Es así, que el lenguaje se convierte en un dispositivo que facilita la emergencia del sí mismo social, cultural y político, y que desde su generatividad permite la creación de nuevos mundos posibles que reconfiguran la experiencia humana. El intercambio social propicia los procesos autorreferenciales en el intercambio de ideas, conceptos e historias que legitima la experiencia del Yo Subjetivo y el surgimiento de las diversas voces inmersas en el contexto de investigación/intervención.

\section{Procesos narrativo - conversacionales de la investigación/intervención}

Es importante centrar la propuesta de investigación/intervención desde los procesos narrativos conversacionales, dado que se enmarca el interés por la aceptación de la historia de vida del sujeto, como un elemento fundamental en la construcción del planteamiento del problema, el estudio y la redefinición posterior de la situación problematizadora.

Tal como lo refiere Estupiñan, Mojica, González (2015), los procesos conversacionales organizan la experiencia humana donde se conjuga la experiencia vivida y la experiencia 
narrada, así, tal es su importancia que partiendo de la narrativa conversacional es posible trasformar esta experiencia narrada en experiencia vivida. Estos autores señalan lo siguiente respecto a las narrativas conversacionales:

Para comprender el ser humano es preciso comprender cómo sus experiencias y actos están moldeados por sus actos intencionales - creencias, deseos, intenciones, compromisos -. La forma de esos estados intencionales solo puede plasmarse mediante la participación de los sistemas simbólicos de la cultura, es decir la cultura participa en la manera como se valoran los comportamientos sociales y como se diseñan para conocerlos (p. 69).

Teniendo en cuenta lo anterior, tanto la cultura como las creencias de los actores participantes son puestas en escena partiendo de sus narrativas, donde es expuesto el self a partir de sus vivencias cotidianas y en sus diferentes procesos evolutivos.

En este punto, tanto las narraciones del participante como las voces de las investigadoras/interventoras cobran un sentido constructor, no dentro de un juego de competencia sobre quien tiene la razón, sino desde el aporte de recursos, desde la misma interacción que favorece la visualización de un mejor futuro; es así, como las voces de los sujetos se convierten en un elemento crucial para la construcción de nuevas realidades.

Teniendo en cuenta los puntos de vista anteriores y resaltando la importancia de las narrativas, como interrogantes guía para la generación de identidad y acción, Wittgenstein (1953) resalta como elemento crucial dentro de una conversación y por lo tanto dentro de la construcción de narrativas, la metáfora generadora, refiriendo que las palabras obtienen significado a partir de la 
interacción social donde se desarrollan los juegos de lenguaje combinadas con acciones y con los objetos del entorno.

En este sentido, el cuerpo y los movimientos acompañados del lenguaje conducen a una manifestación narrativa de los sucesos, dicho en las palabras de Gergen (2006):

Para decirlo de otro modo, una historia no es simplemente una historia: es también una acción situada, una representación con efectos de elocución. La historia actúa de ese modo para crear, mantener o alterar los mundos de la relación social (p. 140).

Concluyendo lo anteriormente dicho, se observa la multiplicidad de significados construidos a través de la historia de vida del sujeto, quien considera como cierto y verídicos hechos de su propia realidad, desarrollando una creencia que apoya y sostiene a la persona; pero también, se observa a un equipo de intervención que favorece la multiplicidad de narraciones pero que no se compromete con ninguna, dado que las construye en conjunto, con la interacción. Tal como lo explica Gergen (2006), el Yo no es un producto de la independencia, por el contrario, el Yo es un subproducto de la vinculación y de la relación con los demás, que crea la propia identidad.

\section{Principios Operadores}

\section{Autorreferencia y reflexividad.}

La autorreferencia implica que las investigadoras/interventoras se visibilicé como parte de un sistema que reconoce y comprende sus propias narrativas, creencias, valores, prejuicios, ideas, emociones y acciones dentro de un contexto interventivo, poniendo en juego la intersubjetividad narrativa de las mismas. En este posicionamiento emerge el sí mismo y la experiencia personal para la construcción y configuración de lo novedoso partiendo del intercambio de realidades. 
Añadido a lo anterior, los procesos autorreferenciales permiten asumir desde una postura reflexiva, la construcción narrativa de nuevas experiencias que posibiliten el cambio, y de esta manera posicionar al investigador/interventor y al contexto escolar desde una cibernética de segundo orden.

\section{Recursividad y construcción compleja de narrativas.}

La recursividad permite al investigador/interventor comprender el contexto interventivo desde distintos dominios de información que le permitan, realizar lecturas ecosistémicas complejas del fenómeno estudiado, facilitando tal como lo menciona Estupiñán, González y Serna (2006) bucles de poli-auto-eco-organización.

Lo anterior permite establecer una lectura contextual y ecológica del fenómeno, donde los procesos de reflexividad y autorreferencia posibilitan conexiones entrelazadas de los relatos y a su vez, la construcción conjunta con el otro.

\section{Procesos conversacionales.}

Los procesos conversacionales permiten al investigador/interventor comprender los relatos que le dan sentido a la experiencia e historia narrada, y de esta manera, dar apertura o no de la construcción narrativa. Es en los procesos conversacionales, donde es posible la deconstrucción, construcción y resignificación de lo narrado con el fin de ampliar la visión de los actores participantes, posibilitando una nueva gama de historias, experiencias, acontecimientos, recursos, relatos y formas de relacionarse.

Teniendo en cuenta lo anterior, a partir de los procesos conversacionales se realiza un intercambio de narrativas desde los procesos semánticos, lingüísticos y emocionales, donde desde los relatos dominantes emergen relatos alternos que validan experiencias y saberes del 
otro. Es así, como la investigación/intervención proporciona un espacio conversacional entre los autores y los actores sociales que posibilita la construcción narrativa y la emergencia de nuevos sentidos y acciones para la experiencia narrada.

\section{Conceptos metodológicos de la línea de investigación}

Partiendo de principios orientadores del macroproyecto de narrativas expuestos por Estupiñán, González y Serna (2006) en el proyecto institucional de investigación, se hace referencia a continuación a los constructos asociados a los objetivos de la presente investigación/intervención y que fortalecen el conocimiento, la creación y el modo de operar de los escenarios desarrollados en el contexto social, familiar e institucional:

\section{Experiencia.}

La experiencia se relacionan con las interacciones construidas en la escuela que dan sentido a las vivencias y el diario vivir del estudiante, que emerge en el contexto y en el modo de visibilizar su self y de relatar su historia, que nutren los saberes en común y que dan pauta al surgimiento o no de la violencia.

\section{Acontecimiento.}

En este sentido se entiende la cultura y la historia vivida en el Municipio, en las familias y en la escuela como referentes para una población en común que teje significados alrededor de sus procesos vivenciales y la forma en como estos son aprehendidos en el trascurso de la historia. Es así que el acontecimiento se convierte en una multiplicación de saberes.

\section{Historias.}

La historia es entendida como el entramado de la experiencia vivida y el acontecimiento en el cual emergen narrativas y versiones dominantes de los significados construidos, a través de las 
vivencias y que se convierten en pautas comunes que le dan sentido a la realidad humana de los habitantes del Municipio.

\section{Memorias.}

Se comprende como aquellos relatos o versiones que son traídos al presente como parte de una historia, sin alterar el continuo vivir y que nutren los saberes propios y de una comunidad.

\section{Relatos Alternos.}

Los relatos alternos se comprenden como aquellos que permiten la emergencia de nuevas realidades en la construcción conjunta de mundos posibles; como resultado de la resignificación semántica de las historias dominantes en el contexto relacional de las personas.

\section{Conceptos metodológicos de la investigación/intervención}

Para realizar esta conceptualización se da cuenta de lo que emergió durante el proceso de investigación/intervención y de lo que sería importante para los actores participantes, la evolución de la investigación y los procesos narrativos que emergen por parte de los estudiantes, familias, cuerpo docente y directivos que forman parte de este procesos de investigación/intervención.

Este proceso requirió el compromiso por parte de las investigadoras/ interventoras en la construcción de espacios dialógicos y conversacionales, con el fin de establecer los principios orientadores del cual partiría esta investigación/intervención.

Cómo se ha mencionado este proyecto de investigación/ intervención se orienta bajo una perspectiva sistémica construccionista - constructivista, donde se hacen explícitos los procesos de observación y metaobservación para llegar a la comprensión del fenómeno de estudio, donde los actores sociales se involucran en el proceso de investigación/intervención, a través de los diferentes momentos del desarrollo de la misma. 
Desde esta perspectiva las investigadoras / interventoras parten de la curiosidad, la creatividad y la imaginación por descubrir cómo este fenómeno de investigación puede emerger de manera constructiva, la forma de interrelacionarse los niños, niñas, y jóvenes, observando las diferentes formas de actuar con sus padres, familiares, docentes y entes encargados del cuidado de la integridad de cada uno de estos niños, niñas y jóvenes.

Para el estudio de la investigación /intervención se toman los conceptos que hacen referencia a la línea de investigación que se han vinculado al fenómeno de estudio, donde se parte de la comprensión del supuesto metodológico y cómo éste se ha transformado a partir del relato en los procesos narrativo conversacionales:

\section{Violencia escolar como una construcción social}

Para esta investigación/intervención la violencia escolar es entendida como una forma de comunicación que ha emergido entre los niños, niñas y jóvenes, comprendiendo la violencia escolar cómo una construcción social aprehensiva, y una manera de defensa de situaciones perturbadoras que estos pueden estar vivenciando a diario en su entorno escolar en particulares pautas de interacción. Aquí la violencia se vuelve el foco desencadenante de eventos fortuitos y mal interpretados a partir de semánticas y acciones violentas o agresivas, acompañadas de eventos dolorosos, intimidantes y humillantes entre otros conceptos que los mismos niños, niñas y jóvenes experimentan con angustia y confusión.

Por otro lado, cabe destacar que esta construcción social no solamente involucra a los niños, niñas y jóvenes; si no que igualmente, parte de la experiencia y los acontecimientos vividos en un entorno social del cual hacen parte la familia y los demás entes sociales e institucionales. Así, los adultos también hacen parte de la construcción de la violencia escolar, ya sea por su intervención directa como padres de familia o por su desconocimiento del tema. 


\section{Ecología de las interacciones desde la construcción de mundos posibles y la co-evolución}

En el sentido más amplio de esta investigación/intervención se facilitan procesos de interacción y la forma en cómo se construyen en el contexto donde emerge el fenómeno de estudio a partir de las narrativas evocadas por los actores participantes, construidas a partir de sus experiencias creadas; asumiendo la violencia escolar como una construcción social que ha emergido desde los sistemas amplios en cuanto a la conformación de sus interrelaciones en los diferentes contextos de vida cotidiana como son la escuela, la familia, los amigos, el barrio, el municipio, la cultura propia de pueblo y otros ámbitos de relación fundamentales en la vida de los niños, niñas y jóvenes.

Teniendo en cuenta lo anterior, comprender a los sistemas que hacen parte del entorno de los niños, niñas y jóvenes en sus interrelaciones para la construcción de experiencias novedosas, impredecibles de vida en común, donde la violencia escolar no sea lo que defina formas de vida cotidiana, se convierte en un referente de las situaciones que emergen en los medios de comunicación, redes sociales, programas de televisión y la historia vivida y por vivir del municipio frente a hechos de violencia durante el recorrido histórico perteneciente a la impronta del municipio.

Lo anterior invita a observar la violencia escolar de una manera amplia, en donde no solo se involucren a los estudiantes en la relación lineal víctima- agresor, sino donde los demás entes sociales puedan trasmitir mensajes como parte de la comunidad educativa y familiar para que los niños, niñas y jóvenes no participen de estos actos de acoso escolar y tengan unas motivaciones que los incorpore a nuevos escenarios. 


\section{Emergencia del sujeto autónomo desde la multitemporalidad}

A partir del fenómeno de estudio esta investigación/intervención pretende que las personas involucradas en el proyecto cómo son los niños, niñas y jóvenes, protagonistas de este trabajo, para que en la relación con sus padres y demás familiares; todas las personas del sistema educativo y diferentes miembros de la comunidad reconozcan sus potencialidades y los recursos con los que cuentan para darle una mirada diferente a la situación conflictiva que han mantenido durante bastante tiempo, dando curso así a sus procesos de autonomía y co - evolución; entiéndase la emergencia del fenómeno de estudio como una herramienta que le permite fortalecer su autonomía en medio de las interacciones que construye en su medio educativo, visto desde una mirada que lo lleva a potenciar sus habilidades para organizar sus propios comportamientos frente a su grupo de pares donde está intercambiando un flujo de información donde se puede convertir en una paradoja de cómo se narra el individuo “ yo me hago más fuerte por mi grupo de relaciones", a partir de experiencias subjetivas e intersubjetivas donde se involucran sentimientos, idiosincrasia, experiencias y aprendizajes, no solo del contexto educativo sino también de casa, amigos, vecinos, instituciones y el entramado eco-etoantropológico del que hace parte.

La multitemporalidad es entendida para la presente investigación/intervención a partir de cómo es vivida la violencia en los diferentes contextos, situaciones y etapas de las actores participantes; en este sentido el sujeto y la misma violencia emergen en los tiempos de la experiencia personal, familiar, social y cultural de cada uno de los actores involucrados.

Las concepciones del tiempo son diferentes para cada persona, cada quien toma el tiempo que le corresponde y cree necesario para llevar a cabo sus procesos de vida cotidiana, es así como los acontecimientos ocurren en un tiempo determinado guiado por unas intenciones, a la vez que se 
debe respetar el tiempo que cada uno tome en realizar sus actividades, cambios o circunstancias a las que este expuesto, lo cual invita a tener puntos de vista amplios y que son todos diferentes.

\section{Contexto y actores de investigación}

Los escenarios de investigación/ intervención se proponen dentro del marco institucional y Municipal de la Institución Educativa Técnica Industrial de Turmequé y sus sistemas amplios. La investigación/intervención contó con la participación de 16 niños, niñas y jóvenes con sus respectivas familias, como representantes de cada grado escolar pertenecientes a todos los ciclos académicos (desde primero a once), de igual manera se contó con la participación de los entes territoriales (dos funcionarios de comisaria de familia y un funcionario de la alcaldía) y la participación de la institución educativa (rectora, psicopedagoga, profesor, y coordinador).

La Institución Educativa Técnica Industrial de Turmequé, se encuentran ubicada en el Municipio de Turmequé Boyacá, en el área del centro del Municipio, que alberga aproximadamente a 200 estudiantes de la cabecera Municipal y de las veredas aledañas. De la misma manera el Municipio de Turmequé cuenta con una extensión de 106 Km2 Km2, con un total de habitantes de 7777, 2261 habitantes de la cabecera Municipal y 5516 habitantes de la zona rural. Teniendo en cuenta lo anterior, los escenarios se plantean con el fin de incluir a todo el sistema ecológico del Municipio, desde la Institución Educativa, los padres de familia y los sistemas amplios. Los actores se eligen dado a la necesidad que se percibe por las investigadoras/interventoras, en la institución educativa Técnica Industrial de Turmequé, manifestada por el cuerpo docente y directivos, respecto a las formas en como esta Institución observa la relación de los estudiantes y sus interacciones alrededor del fenómeno de la violencia escolar, donde se refiere un grupo de estudiantes que desde el mismo colegio se considera 
necesario para hacer parte del proceso de investigación/intervención. Posteriormente, partiendo del estado del arte testimonial, se hacen partícipes a los sistemas amplios.

A continuación se presenta el cuadro de participantes en la investigación - intervención:

Tabla 6. Voces, actores y participantes de la investigación/intervención

\begin{tabular}{lll}
\hline Voces & Actores & Participantes \\
\hline Voz Organizacional & Equipo Directivo & Rectora (1) \\
& & Coordinador (1) \\
& & Psicopedagoga (1) \\
\cline { 2 - 3 } jóvenes & Equipo pedagógico & Docentes (2) \\
\hline Voz de las familias & Equipo de padres de familia & Un padre representante por \\
& & representantes por curso: 1 \\
& & cada uno de los grupos de \\
& & estudiantes. \\
\hline Voz Municipal & Entes Municipales del & Alcalde Municipal \\
& equipo de primera infancia & Comisaria de familia (2 \\
& y adolescencia & participantes) \\
& & 1 Representante de la \\
& & alcaldía Municipal. \\
& &
\end{tabular}




\section{Diseño de escenarios de Investigación/intervención}

Para llevar a cabo el desarrollo de los escenarios las investigadoras/interventoras partieron de la comprensión de la emergencia, en la construcción social de la violencia escolar a partir de las diferentes interacciones construidas por los participantes de la investigación, los estudiantes, de la institución educativa técnica industrial de Turmequé.

Los escenarios se diseñaron a partir de estrategias que posibilitaran la comprensión de la violencia en los diferentes contextos relacionales de los participantes, y cómo esta pauta se conecta con su contexto escolar.

Para los escenarios de intervención surgieron 4 diseños y 2 neodiseños, para un total de 6 escenarios. Los escenarios se organizaron teniendo en cuenta los objetivos de la investigación/intervención por un lado respondiendo a comprender la configuración de la violencia escolar y por otro lado apuntando a reconfigurar narrativamente la violencia escolar.

Los escenarios responden a unos nodos de intervención desde la conexión ecológica y la activación de red, en los cuales a medida que se iba aplicando cada uno de los escenarios se ampliaban los nodos de conexión. Estos nodos tenían como objetivo principal por un lado respondiendo a la configuración de la violencia escolar: comprender las pautas interacciónales que configuran la violencia y la significación de la violencia escolar en el contexto. Por otro lado respondiendo a la reconfiguración narrativa de la violencia escolar, se proponen como objetivos: potencializar los recursos, deconstruir miradas deficitarias, potencializar redes de apoyo y los procesos vinculares que posibilitan la autonomía, fortalecer los procesos de autonomía, co construir co - evolutivamente nuevas realidades y posibilidades de movimiento y empoderar a los niños, niñas y jovenes como gestores de paz. 


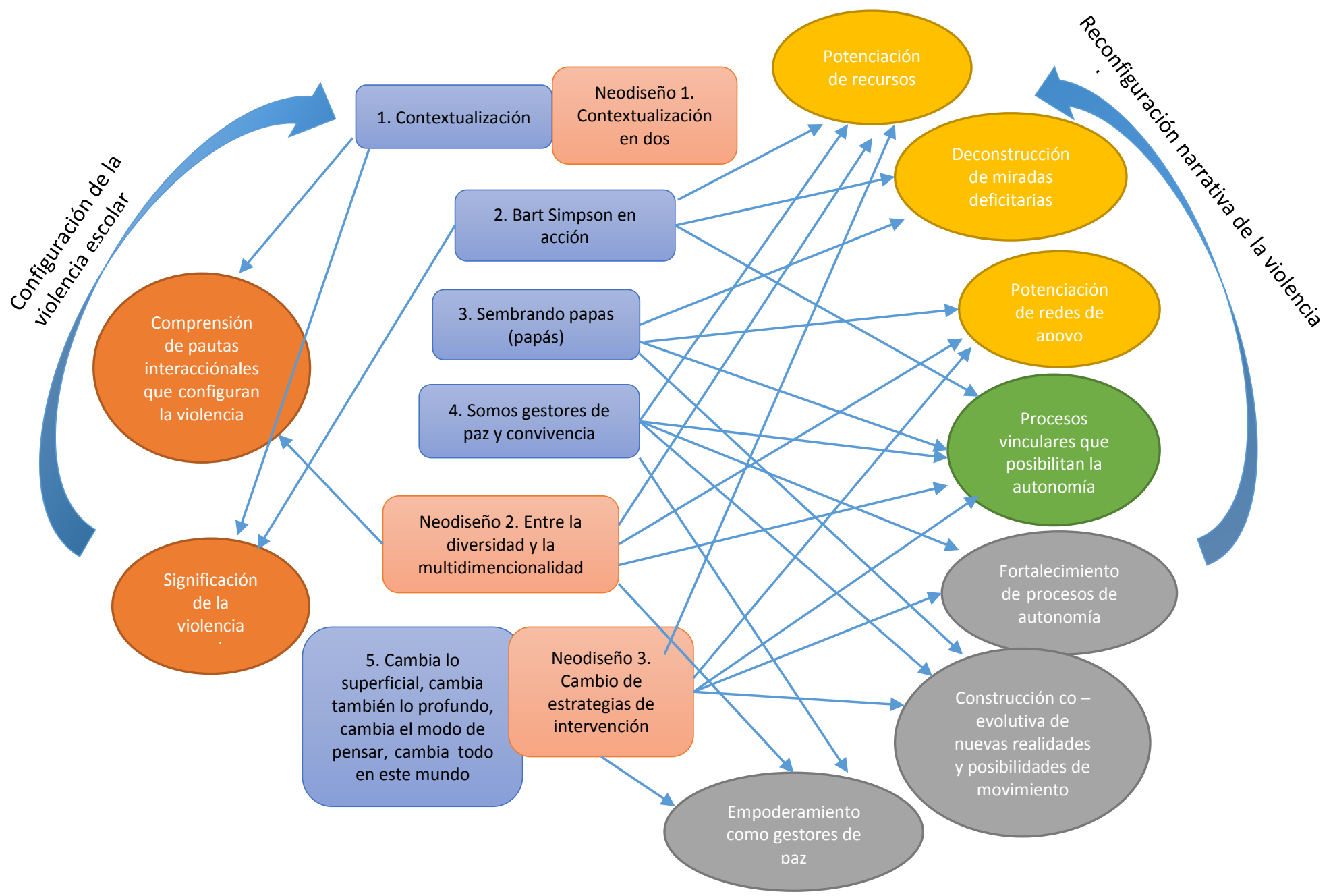

Figura 4: Nodos de conexión ecológica para el desarrollo de la intervención

Teniendo en cuenta lo anterior, los escenarios se organizaron de la siguiente manera.

1. Contextualización; del cual se deriva un Neodiseño dado que el escenario se dividió en dos momentos. En este escenario se llevó a cabo con el objetivo de socializar con la institución educativa, al igual que comunicar a la alcaldía y la comisaria en este mismo espacio, sin embargo surge aquí la creación del primer neo diseño, donde se hizo necesario que esta contextualización se llevara en momentos diferentes, ya que los representantes del colegio, no 
gozan de una buena imagen de la comisaría y la alcaldía y por tanto las interrelaciones estaban organizadas bajo un disgusto.

2. Bart Simpson en acción: El segundo escenario se realizó con estudiantes y docentes con el fin de comprender cómo eran las dinámicas relacionales entre docente y estudiante, que pensamientos existía frente a la violencia escolar, y cómo la violencia influía en el comportamiento de los estudiantes participes de la investigación/intervención, se utilizó como estrategia el equipo reflexivo.

3. Sembrando papas (papás): Un tercer escenario se realizó con los padres para comprender cómo son las dinámicas vinculares al interior del hogar, cómo se ha percibido la violencia en el municipio y de qué manera esta puede influir en las conductas de sus hijos, se utilizó como dispositivo el dibujo de un árbol a través de la metáfora "Sembrando papas": con los respectivos cuidados que debe tener una planta para que dé frutos, allí continuaba la lectura sistémica compleja por parte de las investigadoras/interventoras en cuanto a la interpretación de la violencia escolar como una construcción social.

4. Somos gestores de paz y convivencia: Se continuó con el cuatro escenario que se llamó gestores de paz, en el cual participaron los niños, niñas y jóvenes, se crean estrategias como la construcción de un mensaje a través de un video que invitaba a todos los niños, niñas y jóvenes que atraviesan una situación de abuso, a levantar su voz como un gestor más de paz.

5. Neodiseño 2. Entre la diversidad y la multidimencionalidad: en el que se abrió un espacio para trabajar con la institución, en espacial con la psicopedagoga de la institución con el fin de resignificar la participación de la institución en el fenómeno de estudio, los resultados percibidos hasta el momento y la co - construcción con la institución de acciones interventivas para el 
último escenario que posibilitara la divulgación de la redefinición de la violencia escolar hacia los sistemas amplios, padres, madres, estudiantes, docentes y demás directivas del colegio.

6. "Cambia lo superficial, cambia también lo profundo, cambia el modo de pensar, cambia todo en este mundo": del cual se derivó el Neodiseño 3 por un cambio de estrategias de intervención que no se encontraban previstas en el diseño. El objetivo principal de este escenario se orientaba a co - construir con los gestores de paz estrategias que activaran ecológicamente la resignificación de la violencia escolar. Se utilizaron como dispositivos la construcción de una carta a la familia, creación de una ruta emocional y creación de una canción.

\section{Primer escenario: Contextualización.}

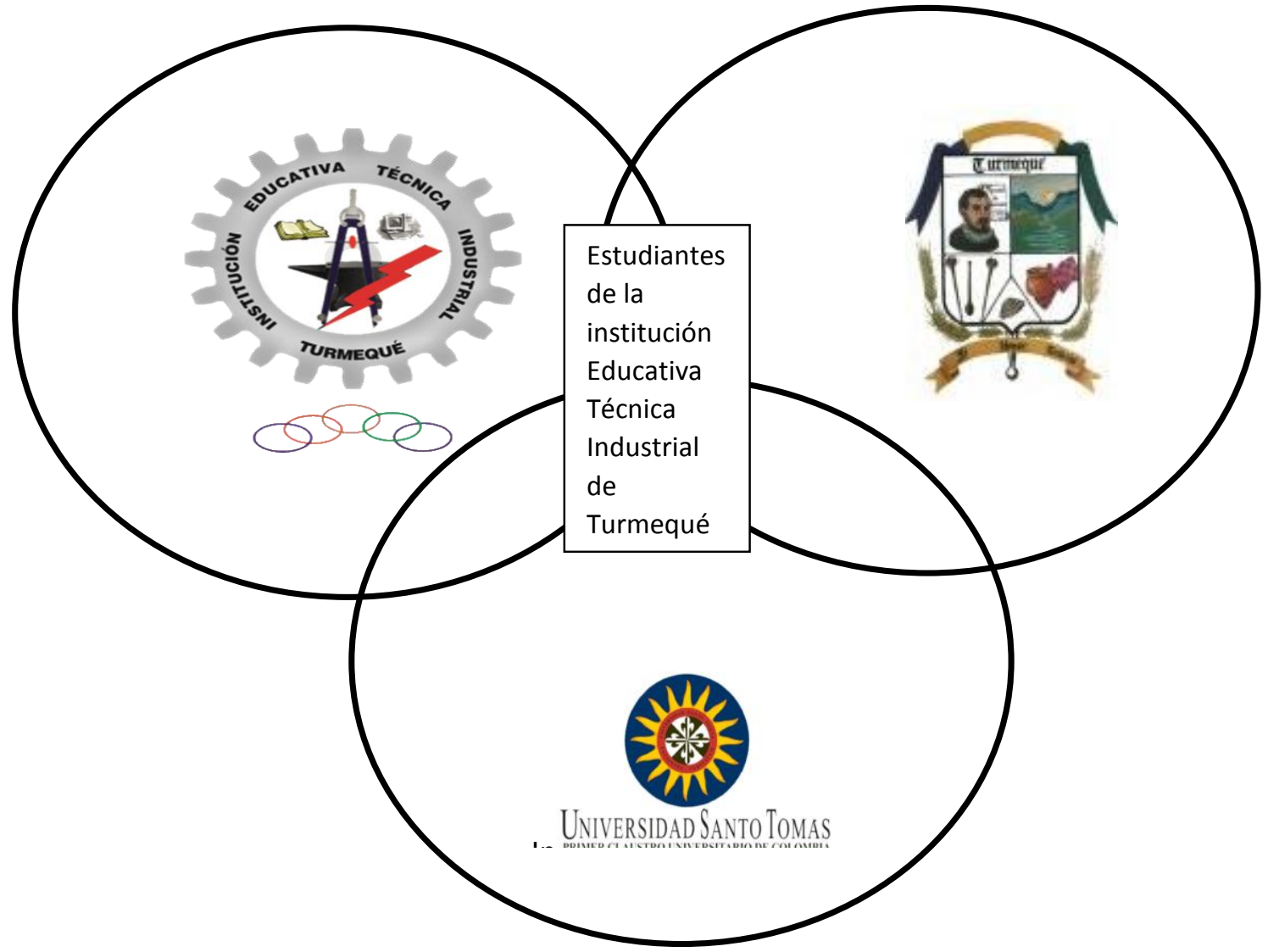

Figura 5. Diseño del escenario numero 1: Contextualización. Conexión de los diversos actores institucionales convocados. 
En este escenario, se conjugan en un mismo espacio los actores convocados: Directivos institucionales, Entes Municipales y las investigadoras - interventoras, lo que permite reconocer la red que los relaciona en la construcción narrativa - conversacional del fenómeno de la violencia escolar.

Tabla 7. Escenario 1: Contextualización.

\title{
Escenario conversacional 1: contextualización
}

\author{
Objetivo del Conocer e identificar los diferentes actores relevantes para el desarrollo de la \\ escenario investigación/intervención, su disponibilidad para participar en ella y las \\ propuestas que cómo entes Municipales e Institucionales pueden surgir \\ alrededor del fenómeno de estudio. \\ Así mismo, presentar la propuesta investigativa, contextualizando hacia el \\ objetivo de la investigación y la propuesta metodológica, donde se aliente el \\ trabajo en red y se establezcan acuerdos para el desarrollo de escenarios de \\ investigación/intervención.
}

Foco Reconocimiento de actores y sus dinámicas de vinculación entre los mismos. Presentación de la propuesta de investigación/intervención a los actores participantes, lo que facilita el trabajo en red, la comprensión del fenómeno de estudio y el conocimiento de las propuestas que surjan en el escenario. Comprensiones del fenómeno, violencia en el contexto educativo donde emergen las narrativas dominantes y se posibilitan la creación de relatos nuevos que visibilice a los estudiantes desde sus recursos y no desde el déficit. 
Sistemas de significados en relación a los procesos de autonomía y co evolución en el contexto educativo en relación con los sistemas amplios. Co - construcción de prácticas colaborativas que permitan el desarrollo de escenarios.

La metaobservación que permite a las investigadoras/interventoras posicionarse desde una cibernética de segundo orden, donde se posibiliten los procesos autorreferenciales tanto de las investigadoras/interventoras como de los actores participantes al escenario.

Hipótesis La disposición de los actores para contribuir como red favorece el desarrollo de los escenarios de investigación/intervención y las comprensiones que surjan alrededor del fenómeno de estudio.

Los relatos emergentes respecto al fenómeno de estudio por parte de los entes Municipales e Institucionales facilitarían la redefinición de la violencia escolar y la percepción deficitaria hacia los estudiantes.

La movilización de los procesos autorreferenciales de los participantes y de las investigadoras/interventoras favorece comprensiones reflexivas del fenómeno de estudio, y la emergencia de propuestas para el desarrollo de futuros escenarios.

Participantes/ Directivos institucionales (Rectora y coordinador académico), Entes actores Municipales (Alcalde Municipal, Gestora Social, Comisaria de familia, Policía de infancia y adolescencia e Inspección de policía), e investigadoras/interventoras.

Preguntas ¿Cómo la emergencia de relatos alternos posibilita novedades en la 
orientadoras construcción del sistema metodológico?

¿Qué espera la institución y qué surge a partir de la propuesta metodológica expuesta?

¿Cómo son las dinámicas que se dan en las interralaciones de los participantes que permiten visibilizar las formas de trabajo en red?

¿Por qué es importante el trabajo en red donde se incluyen los sistemas amplios?

¿Cómo co-evolucionan los procesos de autonomía en el contexto educativo?

Guion

\section{Escena 1: presentación actores}

Metodología:

Se dará la bienvenida a los participantes a este escenario.

Las investigadoras/interventoras se presentan al grupo de actores participantes

Se brinda para que los actores participantes se presenten, refiriendo el nombre y el cargo.

Instrumentos: protocolo en el cual se recogen las experiencias, diligenciado posterior al escenario con el fin de documentar los procesos autorreferenciales de las investigadoras/interventoras.

Estrategia a utilizar: Metaobservación: Lectura de su lenguaje no verbal.

Preguntas guía:

¿Cuáles son sus nombres y las funciones que desempeñan en sus cargos?

Escena 2: presentación propuesta investigación/intervención 
Introducir brevemente por qué las investigadoras/interventoras se encuentran participando en el espacio propuesto.

Se presenta una imagen de un niño siendo violentado, de esta manera se abre el espacio conversacional, donde se espera que de los actores emerja su narrativa respecto al fenómeno de la violencia escolar.

Posteriormente se realiza una breve socialización de la investigación/ intervención y los posibles caminos a seguir, según lo que propagan los actores participantes.

Estrategia a utilizar: protocolo, metaobservación

Preguntas guía:

¿De acuerdo a su experiencia, como comprenden ustedes la violencia que se presenta en el Municipio?

¿Cómo perciben ustedes la violencia escolar que se presenta en la Institución Educativa del Municipio?

¿Ustedes en algún momento se han sentido víctimas de la violencia escolar? Si es así, ¿Cómo han superado esta adversidad? ¿Cuáles son los principales casos que ustedes como entes Municipales conocen relacionados con la violencia de los habitantes de Turmequé?

¿Cómo Municipio que acciones se ha llevado a cabo para prevenir la violencia escolar, y cómo esto favorece al bienestar familiar y Municipal? ¿De qué manera se organiza el municipio y la escuela para atender las situaciones de violencia que se presenta en los niños?

Escena 3: Acuerdos y compromisos 


\section{Metodología:}

Se realiza un equipo reflexivo entre las investigadoras/interventoras donde se manifiesta las impresiones observadas en las escenas anteriores.

Se pregunta a los actores la sensación percibida luego del equipo reflexivo y se invita a generar acuerdos y compromisos para el desarrollo de los siguientes escenarios.

Estrategia: protocolo y Equipo Reflexivo.

Pregunta Orientadora: ¿Qué sensación les deja a ustedes esta conversación que acabamos de tener las investigadoras/interventoras?

¿A qué acuerdos podemos llegar para el desarrollo de la investigación/intervención?

\section{Escenario 2. Bart Simpson en acción}




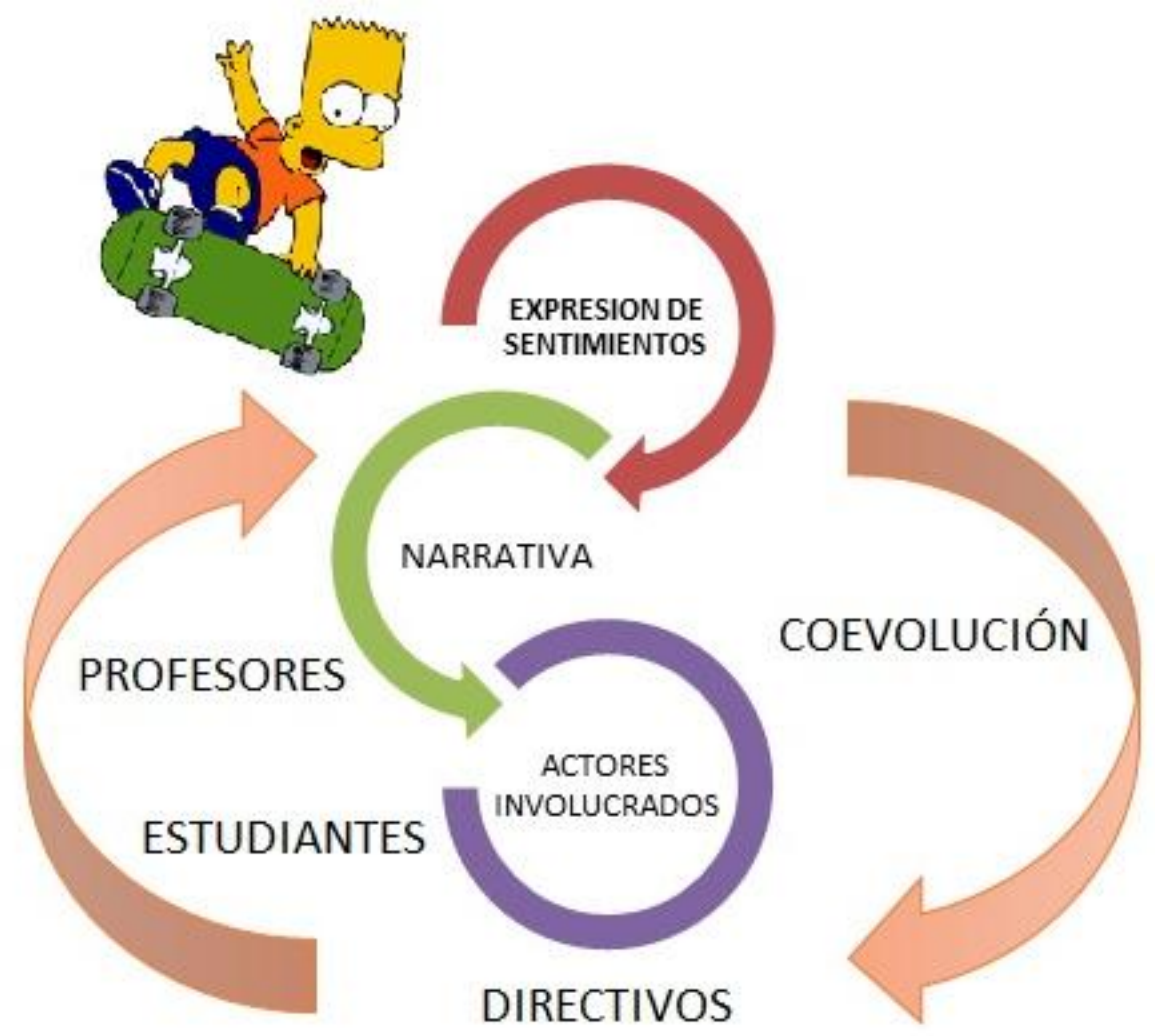

Figura 6. Escenario 2. Bart Simpson en acción

Tabla 8. Diseño de escenario 2. Bart Simpson en acción

\section{Escenario conversacional: Bart Simpson en acción}

Objetivo del Facilitar un encuentro que genere la co - construcción de las interacciones por escenario parte del sistema educativo, que promueva los procesos de autonomía: docentes, niños, niñas y jóvenes que participan en la investigación.

Conocer e identificar los diferentes actores relevantes para el desarrollo de la investigación/intervención, su disponibilidad para participar en ella y las propuestas. 
Las versiones dominantes y novedosas sobre la significación de la violencia escolar en el entorno educativo.

La construcción de relatos emergentes en torno a la potencialización de los recursos de los jóvenes y la deconstrucción de la mirada hacia el joven desde el déficit.

Comprensiones de la construcción coevolutiva en el espacio relacional de los estudiantes en el entorno académico con sus pares y sus entes de autoridad dentro de la institución educativa.

Comprensiones del fenómeno de la violencia en el contexto educativo donde emergen las narrativas dominantes y se posibilita la creación de relatos nuevos que visibilice a los estudiantes desde sus recurso no desde el déficit. Sistemas de significados en relación a los procesos de autonomía y co - evolución en el contexto educativo y que se relacionan con los sistemas amplios.

Co-construcción de prácticas colaborativas que permitan la fluidez en el desarrollo de escenarios.

La metaobservacion que permite a las investigadoras/interventoras posicionarse desde una cibernética de segundo orden, donde se posibilite los procesos autorreferenciales tanto de las investigadoras/interventoras como de los actores participantes en el escenario.

\section{Hipótesis La participación al ejercicio de investigación/intervención posibilita en los} niños, niñas y jóvenes el reconocimiento de su sentir y actuar frente al fenómeno de la violencia escolar, lo que facilita el empoderamiento de sus procesos identitarios y la participación como co-gestores de una convivencia 
armónica.

Los profesores al observar el punto de vista de los niños, niñas y jovenes, permitirían tener una visión más amplia de lo que implica el fenómeno, reconociendo de manera generativa a los niños y re significando la violencia escolar desde el déficit.

\section{Participantes/ Estudiantes representantes de cada grado, docentes y un directivo de la actores Institución educativa. Investigadoras/interventoras.}
Preguntas ¿Cómo el docente juega un papel importante en la construcción y
orientadoras deconstrucción de la pauta de violencia escolar?
¿Cómo se puede posibilitar la resignificación de la violencia escolar a partir de la activación de recursos de los niños, niñas y jóvenes?
¿Cómo se lleva a cabo los procesos co-evolutivos a partir de las experiencias narradas de los niños, niñas y jóvenes?

\section{Guion Escena 1.}

Metodología

Presentación de las investigadoras - interventoras a los estudiantes representantes de grado por medio de una actividad rompe hielo "nombre, animal y fruta", donde se incluya la presencia de los docentes y los entes directivos de la institución

Instrumentos

Protocolo

Estrategias a utilizar

Metaobservación: Lectura de su lenguaje no verbal. 


\section{Preguntas Guía}

¿Cuáles son sus nombres y porque creen que están aquí?

\section{Escena 2.}

\section{Metodología}

Se escenifica el salón de clases en el que estudia "Bart Simpson", introduciendo por medio de un cuento, que será construido por todos los participantes, iniciando por las investigadoras/interventoras donde se orienta hacia la historia de "Bart" todos los días en su escuela e invitando posteriormente a los niños, niñas y jóvenes a nutrir el contexto del cuento. Instrumentos:

Protocolo

Estrategias a utilizar:

Metaobservación: Lectura de su lenguaje no verbal.

Preguntas Guía

La historia permitirá el surgimiento de una serie de preguntas como: ¿Qué caracteriza a un estudiante como Bart? ¿Cómo ven los profesores y los compañeritos de clase a un estudiante como "Bart”? ¿Cómo se siente el personaje al saber que es el chico malo del colegio? ¿Cuáles son las habilidades que tiene "Bart” para ser un chico listo? ¿Cómo "Bart” puede convertir esas habilidades en una forma de liderar con sus compañeros dentro del salón de clases?; preguntas que irán tejiendo con las intervención de los participantes.

\section{Escena 3.}




\section{Metodología}

Al finalizar la historia los actores convocados construirán en la pizarra del salón de clases de Bart, como ayudarían a este niño a convertirse en un líder dentro de su salón de clases donde promueva la sana convivencia y la deconstrucción de la violencia.

Instrumentos

Protocolo

Estrategias a utilizar:

Metaobservación: Lectura de su lenguaje no verbal.

Preguntas Guía

Después de la culminación de la historia se preguntara a los actores participantes: ¿Qué se lleva cada uno del encuentro para sus relaciones en el salón de clases?

\section{Escena 4.}

Metodología:

Conclusiones de lo conversado. Se invita al escenario a los Profesores y directivos presentes, con quienes se conversara sobre lo observado en el encuentro realizando niveles de metaobservación por medio de un equipo reflexivo.

Se propone al grupo (niños representantes y profesores) construir en conjunto con cada uno de sus salones de clase una pizarra con materiales de su propia inventiva que dé cuenta del proceso de redefinición de la significación de la violencia. 
Instrumentos:

Protocolo

Estrategias a utilizar:

Metaobservación: Lectura de su lenguaje no verbal. Equipo reflexivo

Preguntas Guía:

¿Qué fue lo que más los impactó de lo realizado este ejercicio?

¿Qué les gustaría aportar a los niños, niñas y jovenes ahora que tienen esta nueva visión?

¿Qué cambios cree que usted puede dar a partir de esta experiencia?

\section{Escenario 3. Sembrando papas}

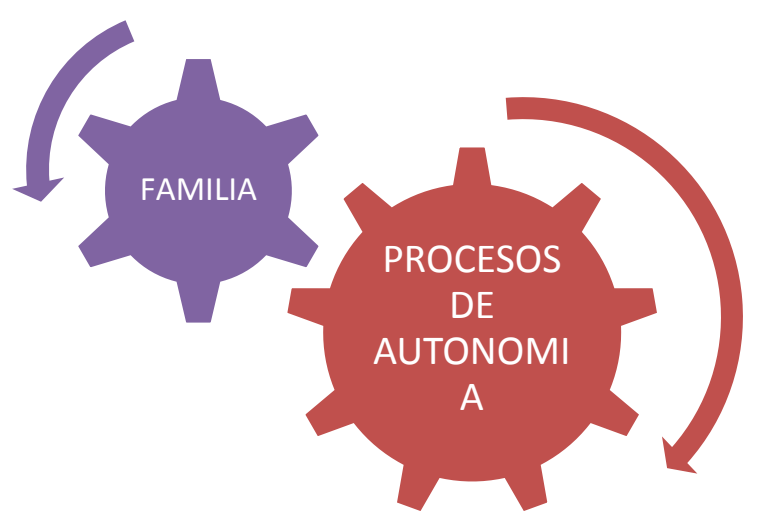

Figura 7. Escenario 3. Sembrando papas

Tabla 9. Escenario 3. Sembrando papas

Actores convocados Estudiantes representantes de cada grado y padres de familia

Objetivo del Posibilitar la emergencia de nuevas narrativas que resignifiquen 


\begin{tabular}{ll}
\hline escenario & a partir el papel de la familia como coautor en los procesos de \\
& autonomía y en la desconstrucción del fenómeno de la violencia \\
& escolar. \\
\hline Focos de & La potencialización de las redes de apoyo familiares para el \\
intervención & fortalecimiento de las habilidades de los niños, niñas y jóvenes \\
& desde el reconcomiendo del sí mismo relacional. \\
& Procesos de autonomía que se exponen al empoderar a los \\
& estudiantes desde el recurso y no desde el déficit. \\
\hline Preguntas & ¿Cómo los padres posibilitan o no la emergencia del cambio \\
orientadoras & frente a la pauta de violencia escolar? \\
& ¿Cómo los vínculos familiares favorecen los procesos de \\
& autonomía de los niños, niñas y jóvenes? \\
& ¿Cómo la participación conjunta entre padres e hijos permite \\
& reconfigurar las pautas interacciónales en los entornos \\
& educativos?
\end{tabular}

\section{Guion}

\section{Conversacional}

\section{Escena 1.}

Metodología:

Se realiza un proceso con varios niveles de observación, donde en un primer momento los padres se reconocen como los observadores y los estudiantes como los gestores del proceso conversacional, posteriormente los estudiantes pasan a ser observadores y los padres refieren sus impresiones de lo escuchado; finalmente se propone un espacio de conversación 
conjunta y al término del escenario se propone un nuevo nivel de observación donde las investigadoras interventoras realizan un proceso reflexivo.

El desarrollo de la primera escena se llevaría a cabo de la siguiente manera:

Los estudiantes ingresan al espacio conversacional donde se orientan preguntas hacia la potencialización del papel de los padres en los procesos académicos de los estudiantes y el rol activo en el fortalecimiento y reconocimiento de los recursos de los estudiantes.

Instrumentos:

Diario de campo

Estrategias a utilizar:

Metaobservación

Preguntas Guía:

¿Niños, niñas y jóvenes que piensan ustedes acerca de la violencia escolar?

¿Cuándo fue la primera vez que usted escucho hablar de violencia escolar?

¿Usted cómo ha visto que se vive la violencia escolar aquí dentro de la institución?

¿Por qué cree que un niño sufre tanto cuando ha sido violentado? 
¿Usted qué cree que es importante, en cuanto a que otra persona lo apoye, lo escuche, lo oriente a esta persona que ha sido o está siendo matoneada y por qué?

¿Niños, niñas y jóvenes ustedes creen que en casa se vive la violencia escolar?

¿Qué hacer para que se acabe la violencia escolar?

\section{Escena 2.}

Se permite la entrada al proceso conversacional a los padres, donde en un primer momento se pregunta sobre las impresiones de lo observado en la primera escena; donde poco a poco se van tejiendo los significados del rol de los padres en la potencialización de los recursos de los hijos. Posteriormente se propone un espacio de creación donde los padres con materiales dispuestos para la siembra, recién una matera y un pequeño arbusto donde se orientan con las preguntas guía.

Instrumentos:

Diario de campo

Estrategias a utilizar

Metaobservación, preguntas reflexivas

Preguntas Guía:

¿Qué creen que han sembrado en sus hijos que los hace las personas que son en este momento? ¿Cómo pueden seguir fomentando semillas de aprendizaje en sus hijos? 


\section{Escena 3.}

Se permite la entrada nuevamente de los estudiantes donde en conjunto con los padres culminaran la actividad de "sembrando papas" donde desde lo escuchado se construya los recursos que desde su autonomía le añadirían al cultivo de su arbusto.

Se concluye con una reflexión de lo generado en el escenario y se realiza un equipo reflexivo entre las investigadoras interventoras de las comprensiones realizadas del escenario. Instrumentos:

Diario de campo

Estrategias a utilizar:

Metaobservación

Preguntas Guía:

¿Qué fue lo que más les impactó de lo dicho por sus hijos?

¿Cómo creen que se podrían anudar fuerzas con la institución educativa para darse otro sentido a la violencia escolar?

\section{Escenario 4: Somos gestores de convivencia y paz}




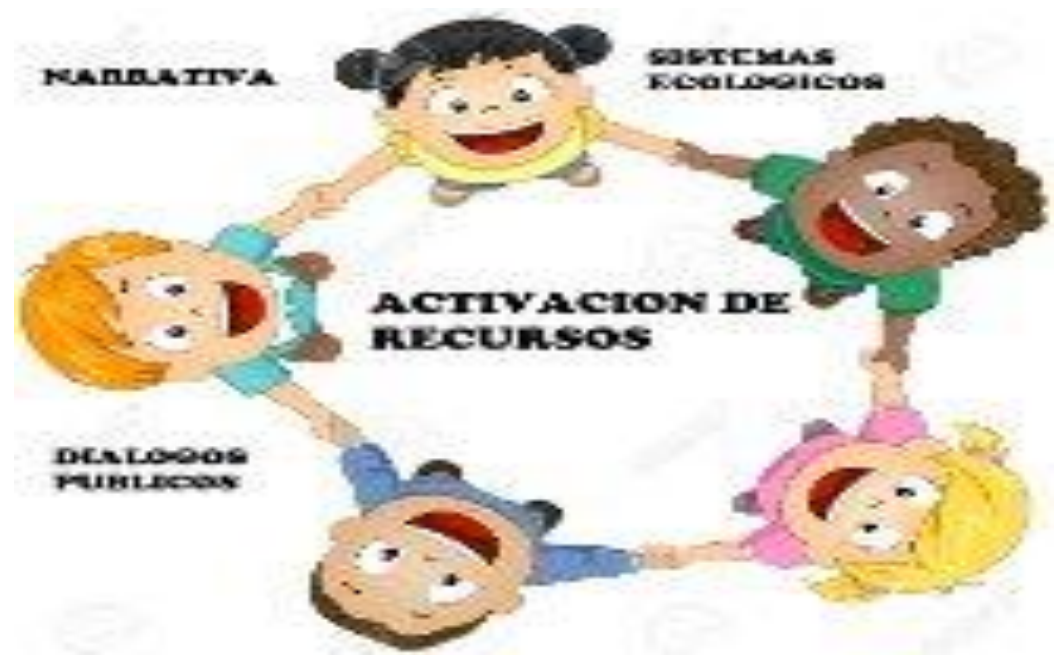

Figura 8. Escenario 4. Somos gestores de convivencia y paz

Tabla 10. Escenario 4. Somos gestores de convivencia y paz

Escenario 4. Somos gestores de convivencia y paz

Objetivo del Potencializar los recursos de los niños, niñas y jóvenes como gestores de la escenario institución y de sus diferentes entornos en la deconstrucción de la violencia escolar.

Foco Construcción de un diálogo generativo que permita la creación de herramientas que faciliten extender lo creado durante el proceso a los sistemas amplios del Municipio.

La potencialización y empoderamiento del sistema escolar como co - gestores de convivencia posibles como relatos alternos

Hipótesis El empoderamiento de los estudiantes respecto al accionar alrededor de la violencia escolar facilita la potencialización de sus recursos y la necesidad de iniciar un cambio desde sus propias propuestas como gestores de convivencia. La creación de dispositivos por parte de los estudiantes favorece nuevas 
comprensiones del fenómeno del violencia escolar y la participación en la prevención de los sistemas amplios.

\section{Participantes/ Estudiantes representantes de cada grado y profesores}

actores

Preguntas ¿Cómo los estudiantes desde el papel de gestores de convivencia proponen

orientadoras dispositivos que propicien la re significación de la pauta de la violencia escolar y su resonancia a los sistemas amplios?

¿Cómo a partir de los recursos de los estudiantes se puede emerger nuevas formas de gestión de la convivencia y de hacer partícipes a distintos sistemas amplios?

\section{Guion Escena 1.}

Metodología:

Se reúnen a los estudiantes representantes de cada grado, donde por medio de preguntas orientadoras se visualiza la posibilidad de ampliar los saberes construidos a los sistemas amplios por medio de un dispositivo que los mismos estudiantes propongan para tal fin.

Instrumentos:

Diario de campo

Estrategias a utilizar:

Proceso conversacional entre los niños y jóvenes participantes y las investigadoras/interventoras, preguntas circulares

Preguntas Guía:

¿Cuál fue el impacto que tuvieron sus compañeros de clase al recibir la 
información acerca de la transformación de la violencia escolar?

¿Qué cosas nuevas surgieron al conversar con sus compañeros de clase?

¿Partiendo del ejercicio de la reunión anterior ustedes que harían por su los

todos los niños y jóvenes que se encuentran viviendo violencia escolar?

\section{Escena 2.}

Metodología

Se propone a los actores participantes la elaboración de un video que exprese un mensaje que como cogestores quisieran llevar a los entes Municipales, a estudiantes como ellos y al departamento. De igual manera se hace un llamado a la movilización por medio de una comparsa construida con todos los dispositivos creados en los escenarios anteriores y con la participación de la totalidad de la institución educativa en un próximo escenario.

Se propone a los docentes salir del círculo conversacional donde cumplan el papel de metaobservadores, percibiendo las propuestas de los niños, niñas y jóvenes; donde se les indica que a partir de esto deben pensar en un mensaje construido como ente institucional que pueda tener trascendencia en el tiempo y en las demás personas.

Instrumentos:

Diario de campo, cámara de video, guion

Estrategias a utilizar:

Preguntas reflexivas, potencialización de recursos, hacer un llamado a las voces que cree relatos alternos, metaobservación

Preguntas Guía: 
¿Siendo líderes del municipio, cómo quisieran que se den a conocer las experiencias a favor de ser gestores de convivencia entre niños, niñas y adolescentes?

¿Qué creen que el municipio necesita saber de ustedes para aportar a la sana convivencia?

¿Si pudieran darle un mensaje a los adultos del municipio qué les dirían? ¿Cuál es el impacto que quisieran generar en el municipio?

¿Qué impacto creen que tendría este mensaje en las demás personas?

¿Cómo quisieran que sus papás participaran, para pensarnos todos como gestores de convivencia que ayude a prevenir la violencia escolar?

¿Qué quiero que el otro sepa para que entienda y comprenda la violencia escolar desde la mirada de ustedes como estudiantes?

\section{Escena 3.}

Metodología:

Se realiza un equipo reflexivo con las investigadoras interventoras sobre las impresiones que surjan en este escenario.

Instrumentos:

Grabadora

Estrategias a utilizar:

Equipo reflexivo entre las investigadoras/interventoras Preguntas Guía:

¿Cuáles son los aportes de los niños... para comprender la violencia escolar? ¿De qué manera los estudiantes han ido tejido nuevos significados respecto al 
fenómeno de la violencia escolar?

¿Qué de lo que los niños, niñas y jóvenes dicen les parece novedoso a como comprendíamos la violencia escolar?

¿Qué emergencia surgió en los estudiantes para que pudiera darse esta re significación?

Escenario 5. "Cambia lo superficial, cambia también lo profundo, cambia el modo de pensar, cambia todo en este mundo" (Mercedes Sosa)

Del escenario que se presenta a continuación surgió un neo-diseño, que se retomará en el apartado siguiente, por lo tanto este diseño no se logró desarrollar tal como se encontraba 
previsto.

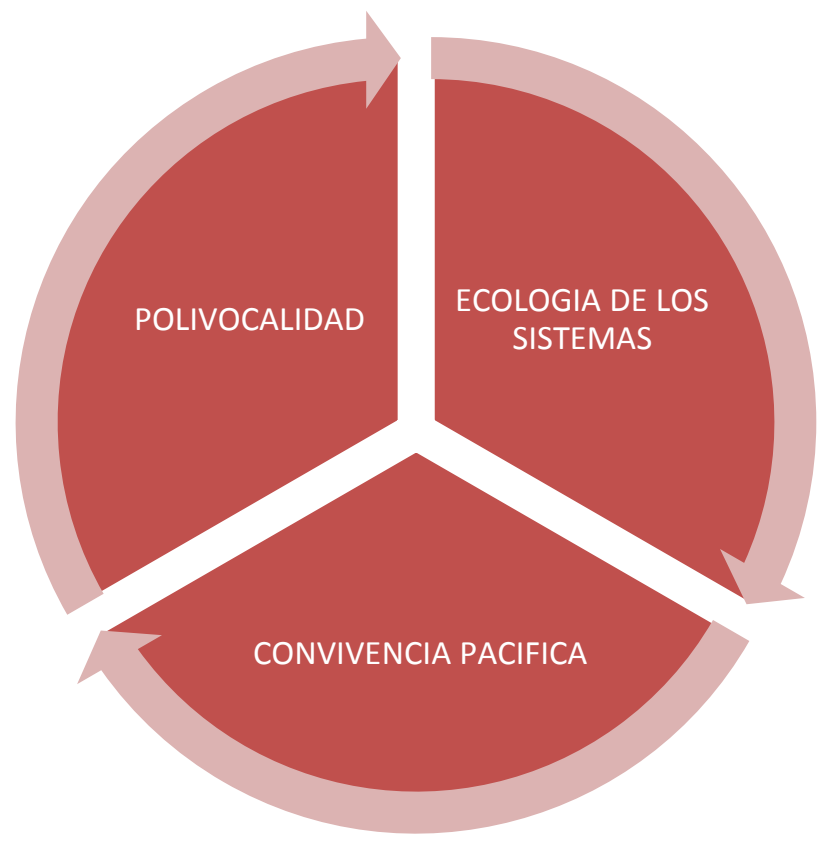

Figura 9. Escenario 5. Cambia lo superficial, cambia también lo profundo...

Tabla 11. Escenario 5. Cambia lo superficial, cambia también lo profundo...

\begin{tabular}{ll}
\hline Actores convocados & Entes Municipales \\
\hline Objetivo del & Movilizar la emergencia de los sujetos en la construcción de una \\
escenario & convivencia pacífica desde toda la ecología de los sistemas. \\
\hline Focos de & Emergencia del sujeto desde la ecología y su compresión desde \\
intervención & la activación de redes en los sistemas amplios. \\
& Niveles de metaobservación con sistemas amplios, que \\
& propicien espacios de conversacional, un llamado hacia la \\
& polivocalidad y un intercambio de saberes. \\
\hline Preguntas & ¿Cómo la polivocalidad permite la emergencia de nuevos
\end{tabular}




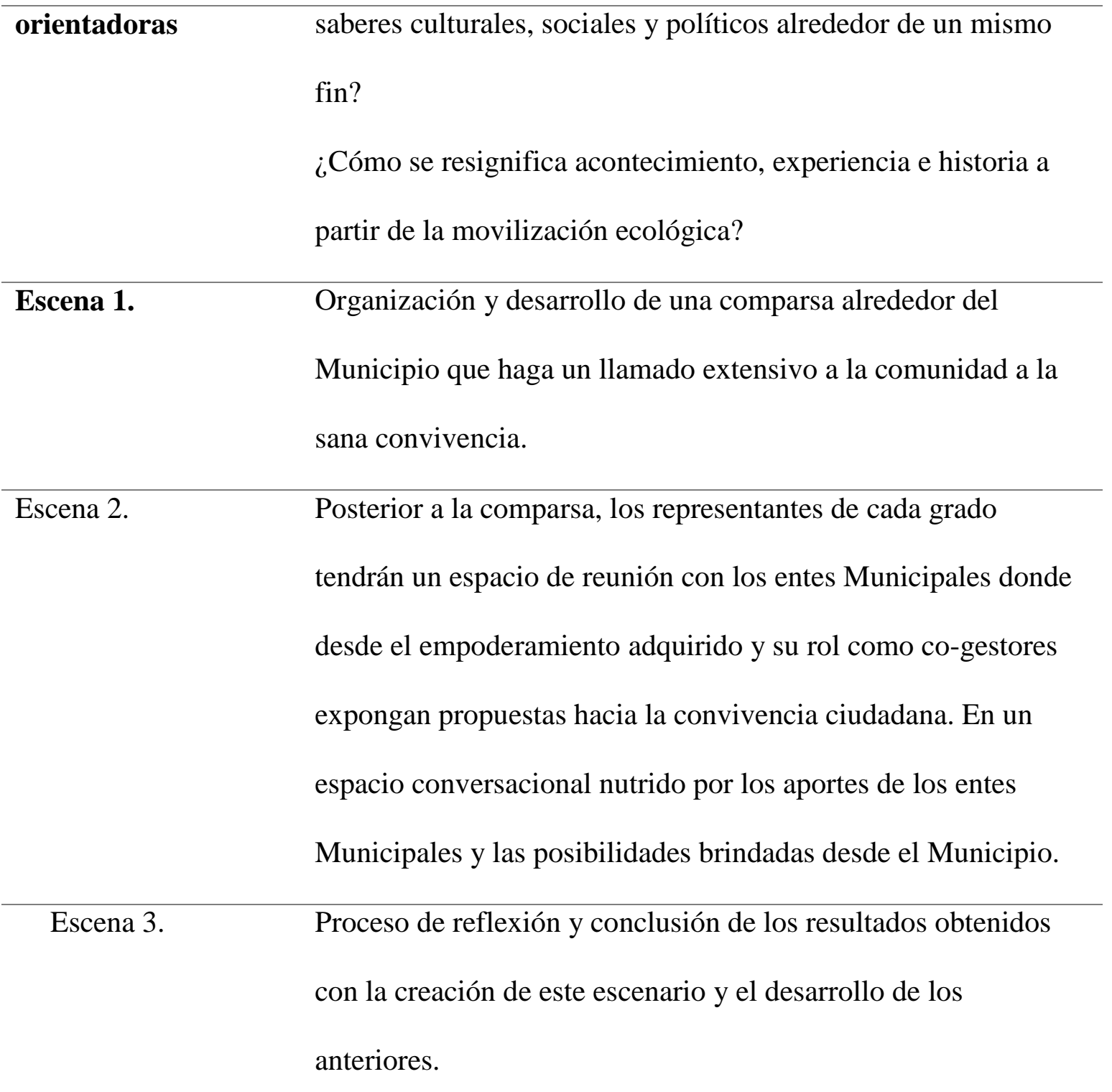

\section{Construcción de Neo - diseños}

Para llevar a cabo esta investigación/intervención se crearon cinco escenarios que podrían dar cuanta del fenómeno de estudio; sin embargo, en el transcurrir de los mismos hizo presencia la complejidad de los seres humanos en los que se está inmerso, el cuerpo directivo de la institución se opuso a que este primer encuentro se realizara con la alcaldía y la comisaría, por tanto prefería que se llevara a cabo por separado, por lo cual se hizo indispensable la creación de un 
primer neo diseño, que complementaría este estudio de la violencia escolar en un contexto educativo rural del Municipio de Turmequé.

Para ello la creatividad y la curiosidad se hacían notar de parte de las investigadoras/interventoras. En un principio se había creado el primer diseño de contextualización donde se pretendía que las entidades del Municipio estuvieran presentes junto con la Institución educativa industrial de Turmequé en un mismo espacio; sin embargo, fue necesario dividir el escenario en 2 momentos dadas las disposiciones de tiempo y espacio de los actores convocados, añadido a diferencias entre instituciones. El objetivo de este primer escenario era dar cuenta de cómo es entendida la violencia en el contexto educativo a partir de la comprensión que han realizado los estudiantes, con la incidencia de la ecología de los sistemas en cuanto a relaciones e interacciones que han construido en su diario vivir.

Seguido a ello el segundo, tercero y cuarto escenario se llevaron a cabo según la construcción del diseño. El quinto escenario dio lugar a un segundo neo diseño con la psicopedagoga que se denominó entre la diversidad y la multidimensionalidad con el fin de re-significar su participación en el fenómeno de estudio y concertar con la institución educativa las estrategias y dispositivos que se consideraran pertinentes para el desarrollo del último escenario.

Finalmente se creó un tercer neodiseño donde la propuesta del escenario se dio a partir de la letra de una canción, "Cambia lo superficial, cambia también lo profundo, cambia el modo de pensar, cambia todo en este mundo", espacio que buscaba la participación de los estudiantes por medio de una comparsa que invitara a toda la institución y a los sistemas a corresponsabilizarse de la violencia escolar y a resignificarla durante el evento de cumpleaños de la institución, sin embargo, por motivos de tiempo y espacio en esta jornada se concertó con las institución educativa y los niños, niñas y jóvenes cambiar la estrategia, lo que posibilito construir un espacio 
en el cual los estudiantes invitaran a los sistemas amplios a resignificar la violencia por medio de una carta a la familia, la creación de una ruta emocional y la construcción de una canción.

Los neo diseños se presentan como formas alternas de comprender a mayor profundidad el fenómeno de estudio, ya que tienen estos cambios unas connotaciones inmersas en el mismo estudio a través de las dinámicas conversacionales, donde se pueden convocar las voces de los participantes.

A continuación se presenta el neo diseño, de escenario uno, cuyo objetivo es mostrar la propuesta investigativa y la propuesta metodológica, donde se aliente el trabajo en red y se establezcan acuerdos para el desarrollo de los escenarios, se desarrolló en dos momentos, el primer momento con la alcaldía y la comisaría y el segundo momento con la institución educativa.

Tabla 12. Neodiseño 1. Contextualización

Escenario 1: Contextualización. Alcaldía y comisaría. Institución educativa

Actores convocados Directivos institucionales (Rectora, coordinador académico, psicopedagoga), estudiantes de los diferentes ciclos educativos y las investigadoras - interventoras 


\section{Objetivo del Presentar la propuesta investigativa, contextualizando el escenario objetivo de la misma, comprendiendo a través de los actores cómo la violencia ha permeado al municipio desde su cultura.}

Focos de Configuración de la violencia por parte de los actores
intervención convocados, entender cómo ha sido inmersa en sus sistemas amplios y cuál ha sido la intervención a partir de sus cargos laborales como entidades hacia la institución.

Cómo se puede facilitar la recursividad por parte de las entidades e Institución en la emergencia de construir una narrativa conversacional generativa hacia los estudiantes que participan de la investigación.

Co - construcción de prácticas colaborativas que permitan la fluidez en el desarrollo de escenarios.

La meta observación que permite a las investigadoras interventoras posicionarse desde una cibernética de segundo orden.

\section{Hipótesis} La disposición de los actores para trabajar en red favorece el desarrollo de los escenarios de investigación/intervención y las comprensiones que surjan alrededor del fenómeno de estudio. Los relatos emergentes respecto al fenómeno de estudio por parte de los entes Municipales e Institucionales facilitarían la redefinición de la violencia escolar y la percepción deficitaria hacia los estudiantes. 
La movilización de los procesos autorreferenciales de los participantes y de las investigadoras/interventoras favorece comprensiones reflexivas del fenómeno de estudio, y la emergencia de propuestas para el desarrollo de futuros escenarios.

\begin{tabular}{ll}
\hline Preguntas & ¿Cómo la narrativa domínate por parte de los actores \\
orientadoras & convocados ha favorecido la construcción social de la violencia \\
& escolar? \\
& ¿Cómo puede ser la participación de la alcaldía, comisaria e \\
& institución en este fenómeno de estudio? \\
& ¿Cuál es la importancia de la participación de la población que \\
& participa en este estudio para la institución? \\
& ¿Por qué es importante el trabajo en red donde se incluyen los \\
& sistemas amplios? \\
& Describir escenas \\
& 3: presentación actores \\
& Metodología: \\
& Se dará la bienvenida a los participantes a este escenario. \\
& Las investigadoras/interventoras se presentan al grupo de \\
actores participantes & Se brinda para que los actores participantes se presenten, \\
refiriendo el nombre y el cargo. & Instrumentos: protocolo
\end{tabular}


Estrategia a utilizar: metaobservación: lectura de su lenguaje no verbal.

Preguntas guía:

¿Cuáles son sus nombres y las funciones que desempeñan en sus cargos?

Escena 2: presentación propuesta investigación/intervención. Metodología:

Introducir brevemente por qué las investigadoras/interventoras se encuentran participando en el espacio propuesto.

Se presenta una imagen de un niño siendo violentado, de esta manera se abre el espacio conversacional, donde se espera que de los actores emerja su narrativa respecto al fenómeno de la violencia escolar.

Posteriormente se realiza una breve socialización de la investigación/ intervención y los posibles caminos a seguir, según lo que propagan los actores participantes.

Estrategia a utilizar: protocolo, metaobservación

Preguntas guía:

¿De acuerdo a su experiencia, cómo comprenden ustedes la violencia que se presenta en el municipio?

¿Cómo perciben ustedes la violencia escolar que se presenta en la institución educativa del municipio?

¿Ustedes en algún momento se han sentido víctimas de 
violencia escolar? Si es así, ¿cómo han superado esta

adversidad? ¿Cuáles son los principales casos que ustedes como entes municipales conocen relacionados con la violencia de los habitantes de turmequé?

¿Cómo municipio qué acciones se ha llevado a cabo para prevenir la violencia escolar, y cómo éste favorece al bienestar familiar y municipal?

¿De qué manera se organiza el municipio y la escuela para atender las situaciones de violencia que se presenta en los niños?

Escena 3: acuerdos y compromisos Metodología:

Se realiza un equipo reflexivo entre las investigadoras/interventoras donde se manifiesta las impresiones observadas en las escenas anteriores. Se pregunta a los actores la sensación percibida luego del equipo reflexivo y se invita a generar acuerdos y compromisos para el desarrollo de los siguientes escenarios. Estrategia: Protocolo y Equipo Reflexivo. Pregunta Orientadora: ¿Qué sensación les deja a ustedes esta conversación que acabamos de tener las investigadoras/interventoras?

¿A qué acuerdos podemos llegar para el desarrollo de la 
investigación/intervención?

Escena 1. Institución Se dará la bienvenida a los participantes a este escenario.

Educativa Posteriormente se realiza una breve socialización de los avances

que ha tenido la investigación - intervención y los posibles

caminos a seguir; luego se concertaran las fechas para el

desarrollo de escenarios y las personas participantes a cada uno

de los escenarios de investigación - intervención. Finalmente se

socializara la pertinencia de la investigación - intervención para

la Institución Educativa, para el Municipio y para la Línea de

Investigación de la Maestría en psicología clínica y de la

familia.

Escena 2. Alcaldía Se dará la bienvenida a los participantes a este escenario.

Posteriormente se realiza una breve socialización acerca de la investigación - intervención y los posibles caminos a seguir;

posterior a ello se realiza una conversación en torno a la

violencia, comprensión que cada uno como entidad tienen frente

a este evento, y como ha entrado a formar parte del entorno

académico de la institución donde se está llevando a cabo el

estudio del fenómeno de la violencia escolar

Neo diseño \# 2. Entre la diversidad y la multidimencionalidad

Tabla 14. Neodiseño 2 
Actores convocados Directivos institucionales ( Psicopedagoga y las investigadoras

- interventoras)

Objetivo

escenario del Resignificar la participación de parte de la psicopedagoga en el fenómeno de estudio y como estas acciones por parte de ella, cómo representante de la institución educativa van a ser divulgados hacia los sistemas amplios, padres, madres, estudiantes, docentes y demás directivas del colegio.

\section{Focos \\ de 1. Nivel de relación que existe entre las investigadoras- intervención interventoras y la psicopedagoga de la institución. Entendiendo que se ha presentado una serie de dificultades para el desarrollo del quinto escenario, añadido a cómo esta pauta interaccional puede dar cuenta de una emergencia soterrada por parte del sistema investigativo y el sistema directivo de la institución. \\ 2. La participación de la psicopedagoga, en cuanto a la resignificacion de la violencia escolar con los padres, madres y estudiantes de la institución. La validación por parte de la psicopedagoga en el ejercicio educativo, y como líder del fortalecimiento de las escuelas de padres y comité de convivencia estudiantil, hace relevante su participación de la investigación, en cuanto a ideas, creatividad y novedad que pueda hacer parte de la resignificacion de la violencia escolar.}


3. Construcción de la violencia escolar, dentro del establecimiento educativo. Los diferentes momentos, históricos, culturales y memorables que han hecho parte de la construcción social del fenómeno de la violencia escolar, como una mirada sistémico-compleja que pueda dar cuenta cómo se ha organizado o instaurado al interior del colegio.

Hipótesis

Preguntas

orientadoras
Tal vez la emergencia de la novedades surgidas en los escenarios de investigación/intervención haya sugerido desde la percepción de la psicopedagoga una amenaza a su rol como orientadora y movilizadora de los procesos académicos de la institución educativa, lo que la lleva a posicionar nuevamente su rol por medio de la delegación de responsabilidades y el cierre de los espacios para la aplicación del ultimo escenario de la investigación/intervención.

¿Cuál ha sido la pauta interaccional que se ha construido durante el desarrollo del estudio de la investigación, entre las investigadoras-interventoras y la psicopedagoga.?

¿Cómo posibilitar un espacio donde se connote la labor de la psicopedagoga en la institución educativa y en la investigación intervención, donde se construyan nuevas ideas para la creación y aplicación del último escenario de la investigación/intervención según los resultados encontrados hasta el momento? 
¿Cómo será la participación de aquí en adelante por parte de la psicopedagoga, en cuanto a la resignificacion de la violencia escolar hacia los estudiantes, padres y demás comunidad educativa?

\section{Guion} Describir escenas

Escena 1: hallazgos de escenarios aplicados Metodología:

Se socializa el objetivo de este escenario, y desarrollo de los escenarios con los debidos hallazgos encontrados a la fecha. Instrumentos: protocolo

Estrategia a utilizar: resignificación de la participación, por parte de la psicopedagoga.

Preguntas guía:

¿Según lo observado durante la aplicación de los escenarios, cuáles cree usted que son los resultados que se han encontrado? ¿Según lo visto en esta socialización previa de resultados, cómo podríamos trabajar en conjunto para ser extensiva la propuesta de los niños, niñas y jóvenes?

¿Cuál sería la manera de poder involucrar con mayor compromiso a los padres, estudiantes, docentes y demás comunidad educativa en la resignificacion de la violencia escolar?

Escena 2: propuesta por la psicopedagoga para el cierre de los 
escenarios.

Metodología:

Escuchar la voz participante de la psicopedagoga en cuanto a las mayores necesidades, evidenciadas en el desarrollo de los escenarios anteriores, para que se pueda construir el escenario de cierre donde se resignifique el fenómeno y Participen las personas que ella considera oportunas y pertinentes, para que pueda beneficiar la comunidad educativa.

Estrategia a utilizar: Connotación positiva, preguntas circulares y reflexivas.

Instrumento: protocolo, Preguntas guía:

¿Cómo se siente usted como psicopedagoga desde su emocionalidad en este estudio que se ha desarrollado?

¿Cómo percibe a la comunidad que ha participado en este estudio, cómo ha sido recibido por los directivos, docentes, el comité de convivencia y demás?

¿Qué cree que dirían los estudiantes de la violencia escolar luego de terminada esta investigación/intervención?

¿Cómo podemos anudar fuerzas desde sus conocimientos y la disponibilidad y participación del colegio para crear un escenario que propicie un mensaje que pueda ser extensivo para toda la comunidad Turmequense? 


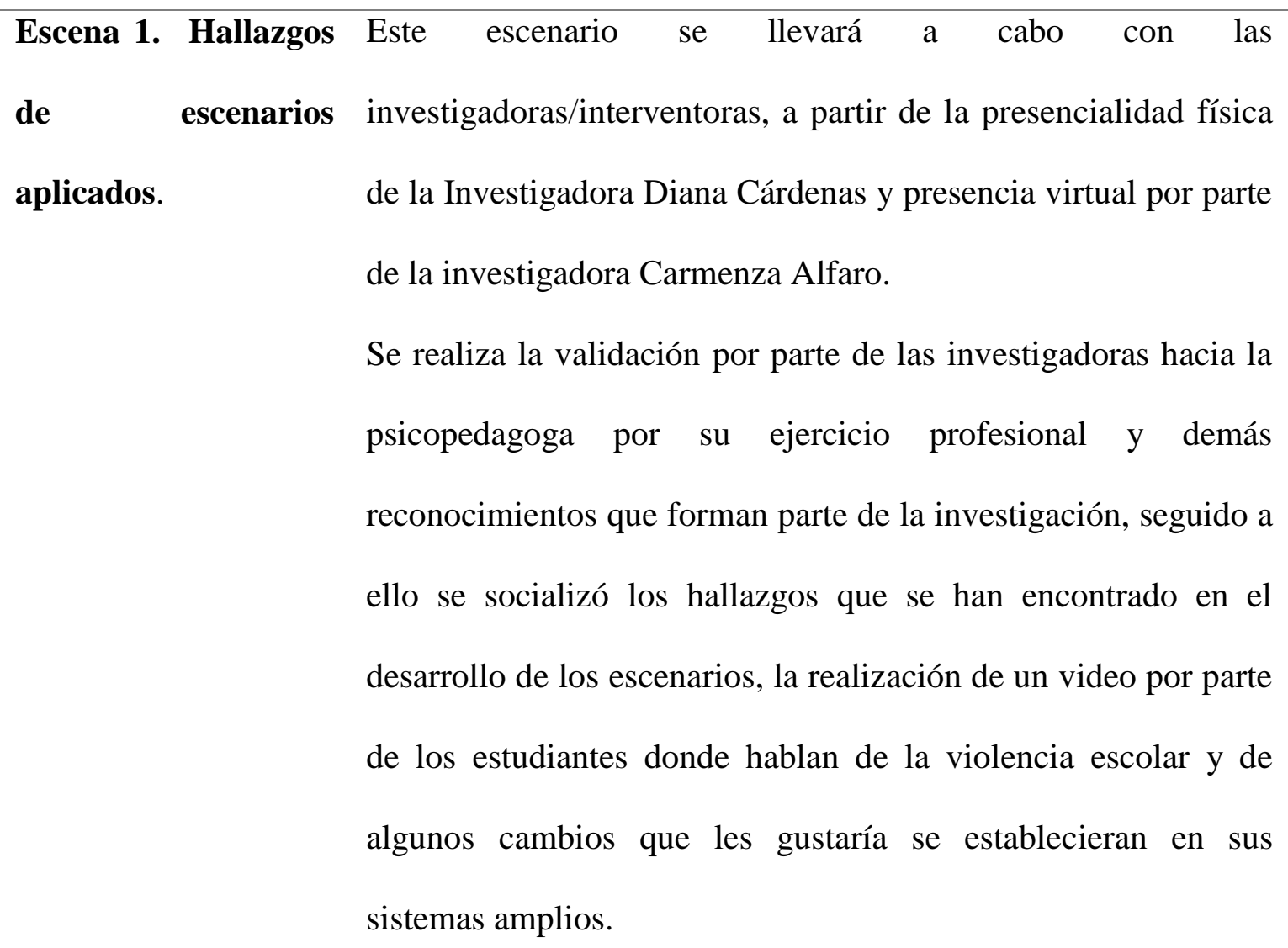

Escena 2. Propuesta Escuchar la voz de la Psicopedagoga, se hace prioridad en este de la psicopedagoga Neo diseño, según las epistemes que haya podido construir a para el cierre de los partir de los diferentes hallazgos encontrados en el desarrollo de escenarios. $\quad$ los escenarios.

Se pretende que ella, la psicopedagoga como representante de la institución, pueda referirnos cómo desea que se lleve a cabo el último escenario, y con cuáles estrategias le gustaría proponer para culminar este proceso en un trabajo conjunto con toda la comunidad; teniendo en cuenta esto, por lo tanto las investigadoras estuvieron al tanto del desarrollo de estas novedades, con la intención de favorecer los distintos sistemas 
implicados en el fenómeno de estudio.

Neo diseño 3. Cambia lo superficial, cambia también lo profundo, cambia el modo de pensar, cambia todo en este mundo (Mercedes Sosa)

Tabla 14. Neodiseño 3

\begin{tabular}{ll}
\hline Actores convocados & Estudiantes de diferentes ciclos escolares \\
\hline Objetivo del & Movilizar la emergencia de los sujetos en la construcción de una \\
& convivencia pacífica desde toda la ecología de los sistemas, lo \\
& que posibilite que la resignificación de la violencia escolar \\
& permanezca en el tiempo y que se haga extensivo a los sistemas \\
& amplios. \\
\hline Focos de & Emergencia del sujeto desde la ecología y su compresión desde \\
intervención & la activación de redes en los sistemas amplios. \\
& Favorecer la continuidad de la investigación/intervención y la \\
& resignificación de la violencia escolar dentro de la institución y \\
& en la interacción con otros sistemas \\
& A través de la creatividad hacer evidente la demanda de los \\
& niños, niñas y jóvenes de ser escuchados y de generar y \\
mantener el vínculo con los adultos. & ¿Cómo la polivocalidad permite la emergencia de nuevos \\
saberes culturales, sociales y políticos alrededor de la violencia \\
escolar?
\end{tabular}


¿Cómo se resignifica acontecimiento, experiencia e historia a partir de la movilización ecológica, de los actores participantes?

\section{Hipótesis}

Los aprendizajes adquiridos durante el desarrollo de los

escenarios han permitido movilizar a los estudiantes como

gestores de paz lo que posibilita la emergencia de la

polivocalidad y la construcción de propuestas que permitan que

la resignificación de la violencia escolar se haga expansiva a

toda la institución educativa y sistemas amplios con el trascurrir

del tiempo.

Los relatos alternos como la resignificación que se dio de la

violencia escolar a través de la aceptación de las diferencias del

otro, que han emergido en el procesos de

investigación/intervención pueden facilitar la construcción de

memorias que permitan el rompimiento de la secuencia

interaccional configurada a través del tiempo en el Municipio.

El hacer evidente la secuencia interaccional alrededor de la

configuración de la violencia escolar y hacer un llamado a las

voces y la participación de los niños, niñas y jóvenes facilita la

emergencia de la conexión cercana y amable con los padres

posibilitando los procesos vinculares.

Guion

Se divide el grupo en tres subgrupos posterior a la presentación

del video y la canción, donde cada grupo rotará cada 20 minutos

para que todos participen en la creación de los dispositivos. 


\section{Escena 1. Canción para todos}

\section{Metodología.}

Se presenta al grupo gestor el video realizado por ellos mismos, con el fin de hacer evidente la demanda de ellos hacia cada uno de los sistemas con los que interactúan. Se realizaron preguntas guía, con el objetivo de hacer un llamado nuevamente a las voces de los estudiantes reconfigurando el fenómeno de estudio; al igual que se resalta la canción como un dispositivo que permitió sensibilizar y generar ideas para la construcción de una canción que los identifique como colegio, como gestores de convivencia y como Municipio, que pueda hacerse extensivo a los sistemas amplios.

Instrumentos:

Diario de campo

Estrategias a utilizar

Sensibilización hacia el fenómeno de estudio a través de la música y el video

Dispositivo interventivo

Video desarrollado por estudiantes en escenario ...

Preguntas Guía

¿Qué surge emocionalmente en ustedes al ver el video que elaboraron?

¿Qué opinan de la canción que está de fondo en el video? 
¿Si ustedes escribieran una canción que letra tendría?

¿Dónde les gustaría que se escuchara esta canción?

¿Qué les gustaría que sucediera con sus profesores, familia colegio cuando ven el video?

¿Cómo quisieran que el colegio diera uso del video que ustedes elaboraron y eso en qué los ayudaría a ustedes?

¿Cómo les gustaría participar en el uso que el colegio le da al video?

Escena 2. Tarjeta a la familia

Metodología

Se construye con los actores participantes una tarjeta que posibilite la vinculación con el sistema familiar desde un mensaje construido por los niños, niñas y jóvenes donde este grupo gestor pueda comunicar la necesidad de ser escuchados a la familia. Por otra parte, al culminar la elaboración de la tarjeta invitar a los estudiantes a proliferar la información a cada uno de sus cursos por parte del grupo que participó en el estudio.

Instrumentos

Diario de campo

Estrategias a utilizar

Metaobservación

Dispositivo de intervención? Cual dirían que es?

Preguntas Guía 
¿De qué otras maneras podemos invitar a otros a lo que queremos decirles?

¿Qué hago yo para que a los otros les interese conocer lo que está pasando conmigo?

¿Por qué usted escogió a esta persona para entregarle la tarjeta?

¿Qué cree que le diría esa persona cuando vea la tarjeta?

¿Cree que esta tarjeta le serviría para acercarse más a esa

persona?

Escena 3. Ruta Emocional

Metodología

Se propone la elaboración de una ruta emocional que sea posible desarrollar dentro de la Institución Educativa y que permita identificar, atender y empoderar a niños, niñas y jóvenes que estén presentando una situación de violencia escolar, con el fin de propiciar apoyo y orientación facilitando el afrontamiento y superación de esta situación.

Instrumentos

Diario de campo, grabación

Estrategias a utilizar

Construcción dispositivo: Ruta emocional de gestión de paz Preguntas Guía

¿Qué necesita un niño que se encuentra atravesando por una situación de violencia escolar para poder salir de esta situación? 
¿Si construyéramos una ruta o camino emocional que pasos

llevaría para identificar, atender y empoderar a niños, niñas y

jóvenes que estén presentando una situación de violencia

escolar?

¿Qué personas se encargarían de atender esta ruta?

¿Qué mensajes les gustaría dejar claros en esa ruta para que

quien la vea se sienta invitado a poder seguir esta ruta?

\section{Modelización de la Investigación/Intervención}

Este apartado de Modelización orienta al lector por el camino en el que han transitado las investigadoras/interventoras y que ha posibilitado cambios, perturbaciones y emergencias en las epistemes, marcos de referencias y en los procesos autorreferenciales que facilitaron la comprensión y el re - definición de la violencia escolar desde una perspectiva ecológica.

La forma en que se operó esta investigación/intervención fue partir de una postura constructivista-construccionista-compleja, y es un estudio cualitativo. Es así que el estado del arte documental amplió los referentes investigativos actuales sobre violencia escolar, donde se visualiza desde una perspectiva lineal y determinista que enmarca a la familia desde una mirada deficitaria, que la culpa y la señala, al igual que excluye a la Institución Educativa limitando su quehacer a la formación académica. Esta realidad permitió la creación de escenarios testimoniales, para conversar con los principales actores y comprender contextualmente lo que 
sucede alrededor de la violencia; de esta manera, se posibilitaron encuentros con madres, estudiantes, directivas de la institución educativa, profesores y expertos investigadores en el fenómeno. Las voces de los actores permitieron visibilizar la necesidad de hacer un llamado ecológico dada la construcción de la violencia desde una mirada social, que no solamente se enmarca en el sistema escolar sino que también hace parte de las formas de interacción en el Municipio. Este avance en los estados del arte, permitió organizar categorías de análisis y ejes temáticos que posibilitaron comprender desde el sistema teórico la configuración de la violencia desde los órdenes de la complejidad y la ecología de los sistemas. Es así que se planean los siguientes ejes temáticos: El fenómeno de la violencia escolar como una construcción social, durante su permanencia en el sistema educativo, procesos narrativo - conversacionales en la configuración y reconfiguración del fenómeno de estudio, autonomía y co-evolución en la dinámica vincular de los diversos sistemas.

El sistema metodológico da a conocer las comprensiones propias frente a la construcción social del fenómeno de la violencia, y como éste favorece los procesos de co - evolución en cada uno dentro del contexto escolar.

Se hace necesario realizar una discusión entre las investigadoras/interventoras de cuáles serían los principios operadores que avalarían este estudio y que facilitarían la interpretación del fenómeno a investigar, de acuerdo a ello parte de la creatividad y la reflexión para la creación de los escenarios que puedan generar bienestar tanto en los participantes como en las investigadoras/interventoras.

Los principios operadores fueron autorreferencia y reflexividad, recursividad y construcción compleja de narrativas, y por último procesos conversacionales. Estos principios permiten a la investigación/ intervención hacer una lectura ecosistemica de la construcción de la violencia en 
un contexto rural, permitiendo hacer parte de un sistema a las investigadoras/interventoras desde las creencias y significados propias a los estilos de vida de cada una, para así realizar procesos de meta observación desde una cibernética de segundo orden facilitando una mirada compleja en la comprensión del fenómeno de estudio.

La complejidad acompañó todo el proceso de este estudio, es por ello que se menciona a Keeney (1994) cuando afirma que la crisis manejada desde la estética invita a realizar una reflexión clara y distinta en cuanto a la armonía y la belleza, encuentro y creatividad, innovación y exploración.

A partir de estas palabras surge la invitación de este estudio amplificando la creatividad, que diera cuenta de una comprensión sistémica en el desarrollo de los escenarios que se iban a realizar al interior de la institución educativa, la complejidad es asumida por las investigadoras/interventoras como una postura que posibilitará las lecturas sistémicas desde una sensibilidad hacia el conocimiento de la otredad, generada por las construcciones propias del municipio en sus diversas interacciones desde lo social, político, educativo, y cultural.

Y esa misma complejidad permitía entender cómo han sido organizadas las relaciones en el núcleo familiar, donde ha estado permeada por el arraigamiento propio de la cultura Turmequense en cuanto a la violencia.

De esta manera iban surgiendo las emergencias para la investigación/intervención durante la puesta en marcha del estudio que se fueron convirtiendo en los principios metodológicos como son: La violencia escolar como una construcción social, ecología de las interacciones desde la construcción de mundos posibles y la coevolución, por último la emergencia del sujeto autónomo desde la multitemporalidad. 
Era un reto para las investigadoras/interventoras realizar tantas miradas complejas que pudieran penetrar al mínimo acto poético, entendido como aquellas situaciones que no se les ha dado voz, pero que están presentes en el diario vivir que surgiera en los espacios de socialización descubriendo cómo ha sido esta construcción social de la violencia escolar, gestándose desde el interior del hogar, los amigos, los vecinos y las interacciones en el contexto escolar, y es aquí donde hace presencia la psicología clínica y de familia, en un contexto rural en la interpretación de los sistemas amplios y la ecología de las interrelaciones que se confabulaban en acciones soterradas que pueden favorecer los procesos de autonomía hacia la co - evolución en el ser humano, en este caso los niños, niñas, y jóvenes que participan de la investigación/intervención.

Los escenarios, eran espacios propios para darle voz a los relatos de los participantes, relatos que estaban precedidos de unas narrativas conversacionales ocultas, por el temor hablar acerca de la violencia escolar, temor al profesor, temor al padre... pero este era un espacio que protegía la integridad del niño, niña, adolescente y joven que podía por primera vez sentirse escuchado, comprendido y orientado hacia la resignificación de este hecho, aunque él o ella no lo hubiera vivido iba a tener las herramientas suficientes para realizar sugerencias a quien estuviera pasando por una situación de violencia escolar.

Los dispositivos que se efectuaron fueron muy lúdicos, teniendo en cuenta que los participantes son niños, niñas, y jóvenes, se utilizó, la elaboración de una canción, elaboración de un dibujo, y elaboración de una tarjeta para la familia lo cual favorecía la participación de los niños, niñas, y jóvenes, situación que facilitaba la comprensión del fenómeno por parte de las investigadoras/interventoras, esto posibilitaba los cambios y la resignificación del fenómeno de estudio por parte de los padres, profesores y estudiantes, entendiendo la violencia escolar como una oportunidad de aceptar al otro tal cómo es, con unas determinadas diferencias. 
En la construcción del sistema metodológico se dio origen a entrelazar los conceptos del macro proyecto, historia, memoria, evento, y experiencia para continuar con la complejización del fenómeno de estudio.

De esta manera se menciona a Estupiñan, Gutierrez y Serna (2006) especificando el sistema conceptual metodológico adoptado en este estudio comprendiendo el significado de acontecimiento cómo tramas y desenlaces que se viven en diferentes situaciones. Experiencia como aquellas vivencias que se relatan cargadas de cierta emotividad e interpretaciones. Memoria, dimensiones temporales que acompañan los reatos a partir del pasado, presente y futuro. Historia son las diferentes significaciones que acompañan la interpretación y orientación de la experiencia.

El orden narrativo de la investigación/intervención se originó a partir de las comprensiones que cada participante, ha construido desde sus conocimientos, idiosincrasia, pensamientos y subjetividades al igual que de las investigadoras /interventoras.

Esta investigación pretende conectar todos los ítems que se han tejido como el estado de arte testimonial, estado de arte documental, sistema teórico, fenómeno de estudio, hipótesis de la investigación, un objetivo general y dos específicos, para complejizar, narrar y comprender como se ha construido la violencia escolar en un contexto rural, en una institución educativa del Municipio de Turmequé.

Es por ello que los escenarios fueron creados desde lo novedoso y lo creativo contando con la participación de los niños, niñas, adolescentes y jóvenes, representantes del comité de convivencia de cada curso, docentes y cuerpo administrativo de la institución, y los padres de 
algunos estudiantes. Espacios que fueron posibilitadores en cuanto a tener relatos alternos, resaltando el trabajo en equipo que se generó durante el desarrollo de la investigación.

\section{Categorización y organización de la información emergente}

Para la caracterización y organización de la información se guarda congruencia entre los conceptos metodológicos de la investigación/intervención y los conceptos del macro proyecto Historias y Narrativas de los sistemas humanos en diversidad de contextos, dado que es, en estos conceptos donde el valor conversacional cobra sentido conectando procesos auto y heterorreferenciales en el desarrollo de los escenarios y en el análisis de los discursos donde emerge la experiencia, memoria, acontecimiento, historia y relatos alternos en la redefinición de la violencia escolar en sistema educativo, de la Institución técnica industrial del Municipio de Turmequé.

Es así, que para comprender a detalle los sistemas de significados de los participantes de la investigación/intervención, se hizo necesario realizar sesiones grabadas que fueron trascritas, con el fin de analizar lo que va más allá de lo dicho y las emergencias que surgieron en cada uno de los escenarios. Se eligió el análisis de discurso ideológico y la narrativa conversacional, como estrategia metodológica para la investigación/intervención, ya que son dos fuentes de análisis de resultados, que brinda la información pertinente para hacer efectivo el proceso de análisis.

Teniendo en cuenta lo anterior, el análisis de discurso ideológico permite visibilizar la relación de las estructuras del discurso y las estructuras sociales que construyen relaciones sociales de clase, género y etnicidad. Comprendiendo que las organizaciones agrupadas como instituciones, roles, entre otras, tiene una influencia desde lo cultural y desde las decisiones y estructuras políticas; lo que permite a la investigación/intervención hacer una conexión ecológica de las pertenencias sociales de los participantes y la implicación de los sistemas amplios en la 
narrativa de los mismos. De la misma manera, se analizan los intereses del grupo que crean identidad, actividades, metas, normas y valores en común, que caracterizan al Municipio de Turmequé y por lo tanto a las forma de interrelación de sus habitantes en la construcción social de la violencia y la convivencia.

De esta manera, el análisis de discurso ideológico permite identificar las relaciones de juicio y opinión a partir de las expresiones que emplean los participantes, donde se tienen en cuenta las palabras y el vocabulario que utilizan en común para identificar pertenencias, acciones y acontecimientos que tienen lugar para un mismo grupo de personas.

Por su parte la narrativa conversacional como estrategia metodológica, permite conectar la narrativa de los participantes con el proceso de pertenencia ideológico expuesto en el análisis de discurso ideológico, es así que este método de análisis permite comprender los procesos emergentes desde una comprensión semántica y pragmática de los campos y actos narrativos (Estupiñàn y Gonzáles. 2015). Por medio de la narrativa conversacional como estrategia metodológica, se comprende la forma en cómo se producen e interpretan los sucesos de la vida cotidiana escolar, familiar y Municipal, donde emergen contextos de relación, narración y conversación en la emergencia del cambio, que configura actos narrativos de la experiencia vivida. Este tipo de análisis permite en la investigación/intervención articular los acontecimientos y experiencias conectadas a la emergencia de historias y relatos alternos.

Para realizar dicho análisis de resultados se desarrolla una matriz en donde se organiza la información y en la que emergen los relatos de los participantes, las categorías y la conexión entre los dos tipos de análisis: análisis de discurso ideológico y la narrativa conversacional como estrategia metodológica. De esta manera, en dicha matriz se ubica la construcción de las relaciones y pertenencia conectada con memorias y acontecimientos asumiendo que estas dos 
categorías permiten comprender las conexiones que se construyen con las ideologías culturales de los participantes, añadido a la motivación/emoción y a las realidades compartidas como parte de la pertenencia que identifica a las personas dentro de una cultura.

Añadido a lo anterior, en la matriz se evidencia la narrativa conversacional donde se categorizan el contex to interaccional, conectado con la experiencia, asumiendo ésta desde la configuración narrativa de lo vivido, y la secuencia interaccional que conecta con la pauta relacional que configura la construcción narrativa. De igual forma, se evidencia la categoría de narrativa que da cuenta de las historias y los relatos alternos que emergen de lo conversado y que permite analizar cómo se significa la relación y la historia vivida.

Finalmente dentro de la matriz se encuentra el apartado de análisis y autorreferencia. El proceso heterorreferencial se encuentra inmerso en cada uno de los análisis que se construyen alrededor de los apartados categoriales de memoria, acontecimiento, experiencia e historia.

A continuación se presenta la matriz de acuerdo al mètodo mencionado anteriormente, análisis de discurso ideológico y la narrativa conversacional como estrategia metodológica.

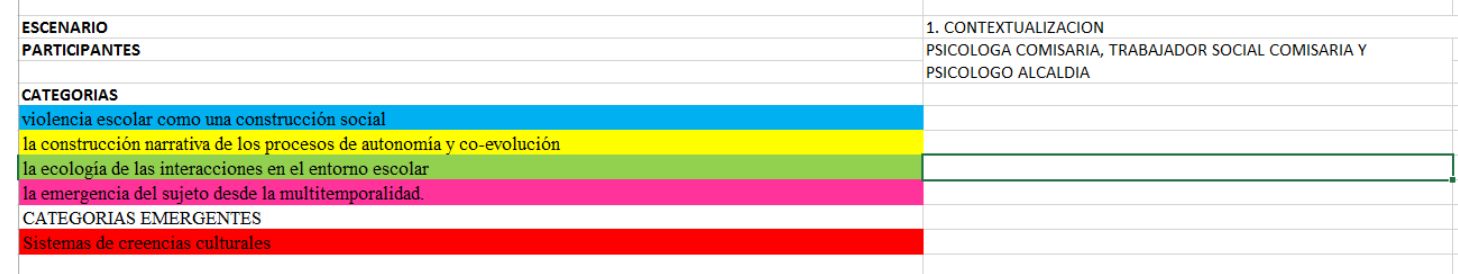




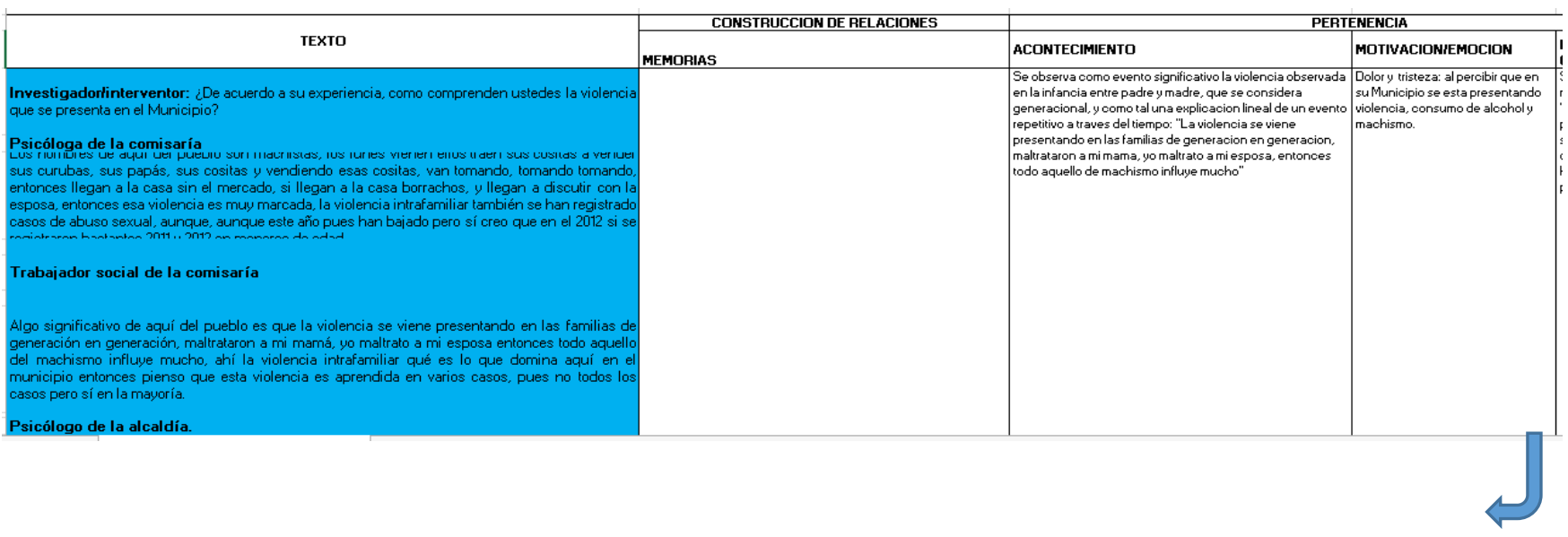

\begin{tabular}{|c|c|c|c|c|c|c|}
\hline & CONTEXTOI & NTERACCIONAL & & & & AUTORREFERENCIA \\
\hline $\begin{array}{l}\text { REALIDAEDS } \\
\text { COMPARTIDAS }\end{array}$ & EXPERIENCIA & SECUENCIA INTERACCIONAL & HISTORIAS & RELATOS ALTERNOS & ANALLISIS & \\
\hline 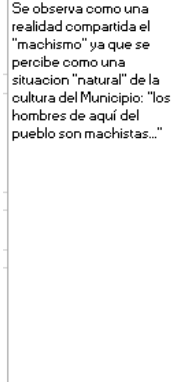 & 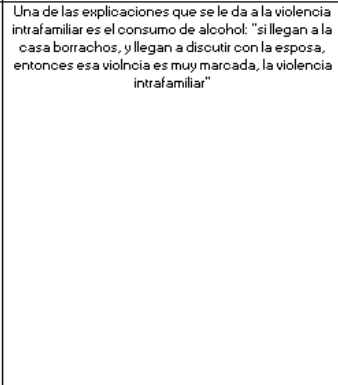 & 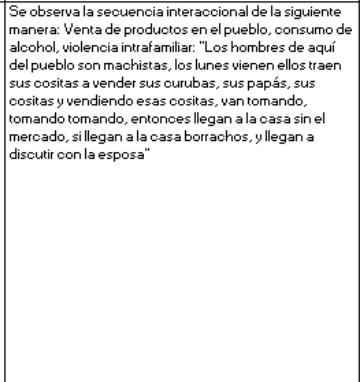 & & & 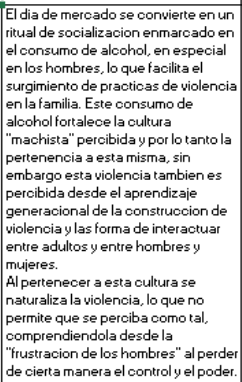 & 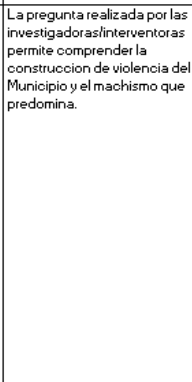 \\
\hline
\end{tabular}

Gráfica 10: Ejemplo de matriz de categorización y organización de la información

Para finalizar este estudio de investigación/intervención se realizan los resultados a partir del análisis propio que arrojó las matrices donde se plasmaron las conversaciones que se desarrollaron en cada uno de los escenarios, donde se visibilizaron aquellas voces que estaban silenciadas a través de actos poéticos, entendidos como la interpretación y participación de lo dicho, (Pakman, 2006), se llevó a cabo cuatro escenarios y tres neo diseños donde se amplía la hipótesis, y las preguntas que se plantearon como también la consecución de los objetivos propuestos, de tal manera que el fenómeno de estudio se podía complejizar en cada uno de los órdenes que permitía la investigación/intervención, teniendo en cuenta los conceptos metodológicos a través del macro proyecto Historias y Narrativas de los Sistemas Humanos en diversidad de contextos. 
En cuanto a la discusión se evaluó e interpretó el análisis de resultados a partir de los aportes de los teóricos consultados como referentes conceptuales ampliando los focos de investigación teniendo en cuenta las preguntas e hipótesis generando unos nodos entre los conceptos metodológicos y los escenarios propuestos a través de procesos recursivos y reflexivos visibilizando los procesos elaborados a partir de interpretaciones auto y heterorefernciales.

Por último el capítulo de conclusiones da a conocer los aportes, novedades y hallazgos que emergieron durante el desarrollo de esta investigación/intervención para la psicología clínica, para el macro proyecto, para la maestría en psicología clínica y de la familia y las implicaciones para las investigadoras /interventoras.

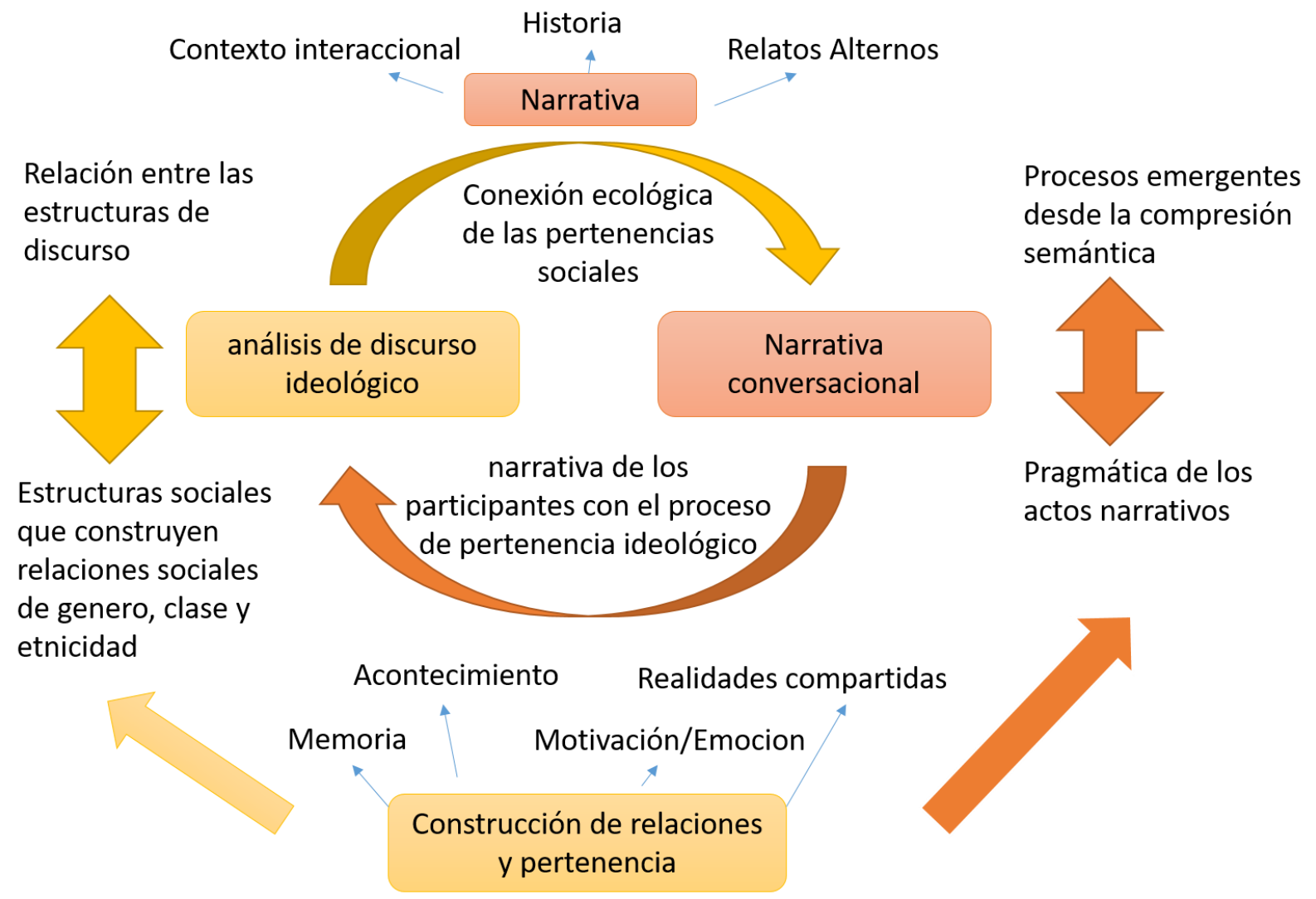

Figura 11. Comprensión del proceso de análisis de resultados 


\section{Resultados}

Este capítulo presenta los resultados que surgieron de la intervención desarrollada en la Institución Educativa Técnica Industrial de Turmequé y de las comprensiones que emergieron del análisis conversacional de los cuatro diseños y los dos Neo - diseños de escenarios.

Este análisis de resultados contempla las hipótesis planteadas para la investigación/intervención y cómo estas posibilitaron un camino guía para la intervención en el desarrollo de los escenarios y para las comprensiones de cambio. A continuación se presentarán los resultados organizados en cuatro apartados un apartado concernientes a la comprensión ecológica/compleja de la violencia escolar, otro apartado concerniente a la reconfiguración narrativa de la violencia escolar, un tercer apartado que hace referencia a la categoría emergente: “la emergencia del vínculo como posibilitador del cambio" y un último apartado donde se describen los procesos autorreferenciales. Los anteriores apartados se encuentran divididos en sección teniendo en cuenta el tipo de análisis de resultados se hace énfasis en la pertenencia 
como parte de un marco ideológico de los actores participantes el cual dará cuenta de acontecimientos culturales, procesos psicológicos enmarcados en la emoción y motivación y realidades compartidas por la comunidad del Municipio de Turmequé; en este mismo orden se observará el contexto interaccional que da cuenta de la experiencia y la secuencia interaccional que llevan al mantenimiento de la pauta de violencia desde un contexto cultural, social, generacional e ideológico, y finalmente se realizará un análisis narrativo que dará cuenta de la historia evocada por los actores participantes y los relatos alternos que emergieron como producto de la investigación/intervención.

\section{Comprensión ecológica/compleja de la violencia escolar}

La violencia escolar como una construcción social se direcciona hacia las distintas formas en cómo se configura el Municipio y las personas inmersas en él, alrededor de la pauta severa de violencia y que organizan modos de comunicación e interacción.

Este subapartado hace referencia a los procesos de interacción que se construyen en el contexto desde una ecología de los sistemas y que permiten comprender cómo la violencia escolar es construida y mantenida por los actores inmersos en el Municipio, al igual que propicia desde una mirada ecológica la emergencia de mundos posibles y la co evolución como parte de la resignificación de la violencia en el sistema escolar y en los sistemas amplios.

Las trascripciones y el desarrollo de los escenarios permitió comprender que la violencia escolar se encontraba permeada por pautas interaccionales violentas que se convertían como propias de la cultura del Municipio de Turmequé, permitiendo visibilizar el carácter 
ideológico de esta construcción social en el desarrollo de los escenarios. Lo anterior permitió a las investigadoras/interventoras comprender que los actos violentos naturalizados en los contextos interacciónales de los habitantes del Municipio marcaban pautas de relación que trascendían en el tiempo en los diferentes microsistemas que configuran toda la ecología que constituye el Municipio. Siguiendo esta lógica los niños y jóvenes al ingresar a un contexto interaccional como el sistema educativo constituyen y crean nuevas formas de relación que dan cuenta de su bagaje cultural e ideológico, añadido a que ingresan a una configuración relacional organizada en ordenes de dominio y control establecidos en jerarquías en las cuales tanto estudiantes como profesores ya hacen parte; pero que a su vez se conectan con la construcción de los procesos de autonomía potencializados en su relación con la familia y la institución educativa lo que les permite como seres autónomos hacer parte o no de la configuración de la violencia escolar. Teniendo en cuenta lo anterior aunque los niños y jóvenes crezcan en un bagaje cultural donde se acepta como parte natural de la sociedad la violencia, esta solo se exacerba en el contexto escolar cuando se anudan situaciones como: poca participación y escucha en tanto en el sistema familiar, escolar y social; desvinculación a sus redes de apoyo; vínculos destructivos y poco movilizantes, y poco reconocimiento de los niños y jóvenes como parte de una sociedad de cambio que les permita crear estrategias de participación y trasformación social; lo que da cuenta de los procesos de autonomía que se fortalece a través de los distintos ciclos vitales por los que pasa el niño y joven.

La emergencia del sujeto autónomo desde la multitemporalidad posibilita el reconocimiento de las potencialidades y recursos de cada uno de los actores participantes de la investigación/intervención donde se activan los procesos de autonomía que se conectan con la co-evolución de cada persona; al igual que se conecta con la 
multitemporalidad como parte del tiempo vivido desde la experiencia, el acontecimiento y la historia que significan la violencia desde una perspectiva individual, familiar y comunitaria.

\section{Pertenencia}

El mantenimiento de la pauta de violencia en el Municipio de Turmequé como situación naturalizada y cristalizada en el tiempo configura procesos de interacción que tienen un alto impacto desde una perspectiva ecológica en las formas de relación de los demás sub-sistemas: familia, escuela, trabajo, y en los procesos de co-evolución de los habitantes del Municipio y de los niños, niñas y jóvenes al sentirse enfrentados a situaciones de hostilidad.

Las interacciones que se dan desde los distintos subsistemas del Municipio de Turmequé se encuentran conectados en una red de interacciones que permite que los niños, niñas y jóvenes en el sistema escolar se organicen relacionalmente teniendo en cuenta todo lo vivido y aprendido en sus diferentes contextos culturales, políticos, sociales y educativos. Estas vivencias y pautas de interacción que se construyen a partir de la cultura y la ideología toman sentido al conectarse con los procesos de autonomía propios del ciclo vital de los actores participantes que a su vez les permite sentirse parte de un sistema familiar y educativo que los reconoce y les posibilita crecer.

El carácter ideológico y cultural de la violencia escolar encuentra una conexión directa con la configuración de violencia del Municipio en general. Como primer punto la violencia en el Municipio se empieza a constituir en las relaciones diferenciadas que se construyen entre hombres y mujeres en las cuales el "machismo" se convierte en un punto que subyuga a la mujer, visibilizándola como "débil" en relación con la autoridad que ejerce el hombre a través de la fuerza y el trabajo. Lo anterior lleva a las familias a puntuar diferencias según el sexo con el que nazcan los hijos o hijas, deseando constituir familias en las cuales se críen hijos hombres y 
no hijas mujeres, con el fin de mantener un posicionamiento social y un "equilibrio" a la pauta interaccional ya naturalizada.

Este posicionamiento se organiza entre los órdenes de poder y dominio, en los cuales la violencia se convierte en una estrategia o en un recurso para mantener interaccionalmente el control sobre el otro. En este orden de ideas la violencia en el Municipio se cristaliza en el tiempo dado que, ideológica y culturalmente, le permite a la persona mantener un posicionamiento. Entendiendo lo anterior, al cristalizarse esta pauta interaccional en el tiempo se naturaliza y se convierte en una forma de relacionarse que se trasmite de generación en generación a lo largo de la historia, permitiendo que los miembros del hogar interaccionen desde el conflicto y el reproche, permeando subsistemas como el contexto escolar.

El sistema ideológico y cultural del Municipio de Turmequé tiende a naturalizar la violencia invisibilizando la violencia escolar, donde los mismos sistemas amplios, como la Comisaría y la Alcaldía, significan la violencia escolar como una "exageración" o un “escándalo" y como un fenómeno que hace parte del proceso evolutivo escolar de los niños, niñas y jóvenes; desconociendo el sentir de los estudiantes, anulando su participación, observándolos desde el déficit y desconociendo sus procesos de autonomía que evidentemente les permitiría co - evolucionar hacia el cambio de las dinámicas relacionales. Teniendo en cuenta lo anterior, al naturalizar de esta manera la violencia, se invalidan de la misma manera situaciones en las que atentar contra la propia vida se convierte en formas de "desahogarse" justificando el "no suicidio" y desconociendo lo que no es dicho. Sin embargo los actores participantes refieren como eventos significativos los suicidios de adolescentes en relación con la violencia escolar: "NA3. Ellos se sienten mal, porque los 
amenazan y por eso se suicidan, por eso hay tantas muertes de adolescentes en el mundo." (ESC 3 , fila 61$)$

Esta naturalización, se termina de configurar en el Municipio dado que aunque los actores inmersos en el sistema social no niegan la existencia de la violencia, la aceptan como parte de la cultura y como una característica más del campesino y ciudadano Boyacense:

"PA2. Pues yo la verdad creo que eso del matoneo no es tan fuerte aquí como en otras partes, uno se da cuenta en las noticias por ejemplo, como esos niños de Bogotá se pelean y llegan a esas cosas. Pero pues acá el municipio se caracteriza por ser una zona muy pacífica.

PA3. Yo estoy de acuerdo aquí somos muy pacíficos, lo niños no ven cosas malas y violentas en las calles, el campo es bonito y tranquilo, y uno como padre le intenta enseñar al chino lo mejor que pueda.

I2. Siendo un Municipio pacifico como ustedes dicen, ¿porque creen que los niños si refieren situaciones que les hace pensar en la violencia escolar?

PA4. Yo creo que si somos pacíficos, pero hay algo que no podemos ocultar y es que aquí se da mucho el machismo, puede que en la calle los niños no vean personas peleando, pero si las ven en la casa cuando el papa le pega a la mama, o cuando los papas les dicen groserías o los tratan mal, o cuando los tienen como las mandaderas de los papas.

PA5. Es cierto muchos papas se pasan de autoritarios y tratan a sus hijos como un trapo, tampoco se puede decir que no ven cosas en la calle porque cuando 
llegan a la calle ven a los adultos borrachos y peleando o los niños acompañando al borracho." (ESC 2, fila $82-86$ )

Es aquí donde entra en juego las interacciones construidas en el sistema escolar, donde al ser cuestionada el surgimiento de la violencia escolar en un contexto académico se posibilita dar aperturas para conversar sobre el fenómeno de la violencia que culturalmente se encuentra naturalizado. Esta emergencia de apertura permite coincidir en una realidad común donde de la violencia se da surgimiento la violencia escolar (concepto aprendido en el contexto escolar por los participantes), por tanto el fenómeno es visualizado como una situación que puede permear los procesos de autonomía en los cuales se exacerba la sensación de miedo y la palabra como acción que destruye la integridad de quien está inmerso, generando sensaciones altamente desvalorizantes, incurriendo en la indiferencia y el rechazo:

"Esto del matoneo o bullying, es un tema que a veces evadimos, mmm, pues por lo menos en Turmequé, pensando que esto no sucede, que los niños son sanos, que el pueblo es sano, y en realidad no todo es color de rosa; evidentemente el Municipio vive rodeado de violencia y los niños la replican en sus salones, solo que nosotros los adultos no queremos verla porque no sabemos cómo esquivarla o como justificar... mmm... lo que hacen los adultos, pelear, tomar, regañar, creer que ellos no se dan cuenta, y seguir fomentando la violencia para las generaciones futuras... mmm... es una zona de confort, de la que tenemos miedo de salir... entonces llegan ustedes y hablan de eso y claro nos chocamos porque nos damos cuenta que nosotros también propiciamos el Bullying...” (ESC 5, fila 29)

Las relaciones de poder se encuentran mediadas por los diferentes ciclos vitales, donde en la medida que los niños, niñas y jóvenes van creciendo se empoderan frente a nuevas versiones de 
jerarquía respecto a sus compañeros de grados inferiores, personas que por sus "diferencias" físicas se convierten en objeto de burla, rivalidades académicas por menciones otorgadas a sus capacidades, observando al profesor, en algunas ocasiones, como un gestor que mantiene y potencializa la pauta al reconocer a unos y desvalorizar a otros según sus logros; visualizando los órdenes de poder construidos socialmente.

En el subsistema escolar surgen niveles de relación que diferencian a unos grupos de otros, por sus características interacciónales, donde los niños que hacen parte de la violencia escolar son vistos como líderes de grupos por su niveles de influencia, relacionada con el manejo del control y la intimidación como parte de estrategias que permiten mantener su posicionamiento como líderes. Desde el sistema escolar se percibe una fuerte relación entre la familia y la configuración de la violencia escolar, donde se observa cómo la vinculación o desvinculación con la familia genera niveles de relación con sus compañeros de clase; en este sentido, al sentirse los niños desvinculados de su sistema familiar buscan nuevas formas de vincularse donde sea posible la satisfacción de sus necesidades y un posicionamiento desde el respeto y el manejo de autoridad. De las versiones que son traídas al presente respecto a las características de los niños que violentan, se refiere la superioridad percibida de estos niños y sus condiciones psicológicas que los muestran como personas "traumadas" con relación a una desvinculación con la familia ya sea por falta de amor, apoyo, acompañamiento y atención.

De lo anterior, se configuró una comprensión que dio cuenta de una emergencia donde los actores participantes manifiestan una necesidad por vincularse afectivamente con su familia, donde el afecto y el amor se convierten en un punto importante para el desarrollo de los niños, niñas y jóvenes en su contexto escolar; así como emergen las estrategias traídas de casa como posibilitadoras de cambio. 
De igual manera, se resignifica la figura del profesor desde una visión más humana, donde se acepta el distanciamiento que genera el posicionarse desde una figura de poder, emergiendo una necesidad de escucha y apoyo:

"P1. Yo creo que hay algo importante que está pasando con los jóvenes y los niños y es que a veces requieren y necesitan que nosotros como adultos, como profesores, como figuras de autoridad, los escuchemos más, y estemos más al pendiente de sus necesidades. A veces nos encargamos de ver solo lo que nos interesa como su estado académico y disciplinario, pero no, hay algo que vaya más allá de eso.” (ESC 3, fila 85)

\section{Contexto interaccional}

El contexto interaccional de la violencia se organiza en rituales de interacción propios del Municipio donde los días de mercado se convierten en un contexto que propicia las relaciones interpersonales y la participación en experiencias que activan las redes sociales de las personas, donde el consumo de alcohol se significa como algo "autóctono" y que posibilita, una vez más, el posicionamiento de la persona con respecto a los otros:

PSCO "Los hombres de aquí del pueblo son machistas, los lunes vienen ellos traen sus cositas a vender sus curabas, sus papas, sus cositas y vendiendo esas cositas, van tomando, tomando, tomando, entonces llegan a la casa sin el mercado, si llegan a la casa borrachos, y llegan a discutir con la esposa.... si llegan a la casa borrachos, y llegan a discutir con la esposa, entonces esa violencia es muy marcada, la violencia intrafamiliar" (ESC 1, Fila 
En este sentido, tal como se mencionó anteriormente, la violencia se ha configurado en modos de relación de los habitantes del Municipio que se naturalizan y se cristalizan en el tiempo, y que al traspasar al contexto escolar se organizan formas de interacción entre docente - estudiantes, estudiante - estudiante, estudiante - docente, docente - docente que contribuye a hacer más de lo mismo y a continuar manteniendo la pauta. El contexto interaccional surge en escenarios como el patio de la institución, áreas comunes y puerta de entrada del colegio. Es así, que las interacciones estudiante - profesor deja entrever como las relaciones configuradas alrededor de la autoridad lleva a situaciones como "regañar, poner sanciones o escribir en el observador del alumno una nota" generar un distanciamiento vincular entre alumno-profesor.

Dentro de la pauta de interacción emerge una sensación de satisfacción que dentro de los órdenes de poder posiciona al otro desde la agresión verbal y subvalorando. Como parte de la secuencia interaccional se observa como los niños, niñas y jóvenes al desvincularse de su familia o de las personas representativas para ellas, buscan nuevas formas de vincularse procurando liderar grupos pequeños de su subsistema escolar donde puedan ser significativos por medio de la adquisión de poder - intimidación; en este punto de la secuencia los niños del subsistema escolar o se unen al grupo de los nuevos líderes o se dejan intimidar.

Al comprender la violencia desde los órdenes de dominio y control, se observa que el combatir situaciones de violencia escolar requiere que tanto la persona como la sociedad reconozca su participación y su poder de decidir en ciertas circunstancias de la vida lo que fortalece sus procesos identitarios y sus procesos de autonomía hacia la co-evolución. Teniendo en cuenta lo anterior, a medida que el sujeto se va sintiendo reconocido por 
parte de los demás va adquiriendo cierta autoridad lo que permite obtener respeto y un sentido de liderazgo o de poder y lo que a su vez fortalece procesos de autonomía de las personas.

En el sistema educativo el aula de clases se convierte en un contexto interaccional donde se posibilita el surgimiento del sujeto autónomo. En este sentido la pauta interaccional emerge cuando los niños, niñas y jóvenes a partir de la toma de decisiones otorgada por el sistema familiar en ciclos vitales específicos (adolescencia) inician una travesía relacional donde pertenecer a un grupo social hace parte importante en sus procesos de crecimiento, es en este momento donde como parte de la experiencia de los jóvenes actores, se encuentra el amor percibido en el sistema familiar que les permite el fortalecimiento del sí mismo y el concepto de sí respecto a las demás personas. Es así que pertenecer a un grupo, sentirse parte activa de la institución educativa, mantener vínculos con el sistema familiar y tomar decisiones encaminadas hacia una prospectiva vital genera un cambio emergente en el sí mismo y en el decidir si hacer o no parte de la configuración de la violencia.

Es aquí donde el sujeto autónomo emerge posibilitando procesos de co - evolución, en donde para los actores participantes, la confianza en sí mismos, la toma de decisiones y el amor propio hace parte de procesos que permite el empoderamiento del sí mismo donde la violencia escolar trasciende hacia la realización de un proyecto de vida donde el valor propio permite niveles de relación hacia el fortalecimiento de los procesos de autonomía. Dentro de una prospectiva vital de los actores participantes, se significa la adquisición de la felicidad como un objetivo de vida a encontrar en los seres humanos, haciendo referencia al encuentro con esta felicidad por medio de la adquisición de bases sólidas de empoderamiento del sí mismo.

Este fortalecimiento de los procesos de autonomía permite a los niños, niñas y jóvenes auto organizarse en la construcción de nuevas formas de pertenecer en el sistema escolar y nuevas 
formas de relacionarse desde la "aceptación de las diferencias", donde se caracterice como punto importante el empoderamiento del sí mismo: "Il. ¿Si pudiéramos poner un nombre diferente al matoneo cual le pondríamos? NA4. Aceptar las diferencias.” (Esc3, fila 78 - 79).

En este sentido durante el proceso de investigación/intervención los actores autónomos se auto organizan construyendo rutas emocionales para la intervención de la violencia escolar, tarjetas para la familia que generan nuevas formas de relacionarse con el sistema familiar, y canciones que empoderan a los estudiantes hacia la toma de sus propias decisiones:

“En tu corazón no guardes rencor, siempre serás el mejor, se fuerte no importa por lo que estés atravesando, aprende a ser feliz, así las cosas no salgan como tanto esperabas, hay mucho camino por vivir, todos llegamos a ese camino de quiebre, pero siempre salimos triunfadores.”(Fragmento Canción)

\section{Procesos de cambio narrativo de la violencia escolar}

\section{Historia}

Al comprender narrativamente la violencia se encuentra como narrativas dominantes de la violencia escolar como una forma "natural" y "normal" de solucionar los conflictos donde en algunos casos emerge una sensación de orgullo al empoderarse del otro por medio de la fuerza.

Se puede evidenciar a través de una narrativa dominante que el matoneo es considerado un medio para agredir al otro y hacerlo sentir mal, donde poner apodos y realizar burlas constantes potencializan el fenómeno de violencia escolar. Al llegar a grados académicos más avanzados se tiende a establecer una ventaja de poder respecto a los que se encuentran en grados inferiores. 
Se referencia a los niños que forman indisciplina como los causantes de las bromas pesadas y como estudiantes con bajo rendimiento académico. Sin embargo existe una relación entre indisciplina y liderazgo, reflejada en la influencia que se ejerce sobre otros, lo que visualiza a los niños agresores como también parte del grupo de líderes, que de alguna u otra manera a través de la fuerza y poder satisfacen sus deseos e intimidan a otros.

Como relato dominante se observa cómo los actores participantes significan las acciones y comportamientos del presente como determinantes para el desarrollo de los proyectos futuros; refiriendo la modelización de la familia como un factor determinista del comportamiento del estudiante.

Teniendo en cuenta que ecológicamente el municipio se configura en pautas de interacción violentas cuando existe una necesidad de adquirir un posicionamiento sobre el otro, se conectan historias que visibilizan el poder como foco que configuran a las interacciones, de los habitantes del Municipio, de la familia y de los niños, niñas y jóvenes desde los órdenes de dominio y control como medio para vincularse socialmente y poder pertenecer, contribuyendo a que los sucesos inesperados (violencia) que incluyen el dolor del otro se vean como "naturales" o "normales" invalidando el sufrimiento de los demás y olvidando el sufrimiento propio. En este sentido, se observa como narrativas dominantes alrededor de la pauta de violencia, la necesidad de imponerse sobre el otro para lograr conseguir poder y autoridad, donde la cultura del Municipio es permeada por figuras de autoridad que obtienen el control ya sea desde la adquisición del conocimiento o a través de la fuerza física. Por otro lado, la necesidad de poder se conecta con la necesidad del hombre de imponerse sobre la mujer, para continuar manteniéndose como figura de autoridad y no 
perder el control de la situación, de esta manera se organiza un juego relacional de competencia.

Se observa como una narrativa dominante la naturalización de la violencia como explicación de los juegos de poder:

"pues teniendo en cuenta la parte del bullying que no se hablaba de bullying, pero sí habían algunos muchachos que eran objeto de burla, de crítica constante y de que se la tenían montada a otras personas, también pienso que es un proceso que se da de cierta manera natural, hay una tendencia de buscar a alguien hacia quién dirigir una agresividad, mostrar que no hace parte de la autoridad del grupo o cosas..."(Esc1, fila 37)

Dentro de estos juegos de poder existe dentro de la semántica del relato la exclusión del que tiene menor autoridad como una reafirmación del - no pertenecer - limitando por lo tanto la co evolución de los procesos de autonomía del joven dentro de su proceso de crecimiento.

Sin embargo en búsqueda de la autonomía de los niños, niñas y jovenes tanto el sistema educativo como el sistema familiar se entrampan en justificaciones donde se culpan unos a los otros, perdiendo el horizonte que les permita anudar fuerzas como corresponsables de los procesos de co - evolución de los estudiantes.

\section{Relatos alternos y memoria}

Emerge como relatos alternos de los participantes las posibilidades propuestas como parte del cambio y que contribuyen a deconstruir la violencia y construir socialmente nuevas posibilidades de interacción. En este sentido dentro de los procesos co-evolutivos emerge la participación de otras personas que enriquecen esta experiencia de vida, donde reconocer los actos violentos 
como equivocaciones rompe con la barrera generacional que en el transcurrir de tiempo genera novedad, en las cuales la familia encabeza los procesos de cambio.

El Municipio de Turmequé ha naturalizado la violencia lo que ha generado que a través del tiempo se cristalice esta como una forma de interacción y relación, invisibilizando el fenómeno de la violencia escolar donde se le resta relevancia a los procesos de desarrollo personal de los estudiantes. Los procesos de cambio emergen cuando se acepta y visibiliza la violencia como parte de la configuración relacional del Municipio, facilitando el posicionamiento de los estudiantes y el fortalecimiento de sus procesos de autonomía, lo anterior facilita la movilización de la institución educativa y la familia como corresponsables de los procesos de desarrollo de los niños, niñas y jóvenes. Los profesores y la institución educativa se movilizan al romper las barreras relacionales entre estudiante - profesor cómo el posicionamiento de poder alimenta la pauta relacional de la violencia escolar:

"PA9. Ser más escuchados de los profesores, creo que es la clave, pero trabajar en equipo con los papas, realmente empezar a considerar al colegio como el segundo hogar.

PA10. Si esas dos cosas, escuchar, trabajar en equipo y otra más, acompañar, son cosas tanto para el colegio como para la casa.” (ESC 2, fila 93 - 94)

Emerge como relato alterno la importancia de corresponsabilizarse desde la institución educativa y la familia en la apertura de espacios que permitan visibilizar a los estudiantes desde sus recursos y no desde el déficit, donde el sistema escolar rompa las barreras de lo disciplinario y académico y se focalicen estrategias donde los estudiantes se sientan más vinculados al sistema escolar. 
Es así, que la institución educativa, la familia y los estudiantes deconstruyen el poder entendido bajo el dominio del control, visibilizándolo como un poder donde aunque se continúen los rangos de autoridad se permite contar con la voz de los estudiantes y empoderarlos hacia sus procesos de autonomía. En la institución educativa se cuenta con recursos académicos y organizacionales que permitiría una nueva acogida del estudiante donde se visualicen nuevas formas de hacer parte o pertenecer, desde una educación afectiva cercana:

"P1. Una de las cosas que dijeron los estudiantes es que se debe tener en cuenta las capacidades de los niños para hacerlos sentir parte del grupo y re - direccionar su agresividad o su tristeza a cosas más positivas para ellos. Yo creo que la cuestión de los multiplicadores esta precisamente en que desde la institución nos sentemos a ver qué actividades nos sirven para verificar esas capacidades y orientarlos hacia un objetivo común, donde podamos sentarnos todos no para regañar, poner sanciones o escribir en el observador del alumno una nota, porque eso quizás los distancia más de nosotros y los excluye, o nos pone a nosotros los adultos como los que tenemos el poder y ellos no saben nada... mmm... sino para sentarlos y sentarnos todos a compartir momentos agradables que rompan la barrera de la violencia.

PSA. Profesor eso me pone a pensar a mí en que deberían haber espacios o materias donde se hable... mmm... de la vida, pero desde la visión de un niño o adolescente y no donde se sientan obligados sino donde disfruten del espacio, donde eso que dijeron de aceptar las diferencias se dé, hasta deberían estar revueltos por salones. 
P2. Claro que no podemos dejar de lado que es esos multiplicadores también deben ser los papas, o porque no que los mismos niños enseñen a sus padres lo importante que es para ellos que en la casa también se traten bien y se amen.” (ESC 3, fila $92-94)$

Se resignifica el rol de los docentes, posicionándose desde una relación cercana con los estudiantes, observando los roles habituales de profesor (poder - autoridad) y estudiante (disciplina y aceptación) como una solución que solo ha permitido hacer más de lo mismo dentro del sistema escolar. Teniendo en cuenta lo anterior, la vinculación profesor - estudiante requiere espacios y estrategias de acercamiento donde se comprenda al estudiante desde sus capacidades, teniendo una comprensión más amplia del rol de estudiante y de su ciclo vital, donde desde la emergencia de sus procesos de autonomía se co - construyan estrategias que permitan convertir al estudiante en un multiplicador de sana convivencia, fortaleciendo el proyecto de vida y los procesos de autonomía:

"I2. Todo esto me pone a pensar en lo importante que es trabajar en equipo desde la familia, el colegio y los mismos niños, ahora a ustedes ¿Qué les gustaría aportar a los niños y niñas ahora que tienen esta nueva visión?

PSA. Es un camino largo, pero creo que los niños deberían saber que nos importan y que el colegio debe verse como un segundo hogar donde les guste llegar no solo a aprender sino a compartir experiencias, que sean los mismos niños los que ayuden a sacar a otros del matoneo.

P1. Que cada vez que van creciendo van aprendiendo a valorar las cosas, pero lo que primero deben aprender a valorar es así mismo, para que se utilice esa 
autoestima de la que tanto hablan, como un motivo para cumplir sus sueños y disfrutar esta etapa de la vida por la que están pasando.

P2. Creo que también deberían aprender a que todos somos personas, y a veces muchas cosas nos distraen y por eso, a veces... mmm... no escuchamos, pero que eso también debería tenerse en cuenta para el profesor, para que en estos espacios también nos sintamos incluidos y rompamos con eso de que el profesor es el que tiene la razón, solo por el hecho de ser profesor, cuando no es así...” (ESC 3, fila $95-98)$

Se crean como relatos alternos la posibilidad de utilizar las habilidades y capacidades de los sistemas inmersos en la violencia escolar, como fuentes de inclusión y participación social desde el liderazgo. Al igual que emerge la corresponsabilidad del sistema escolar (institución, profesores, directivos) y el sistema familiar para la visibilización del cambio. En este sentido la institución educativa se convierte en una red de apoyo y trasformación que durante el ejercicio de la investigación/intervención se potencializó generando una sensación de pertenecer a un contexto que no solo se limita a lo académico y disciplinario, sino que posibilita espacios de escucha, empoderamiento y vinculación.

La corresponsabilidad de los profesores emerge hacia la necesidad de mantener un acompañamiento continuo a sus estudiantes, donde se fortalezca su proyecto de vida y sus procesos de autonomía.

Por otro lado la corresponsabilidad de los padres emerge al comprender que para mantener una armonía entre lo institucional, lo familiar y lo personal es necesario desde casa y desde la institución educativa trabajar conjuntamente donde tanto el colegio como el sistema familiar se 
conecten continuamente con los fenómenos sucedidos alrededor del sistema escolar; así como es clave para el sistema familiar mantener un acompañamiento continuo alrededor de la escucha activa y el apoyo parental, establecer normas y limites desde la enseñanza en casa hasta lo disciplinar en la institución educativa, y empoderar al estudiante hacia su toma de decisiones desde el fortalecimiento del sí mismo. En este sentido si se establecen relaciones basadas en el respeto, afecto, apoyo y escucha desde el sistema familiar y el sistema educativo es posible generar posibilidades de vinculación desde la cercanía, donde los estudiantes puedan ser capaces de tomar decisiones que les generen bienestar a ellos mismos y a las demás personas.

En este fortalecimiento del sí mismo, emerge la utilidad de las capacidades individuales para trasformar y asumir posibilidades de cambio desde el empoderamiento del sí mismo, donde se retoma el liderazgo y la inteligencia como capacidades a potencializar. Al igual que emerge la inclusión como una posibilidad para vincular no desde el miedo o el rechazo, sino desde la posibilidad de emerger diferente dentro de un grupo social, conectando lo anterior con la corresponsabilidad de la familia e institución educativa en estas nuevas formas de vincularse desde la aceptación de las diferencias.

Es así que se resignifica la violencia escolar hacia nuevas formas de relación desde la vinculación estudiantes, familia e institución educativa, donde emergen nuevas estrategias de intervención desde la acogida vincular del resto del sistema escolar, el sistema familiar y los sistemas amplios.

De esta manera, surgen como relatos alternos posibilitadores de cambio la importancia de la institución educativa de establecer un trabajo en equipo con padres y docentes, dado a que se considera una dupla potente para abordar las diferentes temáticas propias de la violencia escolar, y darles orientación de manera oportuna a través de la escucha y el apoyo. En este sentido, se 
hace referencia al dialogo como generador de cambios, dado que posibilita aperturas a nuevas miradas donde prevalece el sentir y el cuidado de la otredad, teniendo como referente que un mejor entorno se construye a través de la paz y no por medio de la violencia.

Por tanto los fines compartidos entre familia e institución requieren de esfuerzos, compromisos y acciones que se puedan vivir desde lo colectivo, y de esta forma poder generar una visión generativa que pueda ser trasmitida a los niños y jóvenes.

La familia por otro lado en los procesos de deconstrucción y construcción de la violencia escolar reconocen que ser co - responsables de sus hijos requiere vincularse en todos sus procesos de desarrollo y evolución según su ciclo vital; donde reconocer que a medida que se va dando el crecimiento, no es posible desligarse como padres y entender la autonomía como una desvinculación de la familia, sino que se requiere de un acompañamiento donde tomar decisiones haga parte de sus vidas con el fin de fortalecerlos como seres autónomos y permitirles interactuar en otros contextos y sistemas:

"PA2. Si ellos necesitan confianza de nosotros, pero eso no se gana a los golpes y regaños, se gana, preguntándoles como están, abrazándolos de vez en cuando, diciéndoles que los queremos, compartiendo en familia y permitiendo que decidan por si solos.” (Esc 2, fila 109)

En este sentido, para la familia es importante las diferentes formas de educar al niño, niña o joven, donde se haga evidente desde el diálogo, fenómenos del diario vivir que enseñen situaciones tanto seguras como de riesgo, que permitan la toma de decisiones desde el acompañamiento y el apoyo del adulto durante los procesos de crianza. 
Desde un punto de vista más individual los actores participantes comparten desde su experiencia los niveles emocionales a los que llegan los niños, niñas y jóvenes permeados por la violencia escolar, donde dan surgimiento a la "autoestima" como medio para afrontar generativamente y desde su subjetividad este fenómeno. En este sentido, la "autoestima" se significa como parte del crecimiento personal, relacionada con el empoderamiento del sí mismo y la toma de decisiones:

"NA3. Yo creo que todos los niños deberían aprender a defenderse, pero no a golpes, sino emocionalmente, ser más fuertes en su autoestima, porque el valor esta sí mismo y en su capacidad para salir adelante sin importar lo que digan los demás.” (Esc3, fila 69)

Emerge en la memoria la utilidad de las capacidades individuales para trasformar y asumir posibilidades de cambio desde el empoderamiento del sí mismo, donde se retoma el liderazgo y la inteligencia como capacidades a potencializar. Al igual que emerge la inclusión como una posibilidad para vincular no desde el miedo o el rechazo, sino desde la posibilidad de emerger diferente dentro de un grupo social. En este sentido los actores participantes manifiestan su intención por corresponsabilizarse entre el mismo sistema escolar y los estudiantes hacia la visualización del cambio, donde emergen posibilidades de trasformación:

"NO6. Yo creo que todos tenemos capacidades, pero creo que los niños que hacen matoneo llevan sus capacidades hacia el lado negativo, ellos pueden ser líderes porque tienen influencia en otros, pueden salir de las dificultades más fácilmente y son fuertes emocionalmente, pero que les hacen falta un empujoncito, porque todos los excluimos o les tenemos miedo, sino somos de su grupo, creo que deberíamos integrarlos más.... Los niños que reciben 
matoneo son inteligentes, aprender rápido y tienen otras capacidades, solo que no se dan cuenta que son buenos, en esto, lo otro y se dejan influenciar, y cuando nos burlamos de ellos también los excluimos y se quedan solos pensando que son bobos o feos, cuando no es así, a ellos también deberíamos incluirlos más.

NO1. Toca explotar esas capacidades que les sirve para hacer mal las cosas para incluirlos más en los grupos y comprender que a veces también se sienten solos, o porque esa es la forma de aprender a resaltar o solucionar las cosas." (Esc3, filas $76-77)$

\section{Categorías Emergentes: La emergencia del vínculo como potencializador del cambio.}

Dentro del proceso de investigación/intervención el vínculo como un potencializador del cambio se considera una categoría emergente dado que aunque no se encuentra previsto dentro de los anteriores conceptos metodológicos resultó siendo una categoría de alta importancia para la comprensión del fenómeno. En este sentido el vínculo para la investigación/intervención se comprende como un proceso inherente en el crecimiento y co - evolución de los estudiantes que permite movilizar ecológicamente hablando a los actores desde el cuidado del otro, la corresponsabilidad y el acompañamiento, que potencializa los procesos de autonomía

\section{Pertenencia}

Los niños, niñas y jóvenes dan cuenta de su autonomía cuando empiezan a aglomerarse y a considerarse unos a los otros como redes de apoyo facilitando el trabajo en equipo donde se 
permiten crear nuevas comprensiones de la violencia que observan en su sistema escolar, así como autorganizarse para crear nuevas posibilidades de cambio. Al sentirse parte de un grupo se observa cómo la necesidad de ser escuchado permite en los participantes comprender que no se puede anhelar la independencia, la toma de decisiones y la autonomía si no se tiene el apoyo de un grupo, donde generar vínculos hace parte esencial del crecimiento personal. En este sentido la familia y la institución educativa se convierten en un motor de apoyo, escucha y acompañamiento continuo.

“NO1. Los que más conocemos a los jóvenes somos nosotros los jóvenes yo creo que lo que más debemos hacer es acercarnos a tanto los niños que reciben matoneo como los que los hacen y entre todos mirar que todos tenemos capacidades diferentes y que son esas capacidades las que debemos explotar"(ESC 3, fila 74)

En este orden de ideas cuando los niños, niñas y jóvenes cuentan con las bases vinculares suficientes (apoyo, orientación, escucha) se narran generativamente desde los recursos donde se potencian las interacciones basadas en una convivencia pacífica:

"N2: Bueno para eso necesitamos empezar desde el hogar, dialogando con nuestros padres, dialogando sobre lo que estamos haciendo acá, y después el colegio hablar con las directivas, hacer campañas contra el matoneo eh...la prevención del Matoneo eh.. Por lo cual esto ira haciendo pensar a las demás personas que hablen con sus padres y hacer más cosas como las que estamos haciendo este día para determinar con ellos.

N3: Eh...púes tanto en casa como en el colegio los padres y los docentes nos deben dentro de sus clases preguntarnos acerca de lo que está pasando con el 
matoneo y dar soluciones, charlarlo en casa también para que eso no ocurra en este medio." (ESC 4, fila 42-43)

\section{Contexto interaccional}

Como secuencia interaccional se observa un bucle recursivo organizado alrededor de todos los personajes que hacen parte de la configuración de la violencia escolar en el Municipio de Turmequé. Por una parte los padres se desvinculan progresivamente de sus hijos a medida que el niño, niña y joven va pasado de un ciclo vital a otro, asumiendo que dentro de su proceso de emancipación ya no requieren de la cercanía, apoyo y afecto de los padres. Por su parte en la institución educativa se considera que las relaciones configuradas en el respeto y tolerancia son aprendidas en casa por lo tanto en el sistema escolar se limitan a mantener relaciones desde el orden, la autoridad y la disciplina, y no desde el vínculo. En este orden recursivo los niños, niñas y jóvenes buscan nuevas formas de vincularse con sus compañeros de clase ya sea desde funciones contenedoras, destructivas y forzadas alrededor de la violencia escolar, o desde funciones movilizantes, generativas y aceptadas alrededor del empoderamiento del sí mismo y los procesos de autonomía hacia la co - evolución.

\section{Relatos alternos}

Dentro del proceso de investigación/intervención emergen como relatos alternos la importancia de mantener el vínculo con los niños, niñas y jóvenes donde los padres en su labor de referentes para sus hijos, son fundamentales, ya que las vivencias diarias alrededor del afecto, apoyo, diálogo y escucha activa fortalecen la prospectiva vital de los estudiantes. En este sentido se redefine el desarrollo de la autonomía de los niños, niñas y jóvenes no como un momento de 
plena libertad, sino como un momento donde se es necesario acompañar desde el rol parental y la institución educativa en la toma de decisiones y en la visualización hacia el futuro:

“G4. Nosotros quisimos recoger la formación de los niños en cuatro etapas, entonces la primera hicimos el dibujito de la semilla el cual son los padres cuando engendran al hijo se puede decir, la raíz el, la base principal la cual son los valores con los que vamos a formar a los hijos avanzamos a la primera ramita de la matica es el periodo de lactancia dentro de ese periodo de lactancia y crecimiento le damos a conocer a los niños lo bueno y lo malo ósea, a darle el poder de decidir qué es lo bueno y lo malo ósea que ellos tengan consigo un mérito en la vida, en la segunda etapa vemos sigue siendo la raíz de toda la familia, la familia tiene que ser el centro de atención y el centro de formación de todo a ellos le van creciendo, le van creciendo las ramita y en cada ramita quisimos expresar cada una de las etapas de la vida en la primera etapa el jardín, la primaria y el bachillerato, y dibujamos una nubecita con lluvia y la lluvia digamos que todo arbolito mientras van creciendo son cosas buenas que le deja la vida, digamos la lluvia pude ser enseñanzas de la vida, es fue lo que quisimos decir con eso, para que ellos vallan conociendo la vida y las diferentes etapas, en la siguiente hoja es donde escogen el camino del bien y del mal si es bueno o malo entonces va a hacer un árbol seco sin frutos sin hojas sin nada, ósea a hacer un árbol como decir una persona insípida que hace las cosas porque le toca porque si o porque no simplemente hace las cosas mal hechas, y por último, un arbolito muy bonito en el que escogió el camino del bien tiene muchísimas ramas las cuales dice digamos que nunca se ha encontrado con una mala decisión en la vida o algo y tiene frutos tiene frutos 
como el respeto, la autoestima que es muy importante si uno no tiene autoestima está en la mala, porque simplemente si uno no se piensa respetar a uno mismo y motivarse uno mismo nadie más lo va hacer y va hacer un árbol con muchos frutos dios quiera que tenga su familia sea exitoso y ya" (ESC 2, fila 120)

En este sentido, se hizo importante para los actores participantes vincularse desde una función creativa generativa entre institución educativa y sistema familiar, con el fin de proponer nuevas formas de mantener el vínculo continuo con los jóvenes, y hacerlos sentir parte de un sistema que los apoya, los reconoce, los comprende y los orienta.

Por otra parte, el diálogo es una necesidad que existe en los actores involucrados fundamental para construir soluciones que movilicen hacia el cambio, partiendo de acuerdos que beneficien a toda la comunidad, incluso al municipio.

Un escenario que propició la emergencia de relatos alternos fue el llamado "sembrando papas” donde una actividad de construcción de un árbol permitió diversas comprensiones del fenómeno. El árbol es utilizado como una metáfora para hacer referencia al cuidado, el cultivo y la transformación por la cual todas las personas inmersas en un sistema familiar deben vivir para posibilitar pautas de vida que permitan sentirse vinculado y parte de un sistema.

\section{Autorreferencia}

Las investigadoras/interventoras al configurar un espacio conversacional en cada uno de los escenarios que se llevaron a cabo emergieron procesos autorreferenciales que dieron cuenta del fenómeno de estudio y de los procesos internos qué cada una vivió durante el desarrollo de la investigación, por lo tanto era importante tener claro que personas iban a ser convocadas para el 
desarrollo de los escenarios, ya que iban a ser la fuente de la comprensión de cómo la violencia escolar estaba organizada a partir de una construcción social.

Se hacía necesario llevar a cabo lecturas ecosistémicas y complejas a través de una metaobservación y recolección de datos necesarios que permitiera la comprensión de la violencia en el contexto escolar de Turmequé. Los espacios conversacionales conducirían a crear bucles recursivos que evocaran y exploraran de qué manera estaban organizadas las narrativas conversacionales, posicionándolas en emergentes, privilegiadas y dominantes, reconociendo cuales son las pautas relacionales y como se llevaría a cabo la comprensión del fenómeno de estudio: "Para las investigadoras/interventoras era importante indagar de qué manera la violencia escolar se formaba a través de una construcción social, a partir de experiencias vividas ya sean propias o de otras personas". (Esc 2, línea 21)

\section{Pertenencia}

En este apartado se hace necesario descubrir cuáles son los actos a los que acuden con mayor frecuencia los niños, niñas y jóvenes en el fomento de mantener la pauta de violencia escolar, y cuales acciones donde se quiera evitar, este espacio propiciaba en las investigador /interventoras realizar una meta observación para comprender cómo se ha configurado la violencia escolar en la institución educativa.

“En este apartado se hace necesario descubrir cuáles son los actos a los que acuden con mayor frecuencia en el fomento de mantener la pauta del matoneo" (Esc 2, línea 35) 
Por tanto es relevante entender cómo se tejen las relaciones al interior de las familias, a partir de sus creencias e ideologías. En este sentido, el espacio que propicio la investigación/intervención permitió construir grupo, en el cual las investigadoras/interventoras eran una extensión más del grupo que co - evolucionaba, lo que permitía corresponsabilizarse de los procesos de desarrollo y fortalecimiento de la autonomía, así como también el espacio permitió empoderarse personalmente de la necesidad de crear y unificar la red.

Lo anterior permitió crear una biosfera terapéutica de cambio en la cual la voz del otro era parte importante y primordial para el crecimiento del sí mismo y del grupo que se unía hacia un mismo objetivo: aceptar las diferencias del otro, fortalecerse como agentes autónomos, participar micropolíticamente. Es así, que las investigadoras/interventoras se conectan con la necesidad de los estudiantes de ser escuchados, donde el escenario se convierte en un espacio que propicia la expresividad, la participación y el empoderamiento.

Con lo anterior, se asocia lo dicho por los actores participantes con los objetivos de la investigación y el fenómeno donde los procesos de autonomía se encuentran inmersos en la re significación de la violencia escolar.

\section{Contexto interaccional}

Conocer el contexto interaccional era parte importante de las investigadoras/ interventoras, a través de lecturas ecosistémica, se hacía necesario observar cuales son las entidades, actores como familia e institución educativa que están presentes y vinculadas en brindar orientación a la población sobre dicho fenómeno. 
"Para las investigadoras/interventoras era importante indagar de qué manera el matoneo se formaba a través de una construcción social, a partir de experiencias vividas ya sean propias o de otras personas" (Esc 2, línea 21).

Comprender cuál es el rol que ocupa el docente y cuáles son las acciones a desarrollar para tener un manejo adecuado frente a situaciones donde están implicadas las pautas comportamentales de la violencia escolar, y de que forma la familia se ha involucrado en este entramado.

"Para las investigadoras es indispensable observar cual es el rol que ocupa el docente y cuáles son las acciones a desarrollar para tener un manejo adecuado frente a situaciones donde esté implicado pautas comportamentales de matoneo"(Esc 2, línea 29).

De igual manera se llevó a cabo una metaobservación en los relatos recogidos del escenario de contextualización, donde las entidades referían el papel del hombre en su rol dominante.

"Las investigadoras/interventoras dan cuenta de su percepción desde su naturaleza femenina en la comprensión del sentir de las mujeres de Turmequé respecto a la figura masculina". (Esc 1, línea 27).

La familia, aquella institución irremplazable, es el lugar donde se debía realizar una lectura sistémica compleja de la forma en que se han organizado las vinculaciones y narrativas que rodean el entramado de aprendizajes de interacciones para los niños, niñas y jóvenes.

"Es relevante escudriñar como se teje las relaciones al interior de las familias, a partir de sus creencia e ideologías" (Esc 2. Línea 65)

\section{Narrativas (historia y relatos alternos)}


Para las investigadoras se hacía indispensable, como cada niño y niña que maneja sus propias realidades ha venido construyendo en sus significados e imaginarios la construcción del fenómeno de la violencia escolar.

Existe una corresponsabilidad, igual, en las investigadoras interventoras al estar inmersas en los procesos de resignificación de la violencia escolar; donde se percibe que en el escenario no existe esa barrera de poder, donde es posible a los actores participantes emerger de diversas formas.

Los espacios conversacionales permitió conectar el sentir propio con el sentir del otro, lo que propicio construir una la ruta emocional que quedo instaurada en el colegio, para dar apoyo y contención a quien necesite en caso de pasar por una situación de violencia escolar, así mismo con respecto a la relación con los padres en la creación de la tarjeta, y donde se podía mayor acompañamiento en la crianza por estos referentes de autoridad para posicionarse desde una mirada de confianza y seguridad en diferentes contextos relacionales, por su parte los padres cuando realizaban la figura del árbol y se trabajaba en forma de la metáfora reconocía que sus hijos era aquel arbusto que día a día se debía cultivar para formar una persona con valores, capacidades y amor incondicional.

Las investigadoras interventoras perciben cómo los procesos conversacionales permiten en los actores hacer conexiones ecológicas que empoderan los procesos de autonomía de los estudiantes.

"Las investigadoras/interventoras conectan la multitemporalidad como parte del cambio de cada persona” (Esc 1, línea 67). 
Entendida la autonomía como un proceso que se construye en otredad a partir del tiempo, para organizar los cambios emergentes de acuerdo a sus diferentes contextos de interacción.

Para la investigación este punto es relevante, que los estudiantes objeto de estudio pueden identificar como ha favorecido los procesos evolutivos en medio de la crisis que se ha podido vivir cuando se han recibido violencia escolar.

"Las investigadoras/interventoras se conectan con la necesidad de los estudiantes de ser escuchados, donde el escenario se convierte en un espacio que propicia la expresividad" (Esc 3, línea 21)

El escenario es un espacio protegido y seguro, donde sus narrativas que evocan, silencios, temores, incertidumbres pueden ser externalizados sin ninguna restricción por miedo a ser juzgado, o rechazado, por cuanto para las investigadoras/interventoras era un momento oportuno para construir cambios con los participantes.

"Las investigadoras interventoras se sienten satisfechas al observar los niveles de reflexión que han propiciado el desarrollo de los escenarios" (Esc 5, línea 28).

En este momento de la investigación se logra identificar como se ha organizado la violencia a través de una construcción social, y los actores involucrados, en cada uno de los contextos internacionales de los niños, niñas y jóvenes, es así que a través de actos reflexivos y poéticos se logra hacer visible lo que está inmerso en los participantes aunque no sea evidente.

"Estas narrativas dan motivos a las investigadoras/interventoras para escuchar las voces de los niños, niñas y jóvenes que se encuentran silenciadas por la misma naturalización de la violencia e invisibilidades" (Esc 1, línea 31) 


\section{Discusión}

Para la elaboración de este apartado, se hizo pertinente realizar un recorrido por los ítems que se desarrollaron a lo largo de la investigación/intervención partiendo por el fenómeno de estudio, estados del arte y sistema teórico, para realizar la comprensión de la concurrencia, antagonismo y complementariedad del fenómeno.

Esta discusión permite comprender cómo se ha construido la violencia escolar en el Municipio, a partir de la construcción social y actos narrativos conversacionales que dan cuenta de las experiencias de vida que se construyen con la otredad. Así como también, devela los procesos de reconfiguración narrativa y las emergencias que posibilitaron el cambio en el 
proceso de intervención. Se hizo indispensable para este ejercicio la autorreferencia, donde se amplían las comprensiones y los procesos de resignificación de la violencia escolar.

De igual manera estuvo presente en la construcción de la discusión los conceptos metodológicos que se elaboraron para la comprensión de la violencia en el contexto escolar, es así que se mencionaba, la violencia escolar como una construcción social, la ecología de las interacciones desde la construcción de mundos posibles y la co-evolución y la emergencia del sujeto autónomo desde la multitemporalidad.

\section{Configuración de la pauta relacional de la violencia.}

Con el fin de generar procesos de comprensión de la construcción social de la violencia y la reconfiguración narrativa de la violencia que se presenta en el contexto escolar, era necesario para las investigadoras/interventoras posicionarse desde una epistemología de segundo orden que permitiera comprender cómo se configura y se significa la violencia en los sistemas escolares desde una intervención clínica sistémicamente orientada, en la cual la complejidad posibilitara niveles de movimiento diferentes en los procesos de intervención.

En este sentido, tal como lo refiere Munné (2004) no es posible la complejidad si no se entienden los grupos sociales, lo que lleva a la investigación/intervención a comprender como se está construyendo socialmente la violencia.

En este sentido al posicionarse desde una psicología sistémica compleja y como parte de un antagonismo de la investigación/intervención era necesario comprender tanto a los participantes como a las investigadoras/interventoras como agentes autónomos que se autoorganizan para crear nuevas posibilidades que permitieran co - evolucionar en grupo, activar la función creativa que deconstruyera la violencia y construyera distintas formas de vincularse desde la diversidad y 
el pertenecer. Lo anterior se hace posible a partir de espacios conversacionales que emergieron durante los encuentros, donde cada actor participante y las investigadoras/interventoras se autoorganizaron en un espacio de participación y de expresión emocional; por lo tanto a medida que los escenarios avanzaban se tejía una red vincular que co - evolucionaba hacia un mismo objetivo: deconstruir la violencia escolar.

Posicionarse desde la construcción social de la violencia implicó para la investigación/intervención realizar lecturas contextuales, que dieran sentido al esbozo cultural, social y político del Municipio de Turmequé, lo que posibilitó comprender pautas interacciónales violentas vividas desde la experiencia en sistemas familiares, escolares y sociales que permeaban la configuración relacional del niño, niña o joven en su sistema educativo. Lo anterior como concurrencia, da sentido a lo propuesto por Castillo (2011) al considerar la sociedad Colombiana como partidaria de hechos violentos que se establecen desde entorno familiares. en este sentido las organizaciones familiares, la cultura y la condición socio - política del país emerge recursivamente en entornos contextuales tan pequeños como el sistema escolar, dado que tal como lo refiere Garzón (2006) la violencia en la familia es construida desde una cultura Colombiana de la violencia con incidencia social y política.

Tal como lo refiere Kaplan (2009) para explicar un fenómeno social es necesario observar, comprender y analizar las características estructurales de los grupos sociales, en este sentido la pauta interaccional configurada desde los macro y micro sistemas en la construcción social de la violencia, como parte de una complementariedad pone en evidencia una organización social desde los órdenes de dominio y control como una estrategia para posicionarse implícitamente como figura de autoridad sobre el otro, dando cuenta de una búsqueda de reconocimiento y una escases de recursos para la solución de problemas. 
Al configurarse la violencia en modos de interacción específicos de un contexto social se cristaliza y naturaliza la organización como formas rígidas de relacionarse con el otro, que se trasmiten de generación en generación, lo que complementa lo referido por Hernández y Bravo (2008) al manifestar que la ritualización generacional conlleva al surgimiento de formas de interacción que llegan a trasmitirse desde el sistema familiar a un entorno socialmente estructurado; que reafirmando con lo dicho por White (2002) y Foucault (1983) las personas al separarse o al naturalizar los fenómenos "problemas de su sociedad" se cosifican con el fin de mejorar y extender el control social que subyuga a los demás por medio del poder.

Las versiones dominantes que cristalizan la pauta interaccional llevan a comprender como la cultura justifica la violencia invisibilizando los factores de vulnerabilidad que se desprenden de ella, por medio de actos semánticos que destruyen interaccionalmente al otro. De esta manera, la violencia es construida, también co - construida, por seres micropolíticos (Municipio, estudiantes, entes territoriales e institucionales, sistema escolar, sistema familiar), que se organizan dentro de procesos sociales, culturales y políticos que crean realidades distintas sobre las cuales el ser humano opera dentro del mundo (Pakman, 2006).

En este mismo orden de relacionamiento, se da surgimiento a un antagonismo, que devela como por medio del dominio y el control se construyen niveles de relación entre adultos niño/joven, posicionando al adulto como una figura de autoridad que subestima la capacidad creativa de los niños, niñas y jóvenes como agentes autónomos visibilizándolos desde miradas deficitarias. Sumado a lo anterior, esta configuración relacional entre adulto-niño/joven lleva a una comprensión de la autonomía desde la desvinculación para las figuras paternas, fomentando una extinción de la voz del niño, niña o joven en los procesos de participación familiar y social 
creando una preocupación superficial por sus procesos de desarrollo; nivel de relación que se replica en el contexto escolar entre profesor/estudiante.

Al aterrizar la violencia al contexto escolar, en una búsqueda por vincularse desde la emoción, la participación, la aceptación y el reconocimiento se organizan modos de relación entre los estudiantes en los mismos ordenes de dominio y control construidos socialmente, convirtiendo la pauta interaccional en un bucle recursivo que fragmenta los recursos y las posibilidades creativas que los llevan a construir nuevas formas de relación desde el respeto y la aceptación de lo diverso.

Por otro lado el antagonismo rompen los esquemas bivalentes de víctima - victimario dado que el dilema posiciona tanto al agresor como al agredido en un mismo nivel de sufrimiento, entendiendo la necesidad de las dos partes por pertenecer haciendo uso de los recursos con los que se cuenta según los espacios de movimiento que ha construido. Es así que, por una parte la búsqueda por pertenecer y la escases de recursos lleva a los estudiantes a vincularse desde el dominio, la autoridad y el control; sin embargo, por otra parte la violencia se convierte en una forma de reconocer al otro, donde la misma escases de recursos imposibilita empoderarse desde los procesos de autonomía, detener la violencia y vincularse de diferente manera.

Siguiendo como complementariedad lo dicho por Hernández (2010) los conflictos sociales se pueden entender como expresiones del sufrimiento humano por la imposibilidad de ejercer la autonomía en diferentes contextos vitales manteniendo una perturbación a nivel comunicacional en los diferentes sistemas asociados, donde las creencias, los valores, el conocimiento y el reconocimiento operan en la construcción de vínculos y los procesos de autonomización.

Es así, que los estudiantes desde su ciclo vital como seres micropolíticos construyen realidades organizadas en un tiempo que es actual, novedoso y creativo para ellos, pero 
modelados por un tiempo que se cristalizó en historias y acontecimientos violentos, que perpetúan la violencia.

Niño y Castañeda (2010) afirman que la perspectiva sistémica familiar da cuenta de las diversas construcciones tanto en lo ecológico como en lo contextual, por tal motivo la construcción de las realidades de los niños, niñas y jóvenes se relaciona directamente por la forma en que a través de su desarrollo integral aprenden a relacionarse con el medio que los rodea a través del tiempo. Dando surgimiento como concurrencia en voz de Boscolo y Bertrando (1996): “El conocimiento del tiempo es, por tanto, múltiple.” (pág. 38), ya que la construcción de la violencia se ha organizado bajo un esquema de pautas relacionales cotidianas.

En ese orden, siguiendo las lógicas complejas biologicistas de Kauffam (2003), la configuración de la violencia en el medio social y cultural del municipio se convierte en un régimen ordenado permeado por un equilibrio inestable, donde la naturalización y la cristalización de la misma cumple la función de atractor interno para los agentes autónomos quienes son atraídos para mantener la misma pauta y el mismo orden de equilibrio, considerando lo anterior un antagonismo dada la comprensión compleja que se le da al fenómeno.

\section{Reconfiguración narrativa de los procesos de autonomía hacia la coevolución.}

Posicionándose desde la complejidad, en una psicología clínica sistémicamente orientada y comprendiendo a los participantes y las investigadoras/interventoras como agentes autónomos, se crearon escenarios de intervención que posibilitaran la emergencia de la autoorganización hacia lo adyacente posible. Es así, que la investigación/intervención pensada desde los procesos de consultoría posibilitaba escenarios vistos como una biosfera (Duque, 2015) que permitieran a los agentes autónomos co - construir nuevas posibilidades de movimiento generando apertura 
hacia adyacentes posibles (Kauffam, 2003). Es de esta manera que los escenarios se convertían en un entramado autoorganizado que incluía a las investigadoras/interventoras y a los actores participantes como co - constructores de conocimientos novedosos que deconstruían la violencia y daban surgimiento a la configuración de relaciones en el contexto escolar desde la aceptación de lo diverso, por medio de diálogos conversacionales que producían movimientos reflexivos.

La violencia escolar se convertía en el síntoma que convocaba, dada su construcción relacional en los contextos académicos. En ese sentido los niños, niñas y jóvenes como agentes autónomos saturados, hacían un llamado a la re - organización del sistema que entraba a un régimen caótico debido a la alta sensibilidad a las condiciones iniciales. Lo anterior sumando a la inmersión de la investigación/intervención, como biosfera terapéutica de cambio y como atractor externo, género bifurcación posibilitando apertura hacia adyacentes posibles que posicionará a los participantes y a las investigadoras/interventoras como agentes de cambio que facilitaran una conectividad ecológica en el sistema.

La ecología de las interacciones propone encontrar aperturas que favorezcan los procesos coevolutivos de los niños, niñas y jóvenes interviniendo relacionalmente tanto a nivel interno como externo en el sistema, ya que una convivencia que este mediada por normas que amplíen el dialogo y la resolución de conflictos permiten una organización coherente entre el hacer y el saber; como concurrencia Gergen y Keye (1996) menciona que a través del tiempo el yo y sus emociones, se han catalogado como algo netamente desarrollado dentro del individuo, sin percatarse que dichas emociones involucran y se construyen por las relaciones que el individuo sostiene con el exterior.

Es así, que se da surgimiento a los adyacentes posibles los cuales permitieron que los agentes autónomos se autoorganizan micropolíticamente para transformar desde la conectividad 
ecológica la configuración relacional que construye socialmente la violencia. Pakman (2006) considera que como ser micropolítico el ser humano tiene la capacidad de producir ciertas transformaciones en la sociedad por medio de actos poéticos que crean momentos discontinuos, generativos, interpretativos que desarticulan la continuidad dando apertura a nuevas posibilidades.

En ese sentido como parte de una complementariedad los niños, niñas y jóvenes, desde una posición política, social y autónoma se convierten en un nodo de interfaz que conecta la relación entre familia - escuela - Municipio, posibilitando apertura hacia comprender cómo estos tres sistemas interactúan hacia un mismo objetivo que los convoca desde la corresponsabilidad a pensarse como sociedad y a reinventar la realidad social. La corresponsabilidad da lugar a una apertura autoorganizativa y co - evolutiva por parte de la institución y la familia, hacia adyacentes posibles de cambio donde emergen las necesidades del sí mismo y la preocupación por el otro haciendo activa la voz del niño, niña y joven potencializando sus procesos de autonomía. Niño y Castañeda (2010) refieren que la corresponsabilidad de la familia y escuela emerge en la conversación del diario vivir que facilitaría al hijo y estudiante a configurarse en relaciones sanas.

Al organizarse micropolíticamente se generan movimientos en los sistemas que organizan su contexto relacional, deconstruyendo los órdenes de dominio y control hacia una mirada constructiva del poder (Foucault, 1983) que permita a los agentes autónomos visualizarse como líderes y empoderarse como gestores de convivencia.

La autoorganización permitió la aglomeración de los niños, niñas y jóvenes como agentes autónomos que co - evolucionaban en grupo, aceptaban la diversidad y generan aperturas necesarias para invitar a los sistemas circundantes a conversar sobre aprendizajes pertinentes 
para la vida. En este sentido, emerge la autonomía que permite a los niños, niñas y jóvenes re pensarse dentro de un contexto social, tal como lo manifiesta Hernández citando a Miermont (1995) "La autonomía es la capacidad de un sistema complejo para organizar por sí mismo sus propios comportamientos, para autodeterminarse, constituir, organizar y administrar sus propios recursos, y sobre todo para intercambiar signos de reconocimiento de esta autodeterminación en los contextos vitales que habita y que contribuye a crear”.

\section{Autorreferencia}

Hacer uso de la autorreferencia dentro de los procesos de intervención, facilitó a las investigadoras/interventoras asumirse como agentes autónomos que desde la emergencia de las epistemes, la experiencia y la sistematización posibilitó la generación de fluctuaciones y bifurcaciones dentro de un orden en el límite del caos que permitiera resignificar la violencia escolar, a partir de la co-responsabilidad, la visibilización del otro como agente de cambio y la vinculación por medio de actos narrativos, poéticos y estéticos.

En este orden de ideas, es precisamente en el relato que se le da sentido a la vida, donde haciendo uso de complejidad se fue sujeto de la incertidumbre permitiendo a través de la historia y el relato configurar el pasado, el presente y el futuro facilitarndo una organización del mundo mucho más predecible y significativa (Dante, 2006). Es aquí, donde la intervención psicoterapéutica se hace pertinente entendiendo que es en el encuentro terapéutico donde confluyen las narrativas y se flexibilizan los relatos, tal como lo manifiesta (Dante, 2006):

"Entendido en estos términos, la relación terapéutica resultaría algo semejante a un “encuentro de narrativas" y el de la terapia sería un espacio de apertura para hallar nuevos "cuadros" o "metáforas" que permitan al paciente relatar los acontecimientos desde una 
estructura narrativa, diferente a la original, capaz de conducirlo hacia un desenlace novedoso y más satisfactorio (Schafer, 1981; Spence, 1984; Duero, 2006).”

Es así, que en la intervención se propiciaron los procesos de construcción y deconstrucción narrativa, co -construyendo relatos consistentes que permitieron dar nuevo sentido a la vida y flexibilización en la búsqueda de posibilidades emergentes frente a los dilemas humanos.

La complejidad fue una invitada relevante en el proceso investigativo/interventivo, dado que la comprensión Ecosistémica de la violencia desde los órdenes de la complejidad generó aperturas y emergencias a través de actos reflexivos y recursivos que permitiera un reconocimiento desde lo valorativo y lo participativo rompiendo con comprensiones deficitarias y entrampadas entre la bivalencia de víctima y victimario.

Al ingresar como agentes autónomos en la biosfera terapéutica, se corresponsabiliza, también a las investigadoras/interventoras como agentes de cambio que rompe con los órdenes de dominio y control de las figuras de autoridad posibilitando a los actores participantes emerger de diversas formas. En este sentido, las investigadoras/interventoras se conectan con la necesidad de los estudiantes de ser escuchados, donde el escenario se convierte en un espacio que propicia la expresividad y la reflexividad. Citando a Duque (2015) la co - evolución se asume en la biosfera terapéutica al generarse cambios y trasformaciones ecológicas con los agentes autónomos que se autoorganizan en procesos colectivos que producen conocimiento novedoso a partir de interacciones y actos reflexivos hacia un mundo o adyacente posible.

Lo novedoso también emerge en el compromiso adquirido por todos los actores convocados permitiendo como agentes autónomos activar redes ecológicas que construyen una pauta de corresponsabilidad de los sistemas que a su vez reconocen las diferencias y dan un paso del 
pensamiento individual al colectivo. Los procesos conversacionales permitieron a los actores, desde una posición de agentes de cambio, hacer conexiones ecológicas que empoderan los procesos de autonomía de los estudiantes.

\section{Conclusiones}

En el presente apartado se describen los principales aportes de la investigación/intervención referente al fenómeno de estudio de la violencia escolar en un Instituto Educativo de zona rural del Municipio de Turmequé Boyacá, haciendo énfasis en las principales implicaciones para la Psicología clínica, para el fenómeno de estudio, para la maestría, para el macroproyecto, para la investigación/intervención y para futuras investigaciones.

Para dar cuenta de las conclusiones que emergieron es importante tener presente el fenómeno de investigación y el problema para el desarrollo de este estudio. A manera de síntesis, el fenómeno de la investigación da cuenta de las relaciones que se organizan en el contexto escolar que convocan modos de interacción construidos desde entornos familiares, escolares y sociales que permiten la organización de los niños, niñas y jóvenes en la construcción del sí mismo y de sus procesos de autonomía a través de configuraciones vinculares con el otro que pueden facilitar relaciones movilizantes o que pueden propiciar el surgimiento de la violencia escolar. Es así, que el problema se desarrolla alrededor de la configuración de la violencia escolar en el sistema educativo y la forma en que ha incidido en los procesos de autonomía y co-evolucion de los niños, niñas y jóvenes de la institución.

Las conclusiones emergen desde la novedad y los aportes que se posibilitaron gracias al recorrido de la investigación/intervención. En este sentido durante este tránsito los procesos 
autorreferenciales hicieron parte relevante para la construcción de escenarios que crearan novedad con los actores participantes, así como para hacer visible desde la conexión emocional y las historias de vida con los niños, niñas y jóvenes voces que se encontraban silenciadas pero que se convertían en el pequeño umbral que conectaba la resignificación de la violencia escolar y el empoderamiento de aquellos actores como agentes autónomos que construían paz y sana convivencia.

\section{Para la Psicología Clínica y el Fenómeno de estudio.}

La perspectiva ecológica - compleja de la violencia escolar permitió comprensiones sobre el cómo se configuraba este fenómeno en un contexto académico en conexión con las pautas interacciónales organizadas en los sistemas amplios circundantes (familia, Institución educativa, Municipio), así como facilitó la emergencia de la autonomía de los niños, niñas y jóvenes como posibilitadora de cambio permitiendo procesos co - evolutivos y autorganizadores hacia la emergencia de mundos posibles.

Para la psicología clínica comprender desde la ecología y la complejidad la violencia escolar permite procesos de movilización y creación para futuros investigadores/interventores y terapeutas consultores, que los lleven a realizar lecturas de todo un contexto ecológico circundante que permita crear estrategias de intervención orientadas a los sistemas amplios y a los actores directamente involucrados, deconstruyendo la mirada hacia los estudiantes como el foco deficitario del problema y a la familia como la culpable de las relaciones que se configuran en los contextos escolares. Posicionarse desde una lectura psicológicamente compleja complementa las lecturas ecológicas dada la posibilidad de comprender los roles, organizaciones y juegos relacionales de un contexto determinado que a su vez posibilita visibilizar las pequeñas 
aperturas que dan surgimiento a la re - organización de un sistema y al fortalecimiento de los recursos del mismo.

En este sentido, es importante desde los recursos visibilizados en la narrativa activar los procesos de autonomía como posibilitadores que re - organizan el sistema desde el empoderamiento y la corresponsabilidad por una situación social perturbadora como la violencia.

Comprender la construcción social de la violencia permitió visibilizar cómo un Municipio con una carga cultural y de creencias naturalizaba la violencia y la cristalizaba en el tiempo, imposibilitando la visibilización de los recursos de los niños, niñas y jóvenes y la construcción de vínculos generativos y movilizantes en el contexto escolar, dada la réplica a las misma pautas y secuencias interaccionales que se construían en su diario vivir. Es importante comprender cómo la violencia escolar se convierte en una forma construida por los estudiantes para vincularse con el otro y pertenecer a un grupo social que lo reconozca, como quizás no es reconocido en otros sistemas y contextos que son de función vital para su desarrollo y aprendizaje En este sentido, lograr comprender la violencia escolar como vinculación le permitiría a la psicología clínica hacer uso constructivo de esta vinculación que se crea potencializando los recursos generativos que circundan, pero que no son visibles, las relaciones configuradas alrededor de la violencia, lo que a su vez le posibilitaría a futuros investigadores/interventores resignificar la necesidad de vincularse desde la violencia hacia la potencialización de la autonomía de los estudiantes, deconstruyendo el vincularse para ser reconocido hacia el vincularse para reconocerse a sí mismo a través del otro, lo que da sentido a la aceptación de lo diverso y a la visibilización de los recursos propios que llevan a los seres humanos a ser parte de la construcción de sociedad. 
Añadido a lo anterior, es importante para la psicología clínica comprender la violencia escolar como un síntoma que habla sobre el problema, lo cual posibilita una visión más amplia desde una lectura Ecosistémica del fenómeno, que permita niveles de movimiento que se acerquen a las voces de los actores participantes y a su necesidad de ser escuchados. En este punto, en la Investigacion/intervencion, evidentemente la violencia emergía como el punto focal de la crisis que perturbaba al sistema cuestionándolo sobre el porqué se estaban configurando niveles de relación destructivos en niños, niñas y jóvenes. Es así que la violencia escolar comprendida como un síntoma, hacía un llamado a la re - organización del sistema y a la reinvención de una sociedad.

Este llamado a la re - organización movilizó tanto a los actores participantes como a las investigadoras/interventoras para visibilizarse como agentes autónomos que se empoderan del fenómeno y crean mundos posibles desde la participación y activación de las voces de los niños, niñas y jóvenes como principales gestores de cambio, la aceptación de lo diverso, la deconstrucción de los órdenes de dominio y control hacia la construcción del poder desde los generativo y lo creativo que los posicionaba como líderes de una nueva construcción social, y la emergencia de la conectividad ecológica que moviliza a la familia y a la institución educativa a corresponsabilizarse.

Finalizando este apartado, es importante resaltar que el proceso de la investigación/intervención permitió dar respuesta a las preguntas de investigación/intervención; dado que por una parte se logró comprender cómo se construye narrativamente la violencia escolar en un Municipio con una gran carga cultural que significaba los actos violentos como parte del crecimiento natural de una persona, pero de la misma manera, lo anterior permitió entender los juegos de poder conectados con una necesidad vincular. Por otra parte, se logró 
resignificar narrativamente la violencia escolar hacia procesos de autonomía que permitieron la co - evolución del grupo a partir del empoderamiento en procesos de participación y toma de decisiones, acompañamiento vincular y corresponsabilidad de los sistemas familiar y escolar y la activación de red a partir de la co - construcción y la participación micropolítica.

\section{Para la Maestría}

Unos de los focos importantes de la maestría es la familia; por esta razón surgieron emergencias en torno a la comprensión de las dinámicas relacionales y vinculares en el desarrollo de la investigación/intervención. Se hacía necesario comprender de qué manera las familias que hicieron presencia en este estudio estaban permeadas por la cultura del Municipio trasmitiendo de generación en generación estos legados de violencia tejida al interior de los diferentes sistemas a sus hijos e hijas. Al ir comprendiendo la configuración relacional de la violencia escolar, se convocaron en algunos escenarios de investigación/intervención las voces de la familia, que también requerían ser activadas y escuchadas ante la institución educativa, posibilitando descentrar al estudiante del problema haciendo uso de su capacidad de interfaz para conectar a estos dos sistemas y empezar a conversar entre familia y escuela sobre sus objetivos en común y su corresponsabilidad en el fortalecimiento de la autonomía de los niños, niñas y jóvenes.

Partiendo de los diálogos generativos se priorizan los recursos de la familia y su capacidad para transformar el contexto al mismo tiempo que se transforman a sí mismos, evocando la autonomía de las relaciones a la resignificación de a una autonomía ligada al vínculo, donde se estrechan los lazos filiales y surgen el interés por proteger y cuidar a los hijos e hijas, sin limitarlos en las diferentes dimensiones de vida. Como aporte se encuentra una familia con 
acción transformadora, que conduce a tener nuevas comprensiones que se basa en una mayor cercanía donde el apoyo se convierte en un pilar de las interrelaciones que se construyen al interior de la familia.

A través de la investigación/intervención y su perspectiva sistémica ecológica - compleja se posibilita una visión amplia frente al entramado de relaciones que se construyen en la familia, en la cual se genera la emergencia de un sistema autoorganizado que fortalece el vínculo y moviliza narrativas posibilitadoras de nuevas formas de relacionarse y comprensiones frente a emociones que antes estaban silenciadas. Por cuanto, los procesos conversacionales entre los integrantes de la familia son necesarios y nutricios en la construcción de una red coherente e interrelacionada con los sistemas amplios (en especial con la escuela), a través de relatos diversos que favorecen procesos de autonomía y reflexión trasformando relaciones rigidizadas.

\section{Aportes para el macro proyecto}

Esta investigación parte del macropoyecto de narrativas en el cual se hace indispensable comprender cómo emergen los relatos y la construcción de las relaciones y de qué manera la pertenencia está conectada con la memoria y acontecimientos en la comprensión de las conexiones que se construyen en la ideología cultural que ha organizado la violencia escolar.

Es de resaltar, como a través de los procesos conversacionales se fueron cambiando las narrativas dominantes de la violencia escolar, donde a medida que trascurrían los escenarios se creaba espacios propicios para el cambio y para la consolidación de narrativas novedosas a través de la externalización por tanto, a través de la narrativa la palabra violencia se trasformaba hacia la construcción de nuevos relatos en los cuales emerge la aceptación de las diferencias del otro, a través del respeto y la tolerancia de la integralidad de la otredad. 
En este sentido se podía favorecer la emergencia de agentes autónomos autoorganizados a través de estas nuevas narrativas que se generaban con el fin de potencializar procesos de autonomía que fortalecían su individuación, por tanto la interacción en otros contextos iba a permitir pasar de un pensamiento individual a uno colectivo.

La convergencia de estas epistemologías conducen a evocar un nuevo sistema de relaciones cálidas y amables, donde se realiza una mirada introspectiva conduciendo a un tiempo de cambio y reparación distinguiendo las potencialidades y recursos de cada familia, en donde la narrativa conversacional y los actos reflexivos visibilizaban la capacidad humana, de transformar episodios caóticos en situaciones de renovación y aperturas a nuevos estilos de vida, el tiempo es el encargado de estas co - evoluciones donde lo que antes estaba oculto, soterrado, y desconociendo grandes capacidades privilegiadas, sale a la luz convirtiéndose en oportunidades donde la creatividad es la encargada de dar apertura a nuevas formas de vida, y mundos posibles.

\section{Para el contexto de intervención}

Es en el contexto escolar donde las movilizaciones y las emergencias que surgieron de la investigación/intervención fueron visibilizadas, entendiendo el compromiso y la necesidad de cambio de los actores participantes. En este sentido, un aporte significativo para el contexto se dibuja en la comprensión de la configuración de la violencia, lo que les permite a los sistemas inmersos en el Municipio metaobservar la pauta que cristaliza la violencia y que permea entornos escolares, posibilitando la emergencia de procesos reflexivos que permiten hacer uso constructivo de la voz de los estudiantes y de su capacidad para autogestionar y autoorganizar realidades como agentes autónomos. Estos procesos reflexivos le permiten al contexto cuestionar los vínculos construidos con los niños, niñas y jóvenes, rompiendo con la creencia de que la autonomía es emprender un camino solo. Para la institución educativa queda como un aporte 
significativo la ruta emocional que se construyó en conjunto con los niños, niñas y jóvenes participantes, con el fin de intervenir desde la escucha activa y la necesidad del otro en casos de violencia escolar.

Por tanto el aporte significativo en este apartado es la comprensión de la autonomía con relación al vínculo como forjador de cambio hacia la emergencia de un relato que visibiliza el acompañamiento familiar y escolar, para construir vínculos fuertes como posibilitadores de la autonomía que le permite al niño, niña o joven observarse hacia una prospectiva vital, entendiendo la importancia de la relación con las otras personas a la hora de construir procesos que edifiquen estilos de vida en sus diferentes contextos de interacción.

La conectividad ecológica que posibilitó la investigación/intervención y los agentes autónomos le permite al contexto realizar conexiones entre familia e Institución educativa que los posiciona en un rol de orientador que trabaja hacia un mismo objetivo: el fortalecimiento de la autonomía de los niños, niñas y jóvenes hacia aprendizajes pertinentes para la vida. En este sentido, la investigación/intervención realiza una invitación al contexto, a pensarse como un sistema en conjunto, bajo la premisa de: "no hay nadie más experto en su vida que uno mismo" redefiniendo las llamadas escuelas de padres, las cuales pretenden "educar" a los padres, hacia escenarios de construcción familiar que visibilice la voz del padre, el estudiante y el profesor orientados hacia la construcción de nuevas formas de vincularse, de reconocer al otro, de conversar sobre la vida, de la actualidad, de la historia y de empoderarlos como agentes constantes de cambio.

Podría entenderse la escuela de padres como un dispositivo que proporcione herramientas satisfactorias basadas en la comprensión y el diálogo al interior de la familia, y a su vez sean 
trasmitidas a cada uno de los contextos donde se está interactuando, como facilitador de interrelaciones armónicas y satisfactorias.

\section{Para la investigadoras/interventoras}

La responsabilidad y la ética que asumieron las investigadoras/interventoras para comprender y resinificar el fenómeno de estudio, fue un eje fundamental que propició procesos autorreferenciales, reflexivos y creativos que posibilitaron el ingreso a un contexto escolar como agentes autónomos que conversan con otros agentes autónomos y construyen adyacentes posibles; soluciones que se iban construyendo a través de diálogos reflexivos y miradas sistémicas en torno al fenómeno de estudio con los participantes donde se podía crear mundos posibles a través de la activación de recursos emocionales, afectivos y vinculares. Lo anterior y la perspectiva compleja - ecológica de la violencia escolar llevaba a las investigadoras/interventoras a transitar por la incertidumbre, dado que aunque se encontraban organizados escenarios de intervención, no era posible predecir qué pasaría y cómo emergerían los procesos de cambio... un proceso de investigación/intervención donde lo único claro era la co - responsabilidad que se asumía con lo humano, con los seres que desde Turmequé esperaban un alguien que los acompañara en el tránsito caótico que conlleva al cambio y que los reconociera desde sus recursos.

En este tránsito de incertidumbre y caos emergen procesos de cambio epistemológico, que sin duda también impactan en las formas de intervenir $y$ en las formas de nombrar terminológicamente el fenómeno. Es así, que las investigadoras/interventoras llegaban dispuestas a abordar el fenómeno a partir del término Bullying; sin embargo, al interior de la institución se desconocía éste, lo que llevó a la investigación/intervención a asumir dentro de la institución el “matoneo", lo que una vez más transitando en la incertidumbre cuestionó epistemológicamente 
los movimientos de conexión con el fenómeno de estudio posibilitando la emergencia de la violencia escolar comprendida como una organización interaccional que configura la relación de los actores participantes en conexión con sus sistemas circundantes.

Al comprender la violencia escolar como una construcción social con una alta conexión ecológica, emerge la corresponsabilidad con los actores participantes; en este sentido, incluir a la familia, a los niños, niñas y jóvenes y al cuerpo docente y administrativo de la institución fue fundamental, dado que se posibilitó descentrar al estudiante como eje principal del problema y activar sus recursos hacia el fortalecimiento de sus procesos de autonomía y su empoderamiento como agentes autónomos de cambio.

\section{Aportes para futuras investigaciones/intervenciones}

Durante el proceso de investigación/intervención fue evidente que los dilemas humanos que generan caos y sufrimiento, no necesariamente llegan a escenarios psicoterapéuticos, dado que en muchas ocasiones se naturalizan y se encubren, en particular en el contexto escolar con categorías semánticas como: indisciplina o bajo rendimiento académico, sin embargo no por ello estas situaciones dejan de generar sufrimiento y dejan de considerarse dilemas humanos, que evidentemente competen a los psicólogos clínicos y de familia. En este sentido, es importante también, posicionar a la Psicología Clínica y de la Familia como gestora de cambio que se moviliza a espacios diferentes al consultorio y que propone estrategias de intervención que posibiliten movimiento en todo un sistema escolar y familiar, empoderando a los actores participantes en los recursos que les permitan dar continuidad al cambio a través del tiempo. 
Se deja un camino abierto para que se continúe construyendo una red de manera diferente entre institución y familia a partir de una pauta de corresponsabilidad entre estos dos sistemas que reconozcan y se muevan en lo diverso dando apertura a la novedad, permitiendo que el niño, niña y joven sienta que está siendo reconocido, orientado y empoderado. En este sentido, es importante en el trabajo con niños, niñas y jóvenes activar su voz desde un posicionamiento como gestores de cambio, que les permitan a los sistemas circundantes reconocer los diversos mundos que se pueden construir al activar el carácter creativo de aquellos seres que se encuentran en crecimiento y desarrollo.

En este orden de ideas, es importante continuar deconstruyendo la idea de que para educar y fortalecer la autonomía de los niños, niñas y jóvenes es necesario limitarlos en parámetros sociales rígidos que los desvinculan de la idea de ser seres micropolíticos; al igual que deconstruir la idea que para crecer no se requiere de acompañamiento y apoyo, dado que es necesario construir como sociedad y como profesionales nuevas formas de vincularse con estos actores que activan cada día su función creativa reinventando realidades. 


\section{Post-Scriptum}

El procesos de sustentación se llevó a cabo el día 13 de Septiembre del año en curso a las 2:00 pm en el Auditorio Sanz Tena, estuvo precedido por las jurados Angie Román y Alexandra Gutiérrez, en el evento estuvo presente la directora de la Maestría Doctora Luz Marina Moncada Torres, se contó con la participación de los compañeros; Christian Buitrón, Adriana Caicedo, Marcela Londoño y Ana Mendivelso.

La sustentación duro 30 minutos donde se dio a conocer el trabajo que se organizó durante el periodo comprendido de segundo semestre de 2015 a primer semestre de 2017.

En la presentación se socializo; localización geográfica de la investigación, fenómeno, problema, objetivos, estados del arte, sistema teorico,sistema metodológico, matrices, análisis de resultados, escenarios aplicados con sus respectivos neo diseños, resultados, discusión y conclusiones.

Luego de ello se dio paso a recibir la retroalimentación de los jurados a partir de una conversación entre las docentes. De la investigación/intervención se resalta la rigurosidad con la que se conectan los resultados con la complejización del fenómeno, observando la emergencia de la psicología compleja para comprender un proceso de intervención desde la creación de biosferas terapéuticas que dieron sentido a la emergencia de adyacentes posibles de cambio, en los cuales tanto actores participantes como investigadoras/interventoras se movieron hacia la posibilidad de fortalecer procesos de autonomía hacia la co-evolución. De igual manera, se resaltó la realización de un proceso de investigación/intervención clínica en un contexto fuera de consultorios en el cual se facilitan la realización de lecturas ecológicas, sin embargo, de la misma manera se sugiere contemplar para futuras investigaciones/intervenciones en el marco de la 
maestría procesos de intervención clínica para fenómenos como lo es la violencia escolar, donde desde un contexto dentro de espacios como los consultorios se realicen comprensiones y conexiones que tengan un alto impacto ecológico. Las jurados mencionan la importancia de comprender el fenómeno del problema a partir de factores psicosociales que puedan nutrir y complejizar mayormente el estudio, como también es indispensable hacer uso de datos y cifras con los cuales se evidencie lo que pasa en la actualidad en cuanto al tema de estudio; la violencia escolar.

Las voces de las jurados dan cuenta de la riqueza metodológica de la investigación/intervención, sin embargo manifiestan que en los procesos metodológicos no se permite visualizar con claridad los dispositivos que posibilitaron el cambio, así como, no es posible vislumbrar cómo emerge el cambio de la técnica a la intervención y de qué manera los dispositivos deconstruyeron el fenómeno de estudio. En este sentido, queda en una caja negra la matriz de resultados ya que no se profundiza de donde nace la categoría emergente, quedando oculto. Lo anterior, lleva a la investigación/intervención a presentar dificultades metodológicas durante el proceso de socialización.

Dando respuesta a lo anterior, evidentemente los procesos de cambio no hubieran podido ser posibles sin el uso de la narrativa conversacional, dado que partiendo de una lectura contextual y ecológica de la violencia escolar se permitió comprender la necesidad de realizar movimientos a nivel interventivo que posibilitaran una conectividad ecológica en la cual los actores participantes y sus sistemas circundantes se organizaran micropolíticamente haciendo uso de su voz y su capacidad para proponer nuevas posibilidades de cambio. Teniendo en cuenta lo anterior, desde la narrativa conversacional emergían preguntas circulares y reflexivas que apuntaban a realizar movimientos teniendo en cuenta los nodos de intervención propuestos en los 
escenarios, en los cuales era posible en cada uno de ellos: realizar una comprensión de pautas interacciónales que configuran la violencia, potencializar los recursos de los actores participantes, deconstruir miradas deficitarias, potencializar las redes de apoyo, realizar una conexión con los procesos vinculares que posibilitan la autonomía, fortalecer los procesos de autonomía, construir co - evolutivamente nuevas realidades y posibilidades de movimiento y empoderar a los agentes autónomos como gestores de paz.

Es así, que los dispositivos propuestos se convertían en una alternativa para llegar a la voz silenciada de los estudiantes y descentraizarlos como foco del problema, dispositivos que les permitían a los actores participantes emerger como un nodo de interfaz que posibilitaba la conexión de tres sub sistemas (familia, institución educativa y Municipio) que no se conectaban y se corresponsabilizaban desde el trabajo en equipo por un fenómeno que los convocaba a autorganizarse. En este sentido los dispositivos, desde las lógicas de la complejidad eran también una estrategia autoorganizativa de empoderamiento.

De esta manera, los dispositivos se empaparon de metáforas y diálogos reflexivos que apuntaban al fortalecimiento de la autonomía hacia la co- evolución en grupo. La construcción de un cuento como primer dispositivo permitió por una parte a los actores participantes visualizar que era lo que realmente necesitaba la institución, la familia y los estudiantes para deconstruir la violencia escolar, así como realizar procesos reflexivos sobre la necesidad propia y el cómo poder anudar fuerzas como gestores de paz; este proceso permitió a continuación realizar una conectividad ecológica con la familia y la escuela por medio de la construcción de un árbol, como dispositivo que llevaba a la familia y a la escuela a visualizarse como corresponsables del crecimiento y desarrollo de los niños, niñas y jóvenes, fortalecer la comunicación entre familia y escuela y potencializar los vínculos desde la participación infantil, la guía y empoderamiento en 
la toma de decisiones. Ya posicionados los niños, niñas y jóvenes como agentes de cambio, emerge el tercer dispositivo que les permitió construir un video con el fin de llevar un mensaje que continuara deconstruyendo miradas deficitarias y fortaleciera la autoorganización de los sistemas amplios. Finalmente los últimos dispositivos propuestos por los niños, niñas y jóvenes e institución educativa les permitió construir estrategias que los vinculaban con el sentir del otro, por medio de la creación de una tarjeta para la familia, la construcción de una ruta emocional que organizaba a la institución educativa a visualizar e intervenir la violencia escolar de manera diferente y la construcción de una canción que mantuviera en el tiempo y en los sistemas circundantes su voz y su necesidad de cambio.

Recordando nuevamente el proceso de sustentación, la docente Angie Román realiza dos preguntas reflexivas donde invita a las investigadoras/interventoras a dar respuesta no de manera inmediata sino pensando para el futuro como psicólogas/Magísteres, desde una mirada constructivista construccionista compleja.

¿Cómo las investigadoras/interventoras van a empezar a complejizar los consultorios o la intervención en consultorio desde en relación con el contexto exterior?.

Los consultorios terapéuticos son espacios que permiten visualizar distintos fenómenos y dilemas que trae consigo los seres humanos y a su vez pueden conducir a la curiosidad, llegando fluctuaciones, bifurcaciones y estructuras disipativas que incitan a formar parte del entramado de la vida cotidiana, es así, que se puede dar apertura a una infinidad de emergencias donde se cambia la certeza por posibilidades, donde se conduce a pensar en lo incierto como un puente que permite el paso hacia la evolución. 
Así, un cambio puede favorecer un nuevo estilo de vida, acompañado de madurez, creatividad y novedad, todo depende del sentido que tenga dicha situación, caótica, para generar acciones que le causen satisfacción y lo inviten a salir del circuito estable, donde probablemente se encuentre, experiencia que se puede realizar tanto en el terapeuta como en los sistemas consultantes.

¿Cómo empezamos a pensar los vínculos, cómo se comienzan a regenerar, cómo esos resultados comienzan a generar nuevas posibilidades y también en los vínculos en las mismas pautas de interacción?

Los vínculos son las conexiones que se construyen en relación con la otredad, ya sea con personas, objetos, animales o cosas, capaz de crear uniones muy fuertes, ahora que si se habla de un vínculo en la familia como se llevó a cabo en la investigación/intervención el vínculo fue un proceso que potenció el cambio y transformó las diferentes interacciones que construyen en los diferentes contextos de los participantes, es así que a través de la vinculación se transformó una narrativa deficitaria dominante por una función creativa generativa, donde el dialogo, al afecto y la comprensión estaban de la mano en los procesos de autonomía y co - evolución de los niños, niñas y jóvenes que fueron participantes en este estudio de violencia escolar.

A manera de conclusión del proceso de sustentación y del recorrido de la investigación/intervención, los procesos psicoterapéuticos y de consultoría sistémicamente orientada deben posibilitar en fenómenos donde se encuentren inmersos niños, niñas y jóvenes, el empoderamiento de sus procesos de autonomía a partir de intervenciones en las cuales necesariamente deben incluirse lecturas y movimientos ecológicos, así como hacer uso de la autorreferencia y la heteroreferencia desde la observación minuciosa de la necesidad del otro. De esta manera, es importante comprender a los niños, niñas y jóvenes como agentes autónomos que 
hacen parte de la organización de la relación terapéutica, entre familia, colegio, entidades remisoras y terapeuta, donde el objetivo central se encuentre en el cómo disminuir la saturación a este nodo (niños, niñas y jóvenes) con el fin de descentrar al niño y empezar a crear conexiones. De esta manera, al descentrar al nodo, emerge un sistema borroso adaptativo que genera procesos que permiten co - construir información pertinente para la vida.

La violencia escolar en los contextos educativos, vista como crisis, hace un llamado a la psicología clínica invitándola a salir de espacios como el consultorio y de la confortable espera por intervenir nodos saturados en crisis, a comprometerse (porque de por sí la crisis ya existe) desde una psicología compleja sistémicamente orientada, a llevar un ejercicio micropolíticamente terapéutico directamente en los contextos educativos que generen la creación de escenarios autoorganizativos en seres igualmente micropolíticos que requieren trabajar con la ambigüedad de lo humano redefiniendo las estructuras sociales y reconociendo una borrosidad que gestione estéticamente la vida. 


\section{Referencias}

Aguilo, A; Aguilo (1999). Educar los sentimientos. Cuarta edición.

Aguiló, M. (1999). El paisaje construido. Una aproximación a la idea de lugar. Madrid, Colegio de Ingenieros de Caminos.

Anzola, V. (2003). Construcciones en Psicología Compleja. Aportes y Dilemas. Universidad Santo Tomas.

Anderson, H. (2000). Conversación, Lenguaje y Posibilidades. Cambios en la Cultura de la Terapia: Una Postura Filosófica. Buenos Aires: Amorrortu.

Arias, L. (2012). Algunas Consideraciones Sobre La Familia Y La Crianza Desde Un Enfoque Sistémico. Rev. psicol. Arequipa ISSN 2221-786X 2012, 2(1), 32-46.

Baudrillard, J; Morin, E. (2003). La violencia en el mundo. Barcelona: Paidós.

Benítez y Justicia (2006). El maltrato entre iguales: descripción y análisis del fenómeno. España. Revista Electrónica de investigación Psicoeducativa. Nº9, vol 4:2 $(151,170)$

Boscolo; Bertrando. (1996). Los tiempos del tiempo.

Buitrago, A, Silva, A, Rada, C. (2015) Narrativas, redes y cibesespacio: una reconfiguración del ciberbullying con jóvenes en el contexto educativo. Universidad Santo tomas. Colombia. Bogotá

Bradford, K.(1994). La estética del cambio. Barcelona: Paidós

Bateson, G. (1972). Ecology Of Mind. Originally Published: San Francisco: Chandler Pub.co;1972. With New Pref. Collection of articles reprinted from various periodicals

Baudrillard, J; Morín, E. (2003). La violencia del mundo. Paidos. Barcelona

Cámara de comercio de Bogotá. (2006). Programa para la gestión del conflicto escolar HERMES. Cámara de comercio de Bogotá, Colombia. Recuperado el 10 de Noviembre de 2015 en http://www.unicef.org/lac/Proyecto_Hermes_Colombia_Spanish.pdf 
Castillo, L. (2011). El acoso escolar. De las causas, origen y manifestaciones a la pregunta por el sentido que le otorgan los actores. Magis. Pontificia Universidad Javeriana Bogotá, Colombia. Revista Internacional de Investigación en Educación, vol. 4, núm. 8.

Chaux, Enrique, Lleras Juanita y Velásquez Ana María (Comps.) (2005). Competencias ciudadanas: de los estándares al aula. Bogotá: Ministerio de Educación Nacional Departamento de Psicología y CESO, Universidad de los Andes

Dabas, E. (2006). Compartiendo territorios: relaciones familia - escuela. En: Elina Dabas (comp.), Viviendo redes. Experiencias y estrategias para fortalecer la trama social. Buenos Aires: Ediciones CICCUS.

Dante, D. (2006). Relato autobiográfico e identidad personal: Un modelo de análisis narrativo. Madrid. Revista de Antropología Iberoamericana. Vol. 2., No.2. Biblioteca virtual USTA

Duque, R. (2015). La investigación como una biosfera autoorganizada. Diálogos entre psicología clínica, ciencias de la complejidad y estética de los mundos posibles. Bogotá: Pontificia universidad Javeriana. Tesis Doctoral.

Estupiñan, J, Garzón, D., Niño, J.A. \& Rodríguez, L. (2006). Consultoría sistémica. Un enfoque interventivo, formativo, investigativo. Bogotá: USTA.

Estupiñán J, González O y Serna A. (2006) Dossier, Proyectos de Investigación en Marcha. Bogotá: USTA Ediciones

Estupiñan, J, Garzón, D., Niño, J.A. \& Rodríguez, L. (2006). Consultoría sistémica. Un enfoque interventivo, formativo, investigativo. Bogotá: USTA.

Estupiñan, Mojica, González (2015). Narrativa conversacional, relatos de vida y tramas humanos. Ediciones USTA.

Echevería, R. (2002). Ontología del lenguaje. Santiago de Chile: Dolmen.

Félix, V., Godoy, C. y Martínez, I. (2008). Violencia entre iguales: Resultados de un estudio descriptivo de la provincia de Valencia. Escritos de psicología online (94), 36-48. Recuperado el 12 de Noviembre en: http://scielo.isciii.es/scielo.php?pid=S198938092009000100006\&script=sci_arttext 
Ferrer, B. M., Ochoa, G. M., Muñoz, L. A., \& Gimeno, M. M. (2012). Estatus sociométrico y violencia escolar en adolescentes: Implicaciones de la autoestima, la familia y la escuela. $=$ Sociometric status and school violence on adolescents: Implications of self-esteem, family and school. Revista Latinoamericana De Psicología, 44(2), 55-66.

Fernández, C. (2007). Violencia familiar y adicciones. Recomendaciones preventivas. Centros de Integración Juvenil. México.

Foucault, M. (1983). Potsfacio, el sujeto y el poder. El malpensante. Medellín.

Gergen, K. y Keye, J. (1996). Más allá de la narración en la negociación del significado terapéutico.

Gregory, B. (1987). Steps to an ecology of mind.Jason Aron INC. New Jersey.

Goffman (1955). On Face work: And analysis of ritual elements in social interaction. Psychiatry, 18, n. 3: $213-31$

Garaigordobil, M., Oñederra, J. (2008).Estudios epidemiológicos sobre la incidencia del acoso Escolar e implicaciones educativas.Revista información psicológica (94), 14-35.

Recuperado el 12 de Noviembre en http://www.informaciopsicologica.info/OJSmottif/index.php/leonardo/article/viewFile/23 $6 / 190$.

Garaigortdobil, M., \& Martínez-Valderrey, V. (2015). Effects of Cyberprogram 2.0 on 'face-toface' bullying, cyberbuUying, and empathy. Psicothema, 27(1), 45-51.

Gergen, K. y Keye, J. (1996). Más allá de la narración en la negociación del significado terapéutico.

Gergen, K. (2006). Construccionismo social: aportes para el debate y la práctica. Uniandes Ceso: Departamento de psicología.

Góngora, M., Pérez, B., Usuga, Y. (2006).Convivencia y seguridad en ámbitos escolares de Bogotá D.C. Recuperado el 10 de Noviembre de 2015 en http://www.elespectador.com/files/d8f4461c07272f8357a73012230992f3.pdf

Hernández Córdoba, Ángela. Trascender los dilemas del poder y del terapeuta como experto en la psicoterapia sistémica. Colombia: D - Pontificia Universidad Javeriana, 2009. ProQuest 
ebrary. Web. 25 September 2015. Copyright (C 2009. D - Pontificia Universidad Javeriana. All rights reserved.

Hernández, A. Bravo, L (2008) vínculos, individuación y ecología humana. Editorial Usta Hernández, A (2010). Vínculos individuación y ecología humana, hacia una psicología clínica compleja: Bogotá: ED, santo tomas

Hoyos, Aparicio, Heilbron, Schamun (2005) Representaciones Sobre El Maltrato Entre Iguales En Niñas Y Niños Escolarizados De 9, 11 Y 13 Años De Nivel Socioeconómico Alto Y Bajo De La Ciudad De Barranquilla (Colombia).

Hoyos, O., Aparicio, J., Heilbron, Córdoba, P. (2005). Caracterización del maltrato Entre iguales en una muestra del colegio de Barranquilla (Colombia). Revista Psicología desde el caribe. (14), 150-172. Recuperado el 10 de Noviembre de 2015 en http://www.researchgate.net/publication/28178289.

Hoyos, O; Aparicio, J; Romero, L; Valega, S; Olmos, K. (2008). Creencias de padres y madres acerca del maltrato entre iguales por abuso de poder y exclusión social. Revista Colombiana de Educación, núm. 55, julio-diciembre, 2008, pp. 38-61

Jailler, E. (2003).Realidad y visión investigativa social-reflexiva del mundo: entre la utopía y lo real más allá de lo pensable. Red de revistas científicas de América Latina, el caribe España y Portugal, 18,64-70

Ledford S.Bischof (1983). Interpretación de las teorías de la personalidad.Harper\& Row, publishers. Nueva York, E.U.A.

Kauffam, S (2003). Investigaciones. Complejidad, autoorganización y nuevas leyes para una biología general. Barcelona: Tusquets Editores

Kaplan, C. (2009). Violencia escolar bajo sospecha. Argentina: Miño y Dávila. Retrieved from http://www.ebrary.com

Kuang-Hui YehWei-Chun TsaoWei-Wen, C. (2010). Parent-child conflict and psychological maladjustment: A mediational analysis with reciprocal filial belief and perceived threat. International Journal Of Psychology, 45(2), 131-139.

Kenney, B. (1987). La estética del cambio. Buenos Aires: Paidos. 
M.Auspitz-D.Wang (1997). De terapias y personas. El encuentro, un enfoque humanístico.Abril de 1997.

Macintyre, C. (2009). El acoso escolar en la infancia: cómo comprender las cuestiones implicadas y afrontar el problema. España: Editorial Desclée de Brouwer. Retrieved from http://www.ebrary.com

Menesini, E., Palladino, B. E., \& Nocentini, A. (2015). Emotions of moral disengagement, class norms, and bullying in adolescence: A multilevel approach. Merrill-Palmer Quarterly, 61(1), 124-143. doi:10.13110/merrpalmquar1982.61.1.0124

Mingote, J. C., \& Requena, M. (Eds.). (2010). El malestar de los jóvenes: contextos, raíces y experiencias. España: Ediciones Díaz de Santos. Retrieved from http://www.ebrary.com

Minuchin, S. Cols. (1998). El arte de la terapia familiar. Paidos

Munné, F. (1995). Las Teorías de la complejidad y sus Implicaciones en las ciencias del comportamiento. Revista Interamericana de Psicología, 29(1), 1 -12.

Morin, E. (2003), Introducción al pensamiento complejo, Barcelona, Gedisa.

Munné, F., (2004). El Retorno a la complejidad y la nueva imagen del ser humano: Hacia una psicología compleja. Revista Interamericana de Psicología, 38(001), 23 -31.

Munné, F., (2005). ¿Qué es la complejidad? Revista Encuentros de Psicología Social, 3(2), 6 17. Recuperado de:

http://www.teoriadacomplexidade.com.br/textos/teoriadacomplexidade/QueEsLaComplej idad.pdf

Niño, A. Castañeda, A (2010) Redes conversacionales entre familias y escuelas. Estudio de casos desde un modelo de investigación intervención. Bogotá. Editorial Magisterio.

Ochoa de Alda, Inmaculada ( 2004). Enfoques en terapia fsmiliar sistémica. Barcelona. Barcelona.. ediciones Herder.

Oliva, A. (2006). Relaciones familiares y desarrollo adolescente. Facultad de Psicología Universitat vol. 37, $\mathrm{n}^{\mathbf{0}}$ 3, 209-223. 
Olweus, (1993) Bullying Prevention Program: Implementation and Evaluation over Two Decades. P. Limber 57 To appear in The International Handbook of School Bullying Edited by Shane R. Jimerson, Susan M. Swearer, and Dorothy L. Espelage To be published by Routledge New York, New York

Orozco, G. M., Méndez, P. A. M., \& García, M. Y. E. (2015). Bullying: estampas infantiles de la violencia escolar: exploraciones psicológicas. México: Editorial El Manual Moderno. Retrieved from http://www.ebrary.com (296 págs).

Osorio, R. (2013). Impulsividad y agresividad en adolescentes. España: Ediciones Díaz de Santos. Retrieved from http://www.ebrary.com

Pakman, M. (2006) Palabras que permanecen, palabras por venir. Micropolítica y poética en psicoterapia. Barcelona. Gediza.

Paredes, M., Álvarez, M., Lega, L., Vernon, A. (2006).Estudio exploratorios sobre el fenómeno del "Bullying"en la ciudad de Cali, Colombia. Revista latinoamericana ciencias sociales Niñez y juventud (6), 295-317. Recuperado el 10 de Noviembre de 2015 en http://www.scielo.org.co/pdf/rlcs/v6n1/v6n1a10.pdf

Prigogine, I. (1983). ¿Tan solo una ilusión? Una exploración del caos al orden. Barcelona: Tusquets.

Polaino, L. A. (2013). Violencia juvenil y violencia familiar. España: Ediciones Díaz de Santos. Retrieved from http://www.ebrary.com

Shaffer, D; Kipp, K. (2007). Psicología del desarrollo, infancia y adolescencia. Universidad de Georgia.

Tiina, M (2015).Ministerio Finlandes de educación y cultura. Universidad de Turku. Recuperado de; http://www.kivaprogram.net/copyright_and_disclaimer

Von Foerster, Heinz (1991). Las Semillas de la Cibernética. Barcelona, España: Gedisa. ISBN 84-7432-414-1991.

White, M; Epston, D. (2002). Medios narrativos para fines terapéuticos. Buenos Aires: Paidós. Wittgenstein, L. (1953). Philosophical Investigations. Nueva York. MacMillan. 
Watslawick, P. y otros. 1998. La realidad inventada. Barcelona: Gedisa.

Zlachevsky, A (2003). Psicoterapia sistémica centrada en narrativas: Una aproximación. Chile, Revista Límite $\mathrm{N}^{\circ}$ 10, 2003

Zlachevsky, A; Ojeda. (2003). Psicoterapia Sistémica Centrada En Narrativas: Una Aproximación. Universidad de Chile. Revista Límite Nº 10. 